
GENERAL PSYCHOLOGY IN TERMS OF BEHAVIOR 
Digitized by the Internet Archive in 2007 with funding from Microsoft Corporation 


\section{GENERAL PSYCHOLOGY IN TERMS OF BEHAVIOR}

BY

STEVENSON SMITH, Ph.D.

PROFESSOR OF PSYCHOLOGY IN THE UNIVERSITY OF WASHINGTON

AND

EDWIN R. GUTHRIE, Ph.D.

ASSISTANT PROFESSOR OF PSYCHOLOGY IN THE UNIVERSITY OF WASHINGTON

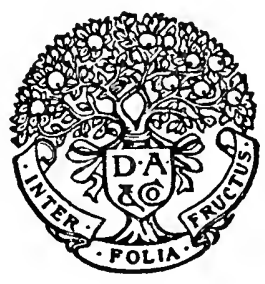

$$
\frac{16975.7}{10 \cdot 3 \cdot 22}
$$

\section{APPLETON AND COMPANY} NEW YORK 
COPYRIGHT, 1921, BX

D. APPLETON AND COMPANY 


\section{PREFACE}

In this book an attempt is made to state in terms of behavior the facts and principles of general psychology. Although the field it covers is somewhat more extended than that of most text-books in psychology, the authors have sought to make the book compact as well as systematic. For efficiency of teaching much traditional but unnecessary detail has been omitted. Only such facts of physiology as have important significance in an introductory course are included. Many blind-alley topics, an acquaintance with which has been considered a polite accomplishment in psychology, have been deliberately disregarded. The facts set forth are those which lead the student to a systematic explanation of his own conduct and that of his fellows. The purpose of the book is to describe man's original nature, the way in which this nature is altered by use, and the common modes of individual and social behavior that result.

S. S.

E. R. G. 


\section{CONTENTS}

Preface - • . . . . . . . . . . . V V chapter

I. The Elements of Behavior . . . . . . 1

Behavior Dependent on Bodily Structure . . . 3

Classes of Sense Organs . . . . . . . . . 6

The Exteroceptors . . . . . . . . 7

The Interoceptors . . . . . . . . 20

The Proprioceptors . . . . . . . . 21

The Nervous System . . . . . . . 23

Regulatory Character of Responses . . . . 28

Delayed Utility of Responses . . . . . . . 31

Apparent Absence of Utility of Some Responses . 32

Orientation, Locomotion, and Intervention . . . 33

Internal Responses . . . . . . . . 36

The Action of a Stimulus-Response Mechanism . $\quad$ - 39

Weber's Law . . . . • • • • . 42

The Interaction of Stimulus-Response Mechanisms . 43

Compromise Responses . . . . . . . 46

II. Instinct . . . . . . . . . . . 48

Reflexes . . . . . . . . . . 49

Instincts Are Chain Reflexes . . . . . . . 54

Precurrent and Consummatory Responses . . . 60

The Effect of Varying Situations upon Precurrent Responses

Individual Differences $\quad \cdot \quad \cdot \quad \cdot \quad \cdot \quad \cdot \quad \cdot \quad \cdot \quad \cdot \quad 70$

III. Learning • • • • • • • • • • • 75

Positive Adaptation . . . . . . . . 76

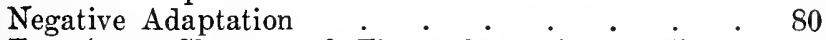

Transitory Changes of Threshold during a Single Practice Period . . . . . . . . . 85

Initial Torpor and Fatigue . $\quad . \quad$. $\quad . \quad$. $\quad . \quad 85$

The Conditioned Response . . . . . . . . 88

Conditioned Emotional Responses . . . . . . . . 91

The Substitution of Similar Stimuli . . . . $\quad$. 94

Facilitating Effect of Conditioning Stimuli . . . $\quad . \quad 95$ vii 
The Neural Basis of Learning • • • • 97

Associative Inhibition $•$ •

The Serial Response . • . • • • . 100

The Effects of Practice on the Serial Response . . 105

Forgetting . . . . . • . . . . 109

Whole and Part Learning $\quad . \quad$. $\quad . \quad$. . 113

Results of the Distribution of Practice . . . 115

Learning Meaningful Material . . . . . 116

Trial and Error . . . . . . . . 117

The Shortening of a Trial and Error Series into a Final Habit Response . . . . . . . 119

Imitation . . . . . . . . . . 130

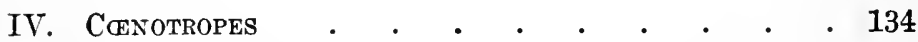

Common Habits.$\quad$. $\quad . \quad$. $\quad . \quad$. $\quad . \quad 138$

Both Instincts and Cंœnotropes Are Common Modes of Behavior . . . . . . . . . . . 145

Play . . . . . . . . . • . 148

Other Examples of Common Modes of Behavior : 153

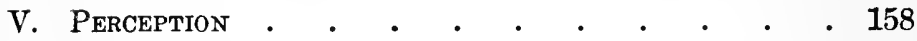

Perception and Speech . . . . . . . 162

At Different Times a Situation May Prompt Us to

Different Perceptions . . . . . . . . 166

Compromise Responses in Perception . . . . 170

Perceptions from Simultaneous Stimuli . . . 171

Space Perception . . . . . . . . . 172

Visual Space Perception . . . . . . . . $\quad$. 173

Visual Perception of Objects . . . . . . 178

Auditory Space Perception . . . . . . 180

Auditory Perception of Objects . . . . . . 181

Olfactory Perception . . . . . . . . . 183

Kinæsthetic and Static Perception . . . . 186

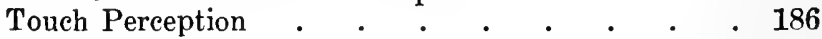

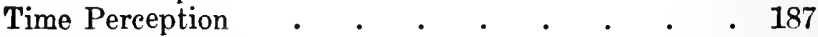

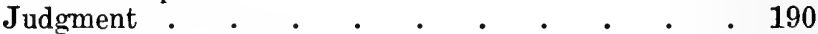

Conviction and Belief $\quad \cdot \quad \cdot \quad \cdot \quad \cdot \quad \cdot \quad \cdot \quad \cdot \quad \cdot \quad 195$

VI. Human Motrves . . . . . . . . . 198

The Delayed Reaction . . . . . . . 198

The Wish . . . . . . . . . . . 203

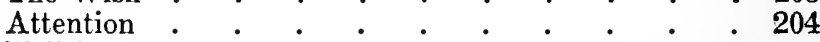

Volition . . . . . . . . . . . . . 205

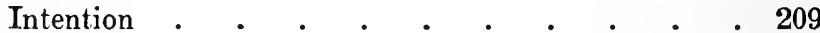

Drive . . . . . . . . . . . . . 210 


\section{CONTENTS}

CHAPTER

Sublimation . . . . . . . . . . . 214

Conflict . . . . . . . . . . . 216

Over-correction . . . . . . . . . 218

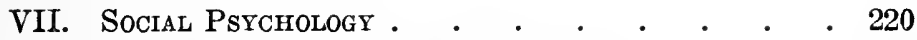

Fellow Man as a Constant Situation . . . . 220

Other Prevalent Situations . . . . . . . 221

Formation of Habits in Common . $\quad . \quad$. $\quad . \quad$. 224

The Spread of Tradition . $\quad . \quad$. $\quad . \quad$. $\quad$. 232

Opinion Spreads from Mouth to Mouth : . . 236

Human Institutions . • • . • . • . 237

\section{APPENDIX}

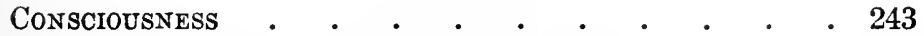

Consciousness and the Nervous System . . . 245

Sensation . . . . . . . . . . . 245

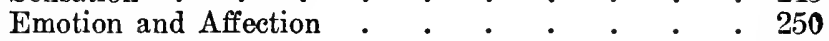

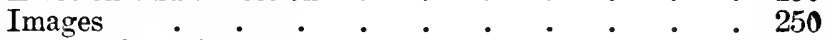

Association of Ideas $\quad \cdot \quad \cdot \quad \cdot \quad \cdot \quad \cdot \quad \cdot \quad \cdot \quad 252$

Imagination . . . . . . . . . . . 255

Attention . . . . . . . . . . . . 256

Perception . . . . . . . . . . . . . 257

The Unconscious . . $\quad . \quad$. $\quad . \quad$. $\quad . \quad 258$

BIBLIOGRAPHY • . • . . . . . . . . 261

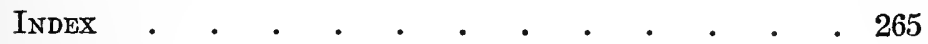





\section{ILLUSTRATIONS}

PI甘URE

PAQR

1. Schematic Diagram of a Section through the Eye • 9

2. Diagram of the Position of the External Muscles That Move the Eyeball . . . . . . . .

3. Schematic Representation of a Section through the Retina, Showing the Position of Rods and Cones, the Layer of Connecting Neurones, and the Direction of Fibers of the Optic Nerve . . . .

4. Drawing from a Model of the Inner Ear, Showing the Cochlea, in Which Are the Sense Organs of Hearing; the Utricle and Saccule, the Organs of Static Sense; and the Semi-circular Canals . .

5. Sehematic Section through One of the Coils of the Cochlea, Showing the Basilar Membrane and Ad-

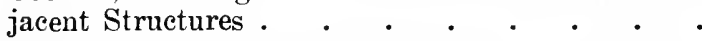

6. Section through the Olfactory Membrane Showing Olfactory Cells and Supporting Cells . . . .

7. Touch Corpusele from the Palm of the Human Finger

8. The Relation of Efferent Fibers of the Autonomic and the Peripheral Nervous Systems to the Central Nervous System . . . . . . . . . 24

9. Schematic Section of the Spinal Cord . . . $\quad 25$

10. Schematic Representation of Sensory Neurone . $\quad 26$

11. Schematic Representation of Motor Neurone . • . 27

12. Scheme of Neural Pathways from a Sense Organ in the Skin to a Muscle .

13. Diagrammatic Representation of the Chain Reflex Mechanism . . . . . . . . . 56

14. Distribution of Unselected Group of Runners . . 71

15. Surface of Frequency Showing the Distribution of the Runners of Figure 14 According to their Time in Seconds .

16. Distribution of Alpha Test Scores for College Students and for the Draft Army. . . . . 
17. Distribution of Alpha Test Scores for Various Groups in the Draft Army . . . . . . . 73

18. Curve of Practice in Mirror Drawing . . . . 78

19. Distribution of German Industrial Accidents throughout the Working Day, in Part the Result of Fatigue . . . . . . . . . . $\quad$. 87

20. Establishing a Conditioned Response . • . $\quad 98$

21. Diagrammatic Representation of the Formation of a Serial-Response Habit . . . . . . 104

22. The Number of Repetitions Required for Establishing Serial Responses of Various Lengths . . . 106

23. The Actual Amount of Work Done in Order to Learn the Series of Various Lengths . . . . . 107

24. The Time Saved in Relearning a Serial Response of $\mathbf{1 6}$ Nonsense Syllables Shown as a Function of the Amount of Yesterday's Practice . . . 110

25. The Rate of Forgetting a Nonsense Series . . . 111

26. Staircase Figure . . . . . . . . . 168

27. The Cube Face that is Perceived as Nearest the Observer may also be Perceived as the Most Distant . 169

28. A Pear is Perceived as behind an Apple because it is Partially Hidden by the Apple . . . . . 176

29. Objects Higher in the Field of Vision tend to be Perceived as More Distant . . . . . . 177

30. Respiratory Antecedents of Voluntary Movement . . 208 


\section{GENERAL PSYCHOLOGY IN TERMS OF BEHAVIOR}




\section{GENERAL PSYCHOLOGY IN TERMS OF BEHAVIOR}

\section{CHAPTER I}

THE ELEMENTS OF BEHAVIOR

Psychology takes the common sense view that any animal is a physical object in a world of physical objects. It assumes that all these objects act upon each other in the ways described by physics, chemistry, and physiology. It considers man's behavior as a physical event that can be analyzed into bodily movements. In this sense man's behavior is mechanical and his body is a machine.

The behavior of animals does not involve new and mysterious forces lacking elsewhere in nature, even though it is true that an animal's structure is too complex to be duplicated, and though any attempt to construct a machine that would respond as elaborately and appropriately as do animals to the world of surrounding objects must certainly fail.

It must not be supposed that thinking is denied by physiological psychology. A behavioristic description of man's mind in no way contradicts the common sense assumption that men are conscious. We shall first find out what man does, and under 
what circumstances he does it, because this is open to observation and may be stated exactly. ${ }^{1}$ An understanding of behavior is essential to an understanding of consciousness.

All that we can observe in our fellow man is his behavior. He moves his body and its appendages as he goes from place to place or as he rearranges the objects about him. In conversation he contracts the necessary muscles and is heard to speak. In emotional expression he blushes, his pulse is altered, his hands grow cold, his liver gives up its sugar, and we see shame, anxiety, or anger. His thoughts, as such, are known to no one but himself.

Any physical object is at all times being acted upon by forces that affect it in various ways. The stone lying in the road is moved about by the impact of rain, warmed and expanded by the sun, and scratched by the wheels of passing vehicles. Its responses to these forces are simple and easily predicted because of the simplicity of its structure.

If we consider not only the stone in the road but also the gopher who sits beside it, we find the same forces acting. The light reflected from surrounding objects falls on both alike, both are struck by the rain or warmed by the sun, but the result of the action of these forces on the gopher is behavior quite

1 The first systematic statement that mind could be described in terms of behavior was made by Dr. E. A. Singer, Jr., in 1911. See articles: "Mind as an Observable Object," Journal of Philosophy, 1911 , p. 180, and 1912, p. 206; "Consciousness and Behavior," ibid., 1912 , p. 15; "The Pulse of Life," ibid., 1914, p. 645; "On Sensibility," ibid., 1917, p. 337. 
different from the behavior of the stone. The light rays reflected from the approaching vehicle cause him to scurry away and those reflected from food cause him to approach. The impact of rain may move him toward the source of impact rather than away from it. Though, like the stone, he is a physical object, he is not merely buffeted about by his environment.

\section{Behavior Dependent on Bodily Structure}

The difference between the behavior of animals and the behavior of inanimate objects depends upon the fact that animals possess specialized structures. The most important of these structures are the sense organs (receptors), the muscles and glands (effectors), and the nervous system. The sense organs are placed in parts of the body where they are exposed to the action of physical forces. The physical forces that arouse the sense organs to action are called stimuli. Because the various kinds of sense organs differ from each other in structure, some are provoked to action by one kind of physical force, and some by another.

The stimulus that commonly arouses the sense organ to its characteristic function is called the adequate stimulus. Light has an effect upon the eye that it does not have upon the ear or upon the skin. Gases emanating from a flower act only upon the olfactory sense organs. In addition to their more 
frequently received stimuli, many sense organs may be stimulated by pressure or by an electric current.

The physical forces that stimulate the sense organs differ in kind. Light, heat, gravity, sound, and impact, are a few of these and each acts upon some sense organ or another. All stimuli may vary in intensity, and their effect upon sense organs may vary correspondingly.

Sense organs are connected with distant muscles and glands by nerve structures. Along these nerve structures pass nervous impulses which result from the stimulation of the sense organs and which, on reaching muscles and glands, may cause muscular contraction or glandular secretion. It follows that any response to a stimulus can occur only when there is a conduction pathway established between the sense organ receiving the stimulus and the muscles concerned in the response. Such a pathway is called a neural arc.

The nervous system contains millions of nerve cells called neurones. These are microscopic in cross-section but are occasionally as much as two feet or more in length. Each neurone consists of a cell body from which extend branching processes which may lie adjacent to other cells. The points of contact so established offer varying resistance to the passage of nervous impulses from one cell to another. Such a connection between two neurones that permits the passage of a nervous impulse is called a synapse. The repeated passage of an im- 
pulse through a synapse is supposed to increase the conductivity of the synapse. Some synapses are present at birth, some occur in the maturation of the nervous system, whereas others are formed in the course of learning.

The great number of neurones and the complexity of their connections account for the fact that an impulse leaving a particular sense organ may find its way to one group of muscles at one time and to another group of muscles at another time.

The muscles and glands are the effectors, or organs of response. They are so situated and so connected with sense organs by nervous structures that their responses are coördinated and meet suitably most situations. Placing something in a baby's hand causes the hand to grasp the object. The nervous impulse that starts from sense organs in the skin finds its way to the muscles which cause the fingers to close. Without such established pathways of conduction, behavior would be inappropriate.

A significant characteristic of all sense organs is that they are most sensitive to situations that affect the life processes of the animal. This adjustment to situations depends, first, upon the position of the sense organs in the body, and second, upon the structure of the sense organs and upon the nature of their adequate stimuli. For example, the eyes are so placed in the front of the body as to receive stimuli from objects which the animal is approaching. Placed at the rear they would be less useful. The 
tongue has a strategic position, as all food must pass its inspection before being swallowed, and the sense organs of taste are affected as are no other parts of the body by the chemical stimuli that are indicative of the food value of any substance taken into the mouth.

\section{Classes of Sense Organs}

According to their location in the body, sense organs are described as the exteroceptors, the interoceptors, and the proprioceptors. ${ }^{2}$ Those on the outer surface of the body, which receive external stimuli, are called exteroceptors. These are the sense organs in the skin that respond to touch, temperature, and destructive stimuli, and along with these the sense organs in the eyes, ears, and nose. The eyes, ears, and nose are also called distance receptors because they respond to stimuli whose origin is commonly at a distance, a classification recognized by as early a writer as Aristotle.

Besides the external surface of the body there is the surface of the enteric tract, which consists of the mouth, pharynx, oesophagus, stomach, and intestines. This surface is also provided with sense organs and these are called interoceptors. Parts of the external world taken into the enteric tract, usually as food, stimulate the interoceptors and the animal's behavior is adjusted to what has been

2 Sherrington, The Integrative Action of the Nervous System, lecture 9 .

3 Aristotle, De Sensu, 436b. 
swallowed. The mouse that is outside a cat stimulates the cat's exteroceptors and the cat responds in a conspicuous and characteristic way. Once the mouse is transferred to the cat's enteric tract, the cat's reactions are less obvious but none the less important. Movements of rejecting food, of swallowing, and of peristalsis, the secretion of digestive fluids, and much of the animal's observable behavior result directly from the stimulation of interoceptors.

Sense organs occur not only on the outer and the inner surfaces of the animal but are also found deeply imbedded in the body tissue. These deeply imbedded sense organs are called proprioceptors. Among the contractile muscle fibers are situated receptors that are stimulated by muscle tension. Other receptors in the tendons receive stimuli in a similar way. The walls of blood vessels are supplied with sense organs, so that circulatory changes affect the animal's behavior. In the head are located the semicircular canals and the organs of static sense, which are stimulated by the movement or by the position of the animal. The proprioceptors are all-important in making possible the coördination of bodily movements. ${ }^{4}$

\section{The Exteroceptors}

The most highly developed of the exteroceptors

4 On the classes of sense organs and their functions see Sherrington, op. cit. 
are the distance receptors, namely the organs of visiou, hearing, and smell. ${ }^{5}$

The Eye.-Anyone having an acquaintance with the camera will find it easy to understand the mechanism of the eye. Light passes into the eye through the anterior wall, which is the transparent cornea. Behind the cornea is a diaphragm called the iris. Behind the iris is the lens and behind the lens, on the inner surface of the eye's globe-like wall, is the sensitive retina. The internal cavity of the eye is filled with a transparent mass. That in front of the lens is called the aqueous humor and that behind the lens, the vitreous humor. As we view our own eye in the mirror we see at the center a black spot, the pupil, surrounded by a pigmented ring, the iris. The pupil is a hole in the iris and appears black because it is an opening into the unlighted interior of the eye. It is the color of the iris to which we refer when we speak of brown eyes or blue eyes. Outside the circle of the iris is the white sclerotic, continuous with the cornea, which, with the cornea, constitutes the external wall of the eye. (See Figure 1.)

By means of six external muscles the eyeball is moved about in its socket, and in this way a person looks up or down, to the right or the left, converges the two eyes in fixating a near object or so directs them that the axes of vision (the lines passing

5 For a more detailed account of the structure and function of sense organs and nervous system see Ladd and Woodworth, Elements of Physiological Psychology. 
through the center of the cornea, pupil, lens, and fovea) are almost parallel in fixating a distant object. To some extent the eye may be rotated about the axis of vision. (See Figure 2.)

The iris is a doughnut-shaped muscle containing, for the most part, circular muscle fibres. When

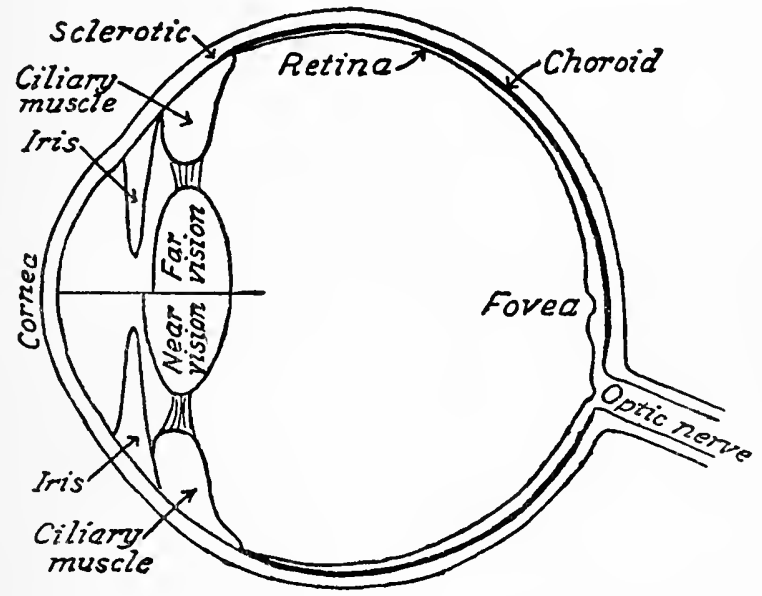

Figure 1. SCHEMATIO DIAgraM OF A SECTION THROUGH THE EYE

these fibres contract, the hole in the center, the pupil, becomes smaller. When the radiating fibres that it contains contract, the pupil becomes larger. For near vision and when stimulated by bright light, the pupil becomes smaller. For distant vision and in dim light the pupil becomes larger.

The crystalline lens is suspended all around its margin by the suspensory ligament which connects 
it with a second doughnut-shaped muscle called the ciliary muscle. When the circular fibres of this muscle contract, the tension on the suspensory ligament is decreased and, because it is itself elastic, the lens becomes more convex. In this shape it focuses rays of light from nearby objects so that the

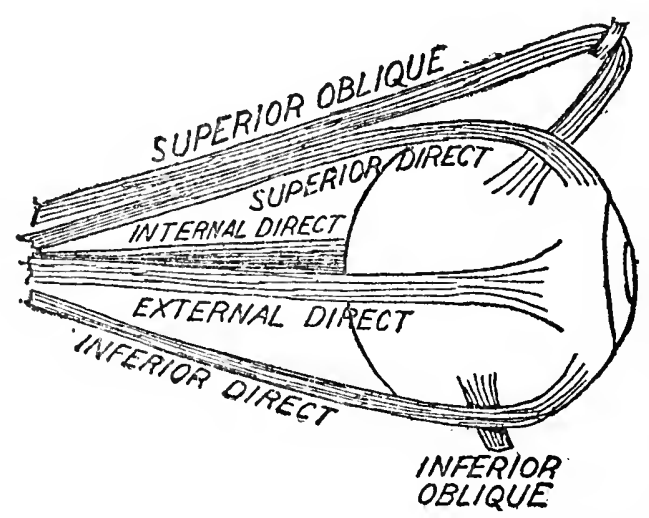

Figure 2. DIAGrait of the position of the external muscles that MOVE THE EYEBALL.

images of these objects are clearly defined on the retina and the images of distant objects are blurred. When the circular fibres of the ciliary muscle are relaxed and the radial fibres contracted, the suspensory ligament is under greater tension, so that the lens becomes less convex and the images of distant objects are clearly defined on the retina, the images of nearby objects being blurred. When the eyelids are closed and the eye is at rest, the circular fibres are relaxed and the lens takes on this less convex 


\section{THE ELEMENTS OF BEHAVIOR}

shape, that is, the eye is accommodated for distant vision.

Accommodation for near vision, then, involves a smaller hole in both the iris and the ciliary muscle and this is brought about by the contraction of the circular fibres in each. For this reason accommodation for near vision, because of the stimulation of sense organs in these muscles, gives us a sensation of muscle strain. In distant vision and dim light, where the circular fibres are relaxed, such sensations are practically absent.

The adequate stimuli to the eye are ether vibrations whose frequency is more than 450 million million vibrations per second and less than 790 million million. Lights of different color have different vibration frequencies and intense lights have a greater amplitude of vibration than have dim lights. White sunlight contains a mixture of rays of all possible vibration frequencies to which the eye is sensitive. Light emanating from a source such as the sun or a candle either enters the eye directly or impinges upon the surfaces of objects from which it is reflected into the eye.

Light passing through the cornea, the aqueous humor, the lens, ard the vitreous humor reaches the retina. In the retina are found chemical substances that change their composition when acted upon by light, and cell structures, some of which are affected by these chemical changes. Exactly what takes place in the retina is not known, but we have reason to 
believe that the pattern of the image focussed upon the retina sets up various changes in the photochemical substances and that these changes affect adjacent cell structures. This is the stimulation that gives rise to nervous impulses.

Apart from supporting tissue, the cell structure of the retina is made up of nerve-cell bodies whose long processes, or axones, constitute the optic nerve; of other nerve cells whose function it is to connect adjacent parts and layers of the retina; and of the rods and cones, which may be regarded as the actual sense organs for vision. (See Figure 3.) The rods respond to dim light as well as to intense light, whereas the cones respond only to intense light. Colored light and white light affect the rods in the same way, no color vision resulting from such stimulation. ${ }^{\circ}$ On the other hand the cones give a specialized response to white light and to lights of different colors, and it is by means of the cones that we distinguish one color from another.

The rods are lacking in the fovea, or that portion of the retina that is directly opposite the pupil. At night when an image of a faint star falls upon the fovea, where there are no rods, it cannot be seen, but it becomes visible when we glance to one side and so cause its image to be displaced toward the periphery, which is well supplied with these sense organs for dim light. The fovea is richly supplied with cones and is the so-called area of distinct

6 For the various theories of color vision see ibid., pp. $340 \mathrm{ff}$. 
vision. The image of the print which is being read falls upon the fovea, and the print could not be read as well if its image were to fall upon the peripheral, or outer, margin of the retina. The extreme periph-

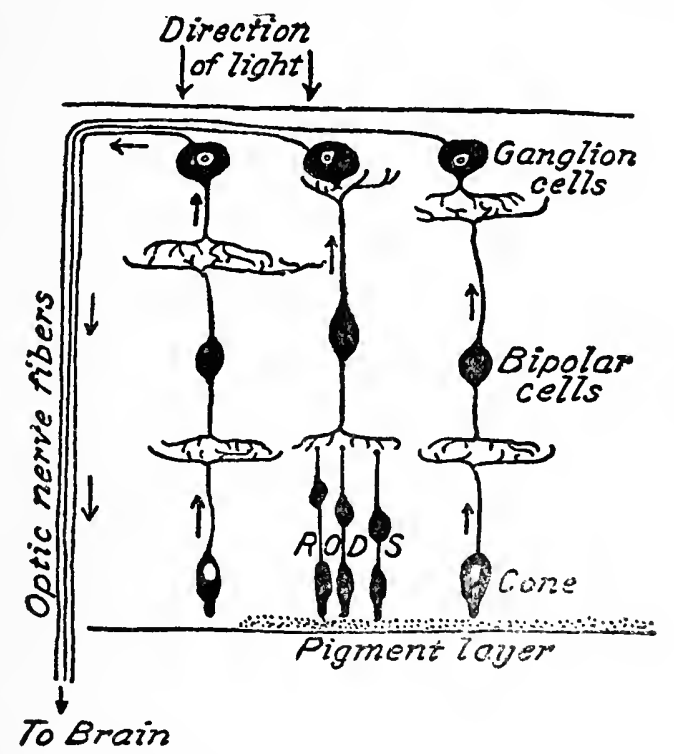

Figdre 3. SCHEMATIC Representation OF a section through the RETINA, SHOWING THE POSITION OF RODS AND CONES, THE LAYER OF CONNECTING NEURONES, AND THE DIRECTION OF FIBRES OF THE OPTIC NERVE

ery contains only rods, and for this reason any object casting its image there appears to be without color.

When the eye has been exposed to intense light the rods become fatigued and do not function in twilight until after a period of rest. For this reason, if we enter a darkened theater in the daytime, we grope 
blindly for the seat, but if we have come in from the dimly lighted street at night, we find our way about without difficulty. In the dark-room it may require a stimulus 8,000 times as great to elicit a response from a light-fatigued eye as is required to secure a response from the thoroughly rested eye. This is true, of course, only of parts of the retina where rods are found The unfatigued eye is sometimes ambiguously called a "dark-adapted" eye.

Ordinarily both eyes are used in vision, and are so directed toward a part of any object that is looked at that the right eye image and the left eye image fall on corresponding areas of the two retinae. When this occurs, the two images appear as one, and are said to fuse. When the two images fall on non-corresponding parts of the two retinae, the object is seen double. In order that the images from a near object may fall on corresponding parts of the two retinae the eyes must be so moved that the axes of vision converge. To secure fusion of the images of a distant object, the eyes must be so directed that their axes of vision are almost parallel.

An important fact is that vision enables animals to respond to objects at a distance.

The Ear.-Three parts of the ear are distinguished, the external, the middle, and the internal ear. The external ear leads into the middle ear and is separated from it by the tympanic membrane. When air vibrations impinge upon this membrane, it 
oscillates back and forth and causes movement in a series of three small bones situated in the middle ear. The movement of these bones is transmitted in turn to the fluid in the cochlea, which is a part of the inner ear. Thus vibrations are set up in this fluid that have the same rate as the air vibrations

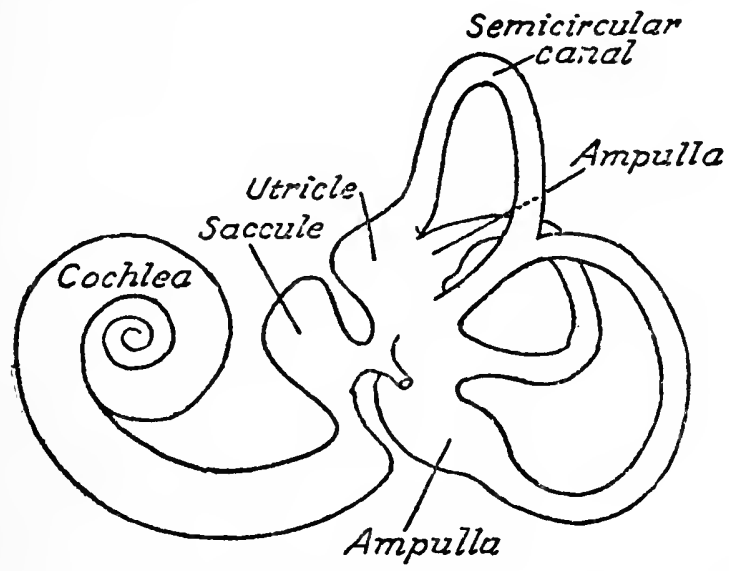

Figure 4. DRAWING From a MODEL OF THE INNER EAR, SHOWING THE COCHLEA, IN WHICH ARE THE SENSE ORGANS OF HEARING; THE UTRICLE AND SACCULE, THE ORGANS OF STATIC SENSE; AND THE SEMICIRCULAR CANALS

outside. The endings of a part of the auditory nerve are situated along the base of a row of rods and hair cells that project into the fluid contained in the cochlea. (See Figures 4 and 5.) It is not certain whether the auditory nerve endings are stimulated by the vibration of this projecting row or by the vibration of the membrane at the base of the row. 
The adequate stimuli to the ear are vibrations in the surrounding medium, usually in the atmosphere. These are condensation and rarefaction vibrations and their rate varies from something more than 16 per second to about 50,000 per second. Sound emanates from a vibrating object, such as a bell or the

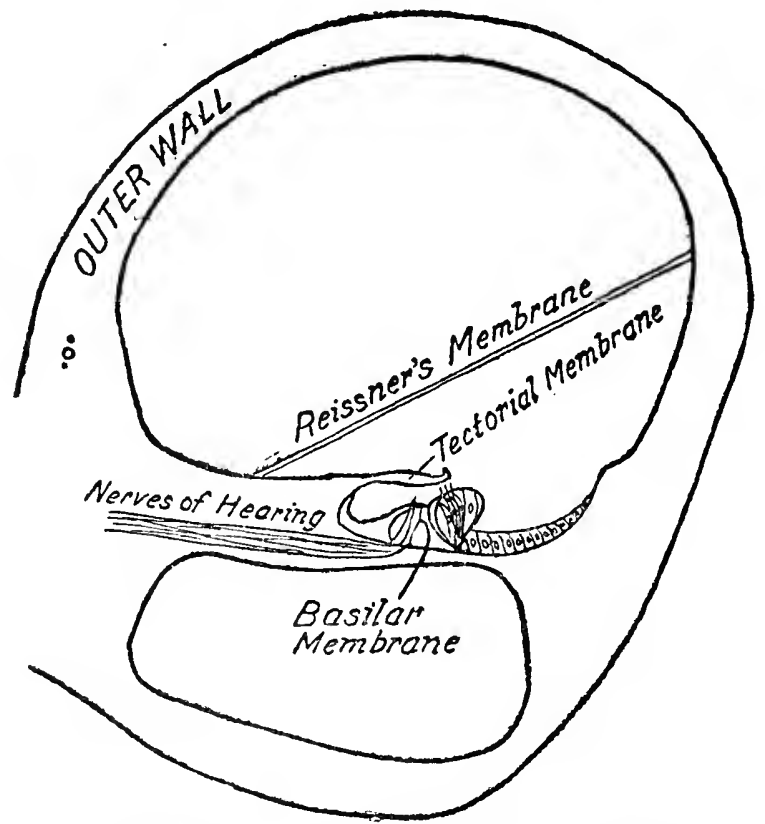

Figure 5. SCHematic section throdgh one of THE coIrs of The COCHLEA, SHOWING THE BASILAR MEMBRANE AND ADJACENT STRUCTURES

vocal cords of an animal, and the vibrations are taken up by the atmosphere and conveyed to the tympanic membrane. This enables an animal to respond to objects at a distance. 
The Nose.-In the wall of a recess that opens upon the air passages of the nose are found the sense organs for odor. The actual sense organs for odor are long nerve cells embedded between epithelial cells and with long processes extending to the surface of the mucous membrane. In the other direction nerve fibres extend from these cells to the brain. (See Figure 6.)

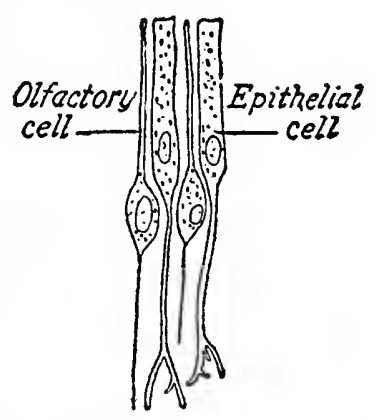

Figure 6. Section throdgh the olfactory Membrane showing OLFACTORY CELLS AND SUPPORTING CEILS

The adequate stimuli to the olfactory sense organs are gases in the atmosphere. These emanate from volatile substances, and upon reaching the nose are inhaled past the olfactory area. This makes it possible for the animal to respond to objects at a distance, although the stimulus may be slow in reaching the animal and gives but little indication of the direction of its source.

Organs of Touch.-There are two kinds of sense organs for touch. On parts of the body where hair is absent, such as the lips and the palm of the hand, 
are found touch corpuscles that enclose a core of cells and nerve fibres. On the hairy surfaces the nerve fibres are found coiled about the roots of the hairs. The touch corpuscles (shown in Figure 7) are plentiful in some areas of the skin such as lips, tongue, and finger tips, and sparsely distributed in other areas.

The adequate stimulus for touch is deforming

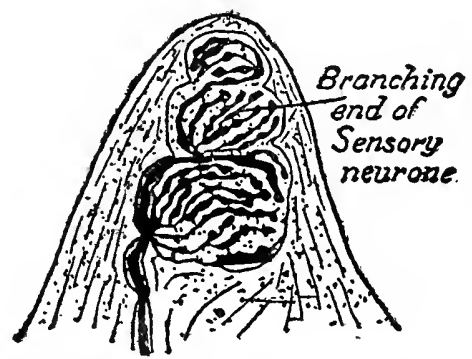

FIgURE 7. TOUCH CORPUSCIE FROM THE PALM OH THE HUMAN FINGEB (AFTER RANVIER)

pressure upon the skin adjacent to a corpuscle, or to the "windward" of a hair, or pressure upon the hair itself, which stimulates the nerve ending at its roots.

Warmth Organs.-The warmth sense organs are probably distinct from the cold sense organs. This conclusion is suggested by the fact that spots on the skin sensitive to warmth are much fewer than spots sensitive to cold. There are, on the average, two or three such warmth spots to the square centimeter of skin surface. The organ is probably a cylindrical end bulb found rather deeply imbedded in the skin. 
The adequate stimulus for warmth is anything that increases within certain limits the temperature of the seuse organ. This may be done by the contact of the skin with objects whose temperature is higher than that of the sense organ at the time, by radiant heat emanating from objects at a distance, and by the dilatation of neighboring blood vessels. Dilatation may be produced by the application to the skin of such substances as mustard or pepper.

Cold Organs.-The sense organs for cold probably have the form of end bulbs, lying nearer the surface of the skin than do the warmth organs. The spots sensitive to cold average between 10 and 15 per square centimeter of skin surface.

The adequate stimulus for cold is anything that reduces within certain limits the temperature of the sense organ. This may be done by the contact of the skin with objects whose temperature is lower than that of the sense organ at the time, by skin evaporation, by heat radiation from the skin, and by the constriction of neighboring blood vessels. Certain substances, such as menthol, stimulate the cold organ either by direct action or possibly by causing bloodvessel constriction. A cold spot, curiously, may be stimulated by a pointed hot rod of a temperature 45 to 50 degrees C. (The temperature of the blood is 37 degrees C.). When such a result is obtained, we have what is called paradoxical cold.

Pain Organs.-Certain free nerve endings that are found distributed over most of the body surface 
are probably sense organs for pain. Pain is also elicited by the stimulation of parts of the body other than the skin surface, and possibly results from the intense stimulation of sense organs not primarily concerned with pain.

The adequate stimuli to the pain organs are mechanical, thermal, and chemical, and must be of much greater intensity than those that are necessary to arouse the organs of touch and temperature. The prolongation of these intense stimuli is usually injurious to the animal.

\section{The INTERUCePtors}

Taste Organs.-The receptors for taste are situated on the upper surface and the margin of the tongue, a few occurring on the uvula, the epiglottis, and the larynx. They are in the form of end bulbs penetrated by the sensory nerve ending and having a minute opening on the external surface. They are grouped together in certain of the papillae of the tongue, which are easily observed as small eminences.

The adequate stimuli for taste may be divided into four classes according to the responses they elicit: sweet, sour, salt, and bitter substances, and there are probably four corresponding kinds of taste organs. In order to stimulate the organs, the substance must be soluble. Many substances such as peppermint, onion, cantaloupe, or cheese are popularly regarded as having characteristic tastes, but 
these are for the most part odors. When the nose is carefully packed, so that no respired air reaches the olfactory surface, it is impossible to distinguish clam bouillon from beef bouillon, black coffee from quinine solution, honey from molasses, or lemon juice from vinegar. These substances are then responded to as though they were merely salt, bitter, sweet, or sour.

Other Interoceptors.-Sense organs are found throughout the mucous membrane of the alimentary tract. Because of their isolated position, less is known concerning their action than is known of the function of sense organs more accessible to experimentation. They are more sparsely distributed than are the sense organs on the skin and, though some respond to pressure and to temperature, they are most affected by chemical stimuli.

Their adequate stimuli are food substances, internal secretions, and the movements of the enteric tract. Thirst results from dryness of the pharynx, and hunger from a vigorous peristaltic movement of the empty stomach that may occur at intervals of about one minute.

\section{The Proprioceptors}

Semicircular Canals.-These organs, though not auditory in function, are contained in three communicating cavities constituting a part of the inner ear. (See Figure 4.) The cavities are, roughly speaking, ringlike in form, each one being set at 
right angles to the other two. Cells with hairlike processes project into the fluid which the cavities contain. When the head is rotated in any plane, the contained fluid, in at least one of these canals, due to inertia, lags behind the walls of the cavity. Because of this, the projecting hair processes are bent to one side and the adjacent nerve fibres are stimulated. This action may be understood by thinking of a bucket filled with water into which projects moss that is attached to the wooden surface. When the bucket is rotated, the water lags behind and the moss is bent. If the bucket is kept twirling for a short time, the water takes up its motion and continues to move when the bucket is stopped, thus reversing the direction of the moss. The semicircular canals act in a similar way, so that when a person has been whirled for a time in a revolving chair and suddenly stopped, he responds as though he were being turned in the opposite direction.

The adequate stimulus to these sense organs is rotary movement of the head.

Static Organs.-On each side of the head adjacent to the semicircular canals and contained in bony cavities are two small membranous sacs, the utricle and saccule. (See Figure 4.) Within them is a gelatinous mass into which project sensory hair cells. Among the hairs are found small particles of calcium carbonate, called otoliths. The pressure of the otolith-weighted mass upon the hair cells varies with the position and movement of the head. 
The adequate stimulus to these organs is the position of the head with reference to gravity, or motion of the head in any direction.

Muscle and Tendon Sense Organs (Kinesthetic Organs).- In the muscles are found sensory "spindles" made up of modified muscle fibres and free nerve endings. Similar organs are found in the walls of blood vessels and in the tendons.

The adequate stimulus for these organs is the mechanical pressure and state of strain in muscles and tendons that results from any bodily movement.

\section{The Nervous System}

A stimulus starts a chain of neural events and a response terminates it. Between stimulus and response many things occur in the nervous system.

The principle has already been stated that a response can not result from a stimulus unless there is a pathway of nervous conduction between receptor and effector. The whole nervous system is an intricate arrangement of such pathways.

The brain is contained in the skull, and the spinal cord is contained in the vertebral column. The brain and spinal cord constitute the central nervous system. Sensory nerves lead from the sense organs to the spinal cord and brain. Motor nerves leave the brain and the spinal cord and lead to skeletal muscles. These sensory and motor nerves constitute the peripheral nervous system. In addition to the 
central and peripheral nervous systems there is the autonomic nervous system. This system serves the involuntary muscles and the glands. The muscles that it affects are distinct in kind from the skeletal or voluntary muscles, being "unstriped"' in appearance and slow in their action. Through the auto-

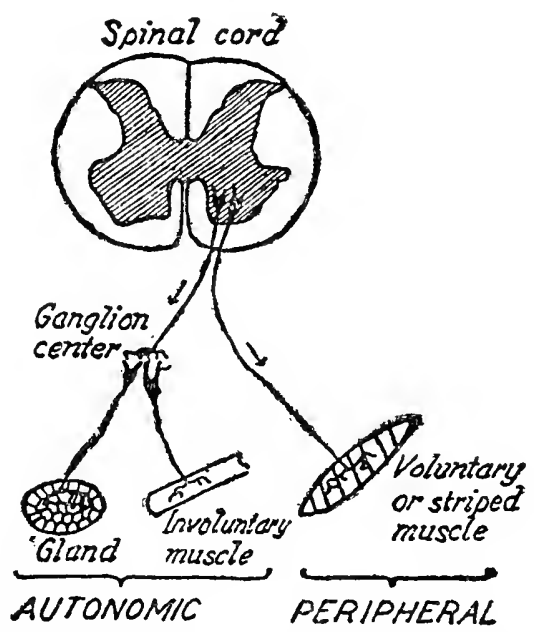

Frgure 8. The retation of efferent fibres of the autonomio AND THE PERIPHERAI NERVOUS SYSTEMS TO THE CENTRAL NERVOUS SYSTEM

nomic system the central nervous system is connected with such effectors as sweat glands, salivary glands, tear glands, adrenal glands, liver, spleen, stomach, intestine, rectum, bladder, genitals, heart, and blood vessels. The autonomic has much the same function as the peripheral nervous system. The relation of the three systems may be seen from Figure 8. 
The Spinal Cord.-A cross section of the spinal cord shows an outer white area and an inner gray area whose shape varies at different levels of the cord but preserves a general resemblance to the letter H. (See Figure 9.) The outer white area is composed of longitudinal columns of nerve fibres en-

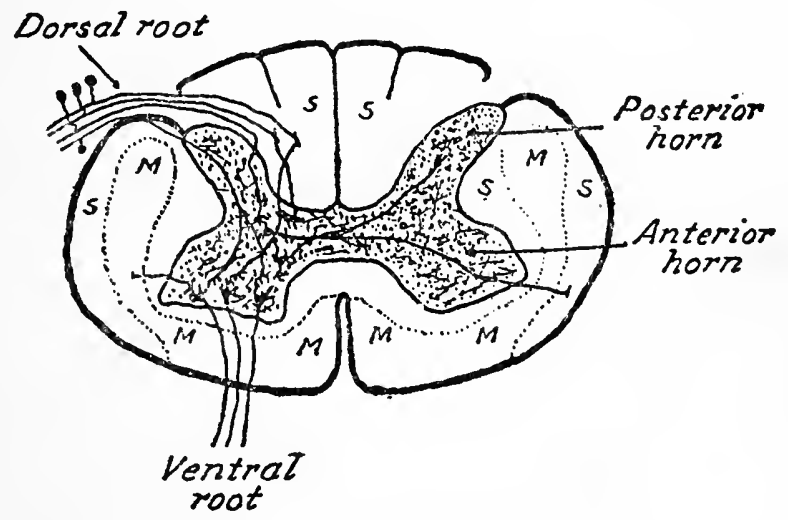

Figure 9. SChEMATIC SECtion OF THE SPINAL CORD. THE DOtTED AREA IN THE CENTER IS GRAY, DUE TO THE PRESENCE OF NERVE CELL BODIES AND UNMEDULLATED FIBRES. THE OUTER AREA IS MADE UP OF COLCMNS OF LONGITUDINAL FIBRES. AREAS OF MOTOR FIBRES ARE MARKED M., AND AREAS OF SENSORY FIBRES ARE MARKED S. OTHER AREAS ARE MAINLY CONNECTING FIBRES

cased in their white medullary sheaths. The inner gray area is made up of two posterior (or dorsal) and two anterior (or ventral) horns with an isthmus of connecting or commisural fibres. Its gray appearance is due to the presence of nerve cell bodies lacking the white medullary sheath that gives their color to the outer columns.

The Brain.-The cerebral hemispheres constitute 
the largest part of the human brain. A cross section of one of these hemispheres shows an outer layer of gray matter that is called the cerebral cortex. This

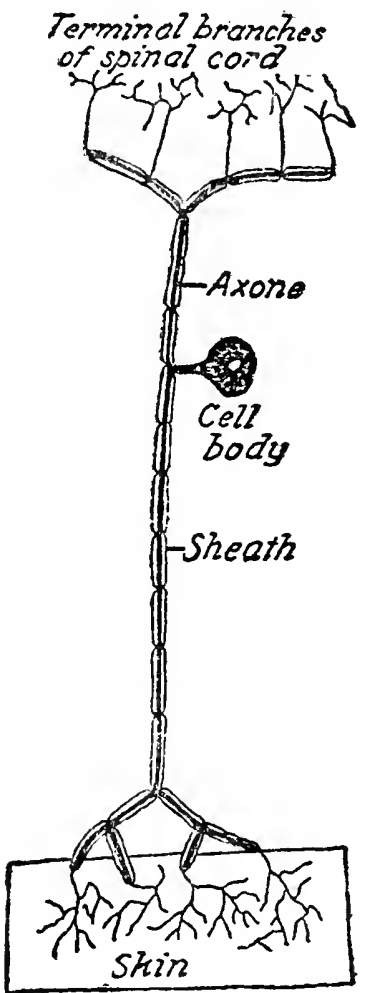

Figure, 10. Schematic Represevtation of SENSObt NeUrone is made up of un-medullated cell bodies and nerve fibres. A large part of the interior of the brain is seen to be composed of white medullated tracts, although there are distributed in this area numerous patches of gray matter. 
Neural Arcs.-A sensory (or afferent) meurone starts at a sense organ and terminates in the spinal cord. Its branched processes, extending upward

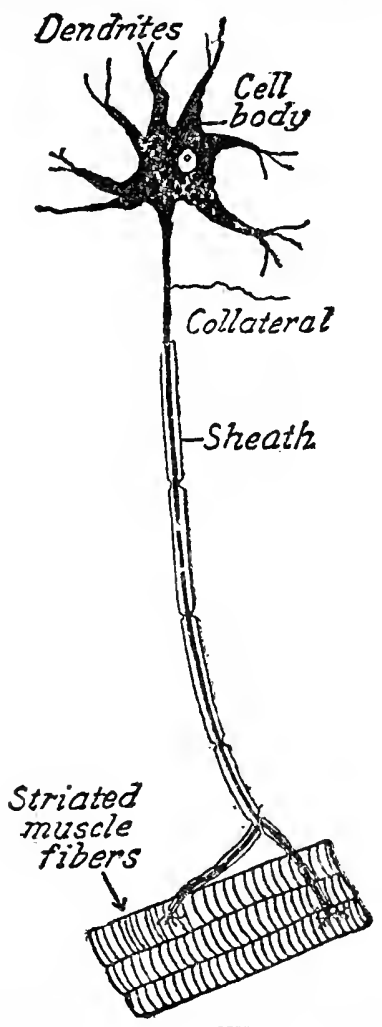

Figure 11. schematic RePresentation of Motor NeURone

and downward, form a part of the sensory columns of the cord, and from these columns its processes enter the dorsal horn at various levels. Connecting neurones, sometimes called association or internuncial neurones, carry impulses from the sensory sys- 
tems to motor systems. Every neural arc contains at least one such connecting neurone interposed between its sensory neurone and its motor neurone. The cortex has many more of these connecting neurones than has the spinal cord, so that in the brain there are many intricate pathways, any one of which an impulse may follow, depending upon the varying resistance in the synapses encountered. Figure 12 shows the relation of these connecting neurones to sensory and motor systems.

The motor pathways in the central nervous system consist chiefly of pyramidal tracts running from the cortex to the anterior horn of the cord. From the anterior horn motor (or efferent) neurones lead to the muscles.

When an impulse passes from a sense organ to a muscle by way of a sensory neurone, connecting neurones in the spinal cord and a motor neurone, its pathway is called a reflex arc. (See Figure 12.) Such reflex arcs are usually instinctive mechanisms. A frog with its brain removed responds to many stimuli by means of these reflex arcs.

\section{Regulatory Character of Responses}

A significant characteristic of responses is that in general they meet successfully the situations that contribute the stimuli that call them forth. For example, a foreign object in the nose calls forth a sneeze response that removes the irritating object. 


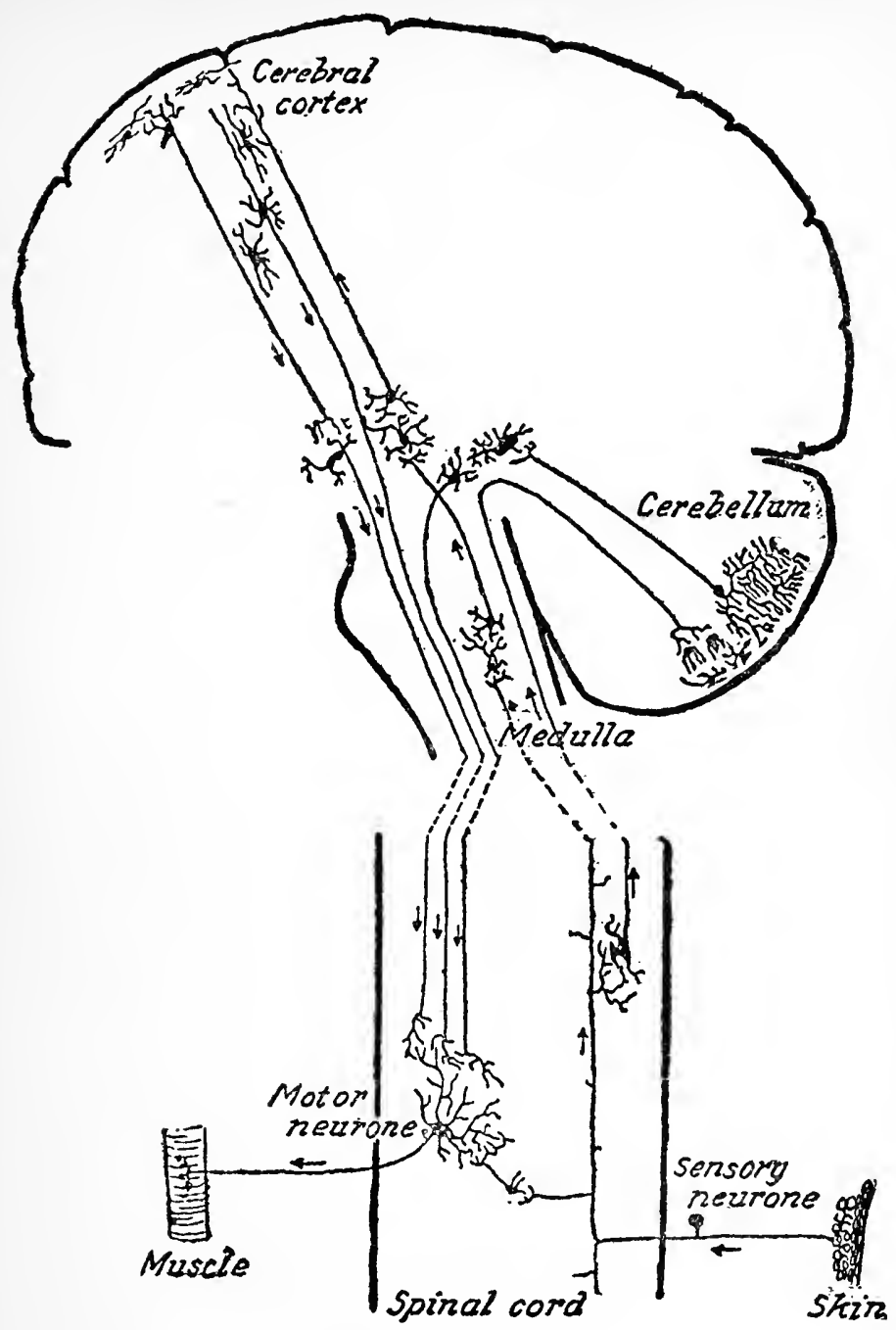

Figure 12. SCHEME OF NEURAL PATHWAYS FROM A SENSE ORGAN IN THE SRIN TO A MUSCLE. ARROWS INDICATE POSSIBLE COURSES TAKEN BY A NERVOUS IMPULSE. THE NEURONES ARE SHOWN ENLARGED OUT OF ALL PROPORTION TO THE SIZE OF THE BRAIN AND CORD (AFTER STARR) 
The visual stimulus of a fleeing mouse causes the cat to make movements that result in the mouse's capture, just as the mouse, receiving the visual stimulus of a cat, is impelled to make movements of flight. A baby will grasp the person who holds him if the support is suddenly released. One of the responses to stumbling is extending the hands, and this protects the more vital parts of the body from injury.

A baby cries when he is hungry, cold, frightened, or in pain. This serves to bring his nurse to the spot. We might contrast this mutual regulation in human beings with the behavior of such a simple animal as the frog. Frogs never come to each other's rescue, even though they have pain and danger calls. The only call which summons the frog's fellow is the mating call.

A familiar response of the dog is his scratching reflex. If stimulated with a pin point behind the right shoulder, the dog makes rapid oscillatory movements with the right hind leg, the utility of which movement is obvious. If the same stimulation be applied a short distance above the tail at a spot which the scratching foot cannot reach, the tongue makes reflex licking movements even though the dog does not attack the spot with his mouth. Thus stimulation of any part of the body brings into play regulatory responses that usually meet the situation appropriately.

The stimuli accepted by the distance receptors

7 Smith, "Regulation in Behavior," Journal of Philosophy, 1914. 
result in responses that adjust the animal to the good or evil that is about to befall it. In their simplest form these responses turn the animal toward or away from the stimulus, or increase or decrease the distance separating object and animal.

\section{Delayed Utulity of Responses}

The utility of a response is often not evident until a long time after it is given. The lapse of time occurring between the response and the advantage the animal reaps from it often makes the response seem a matter of prudent deliberation on the part of the animal, when this is really not the case. All responses of lower animals are evoked by present situations, even when the future situations to which they adjust the animal are far distant. This adjustment to the future, in particular cases, may be fruitless, as the probable event may never transpire, but the response occurs regardless of this uncertainty. These probable events are the situations in the environment of the species that recur periodically, such as night, or high tide, or winter, or new laid eggs. The brooding hen does not foresee the consequences of her act, but is merely responding to the eggs, the nest, and the physiological changes in her own body. The situation that causes the squirrel to store food in October is not the inevitable scarcity of nuts during the following winter, but rather the surplus food supply in the autumn. Some 
anticipatory reactions of animals are of use only to others, and an animal often dies before the utility of his act is manifest. A conspicuous example of this is the behavior of the solitary wasp in catching and storing food for an offspring whose birth she does not ordinarily survive.

The biological utility of the mating and nest building of birds is the birth and shelter of the offspring. The bird, however, responds to the situation at the time with as little regard for the future as man has when he coughs or sneezes in response to foreign objects in the throat and nose.

Apparent Absence of Utmity of Some Responses

Although we may usually expect to find some use served by every response, there are many cases of inappropriate reactions. For example, the instinct that leads a dog to run barking beside the front wheels of an automobile seems to serve no useful purpose either to dog or driver. If we remember, however, that the dog is the descendant of the wolf and that the wolf in killing his prey must depend upon the pack for assistance, it is clear that there was a time when this reaction was of service. By these movements that are so annoying to us in the dog, the single wolf, fleeter than his fellows, overtakes and turns back his prey so that the whole pack take part in the killing. The absence of utility in the dog's act is due only to the fact that he lives in 
artificial conditions. Many of man's inappropriate responses that are spoken of as immoral have, at some period in the history of the race, been a necessary means to his survival.

Living in a complex civilization makes many of our original reaction tendencies inappropriate. Our proneness to anger toward telephone operators, or toward the automobile that resists our efforts to start it, is often of no use to us. Our natural equipment does not include appropriate responses to these situations. Loudness of voice and violent action are the innate responses to situations not wholly dissimilar to an irritating operator or to a recalcitrant machine, so these are the responses given by the unregenerate. When a man steps in front of us in the line waiting for theater tickets, our adrenal response, promoting as it does the clotting of the blood, prepares us for actual bloodshed, although this is usually needless as we may never come to blows.

\section{Orientation, Locomotion, and Intervention}

A response to stimulation is often a turning toward or away from certain objects. These objects are usually themselves the source of the stimulus that causes the turning. The altered position generally serves one of two purposes. It may put the animal in a position to employ mouth or legs to advantage, as when a startled animal takes up an atti- 
tude of defense or prepares for flight. It may change the direction of the animal's sense organs with reference to the provoking stimulus or with reference to other stimuli usually associated with this. For example, the horse cocks his ear toward the unusual sound, thus bringing the sense organ further into play. The herd wheel in the direction from which danger may be expected in response to the danger cry of the leader. Taking up a posture that permits the appropriate action of receptors or effectors, or that withdraws receptors from stimulation, is called orientation.

Many of an animal's movements, such as walking, running, jumping, swimming, crawling, or flying, serve to impel him from place to place. Movements that cause a change of location of the animal as a whole are called locomotion.

Responses of orientation and locomotion frequently occur simultaneously. If a cow is standing by the roadside facing us as we approach in a vehicle, she merely maintains her orientation with respect to the vehicle, by slowly turning her head as we pass. If, on the other hand, we approach her on the flank, her head turns toward the road in response to the sound, but she is also actuated to flight. In order to keep her eye on the vehicle and at the same time to move forward, she wheels slowly and crosses the road ahead of us. What seems to be a mere perversity in the cow is explained as a combination of these two action systems. 
Orientation and locomotion change the position of the animal with reference to objects in the environment, but do not change the position of surrounding objects with reference to each other. Responses that serve to redistribute the parts of the outside world will be called intervention. Responses of intervention, as, for example, picking up an object, always involve orientation, and often locomotion as well.

Movements of orientation, locomotion, and intervention all serve to bring new stimuli to bear on the animal and these in turn are succeeded by new responses. The proportion of intervention responses in higher animals is strikingly greater than in lower forms. In response to variations of season and food supply, birds employ orientation and locomotion, thereby bettering their environment. The hermit crab travels about until he finds a shell that affords him shelter. Man, on the other hand, by means of his elaborate intervention responses, so constructs the world about him as to lessen his dependence upon movements of orientation and locomotion, with a resulting increase of convenience and safety. He plants his crops and breeds his cattle instead of searching for wild vegetables or game. $\mathrm{He}$ is born naked and assumes or discards clothing according to the weather. He brings together into one place shelter, clothing, bed, food, water, fuel, utensils, mate, and offspring. From his immediate neighborhood he removes dirt, enemies, and danger- 
ous objects. He constructs tools and weapons that are of assistance to him in further movements of intervention. By an elaboration of mechanical contrivances he devises vehicles that take the place of his legs in locomotion, and instruments that extend the range and accuracy of his sense organs.

\section{Internal Responses}

The three types of responses just mentioned, orientation, locomotion, and intervention consist in movements of the skeletal muscles. Animals respond also by movements of visceral muscles and by glandular secretion. ${ }^{8}$ The dog that smells appetizing food not only turns toward the food, approaches and tears it with his teeth, but also responds by certain internal reactions of peristalsis and secretion. Peristalsis is a wave-like muscular constriction of the enteric tract that serves to carry food, once taken into the mouth, into stomach and intestines, and to knead the food in such a way that all parts of it are brought into contact with the secreting and absorbing walls. Secretions into the enteric tract serve to prepare the food for absorption. The principal glands that serve digestion are in the mouth, stomach, intestines, pancreas, and liver. At the sight or smell of food, the mouth and stomach are prepared by their secretions to receive it. The flow of these secretions is later increased by the presence

8 For a detailed account of such internal responses see Cannon, Bodily Changes in Pain, Hunger, Fear, and Rage. 
of food in the mouth, by the movements of chewing, and by the peristalsis of which swallowing is a part.

When a cat is enraged by a barking dog, it not only "spits" and assumes the posture of defense, but its peristalsis ceases, and the blood vessels so change their size, by the play of minute muscles in the vessel walls, that a greater blood stream reaches the fighting and fleeing groups of skeletal muscles. Sugar stored in the liver is liberated. From the adrenal glands adrenin is secreted and poured into the blood, with the result that fatigue is counteracted and the vasomotor condition and absence of peristalsis are maintained. Heart beat and respiration show an appropriate increase of amplitude and rate. As a rule, internal responses do not occur alone, but accompany movements of orientation, locomotion, and intervention. They facilitate these movements and, in turn, are further excited by them.

Emotional expression is made up of overt bodily movements and of characteristic internal responses accompanying them. The grouping of responses in each emotion shows great resistance to the rearranging effects of training, as is indicated by their fundamental similarity in diverse races. Grief, merriment, anger, and love are expressed in much the same way the world over. They are aroused, however, by varying situations in different societies. $^{9}$

9 See Darwin. The Expression of the Emotions in Man and in Animals, pp. 83-115. 
When a person is stirred to action by the internal responses of rage, fear, or love, we say he is "moved." This is more than a mere figure of speech. A situation that hampers movement causes the response of struggling with head, body, arms, and legs, but it also, either directly or because of the struggling, causes certain internal responses like those described in the case of the enraged cat. These internal responses stimulate proprioceptors in the viscera. The impulses so aroused are conveyed along neural arcs to the muscles engaged in struggling, and the action of these muscles is thereby strengthened and sustained. If the pathways of nervous conduction between proprioceptors and skeletal muscles should be severed, this reënforcement would not take place and the struggling movements would be less energetic and shorter-lived.

The secretion into the blood of adrenin from the adrenal glands reduces the peristaltic movements in the intestinal tract, increases by its action upon blood vessels the amount of blood in the skeletal muscles, and, by direct contact, makes more energetic the contraction of the skeletal muscles involved in the expression of rage. It probably promotes clotting of the blood, which is of advantage in case the ensuing fight results in the animal's being wounded.

This action of adrenin is another way of eliciting a response. Between the gland and the muscles acted upon there is no nervous connection. The blood 
stream carries the gland's secretion to the muscles, and the secretion has a direct chemical action upon the muscle tissue. Thus the direct action of internal secretions from ductless glands is complementary to the conduction of impulses from visceral proprioceptors through neural arcs. The effect of these secretions is less prompt than is the effect of neural reënforcement, but persists for a longer time.

The Action of a Stimulus-Response Mechanism

Many weak stimuli, which act upon sense organs without causing a response, will be found to call forth a response when the stimuli are increased in intensity. A stimulus of an intensity just sufficient to bring about a reaction is called a threshold stimulus or liminal stimulus. This is not to be confused with the term "adequate stimulus," which denotes the kind or class of stimuli ordinarily capable of exciting a sense organ. We may give a baby a quinine solution so weak that he will swallow it as though it were pure water. If the strength of the solution is gradually increased, we reach a point at which the baby will grimace and turn his head away. This constitutes the threshold point.

If, instead of increasing in intensity a stimulus that is less intense than the threshold stimulus, we repeat such a stimulus again and again, a response may be elicited. Bringing about a response by the repetition of a subliminal stimulus is called the sum- 
mation of stimuli. If, for example, a neighbor comes at night and persistently knocks on a man's door, the man finally rises from bed and lets him in, not because it is more reasonable to do so now than it was when the knocking began, but because of the neighbor's importunity.

The summation of stimuli is used extensively in advertising, the recurring advertisement often leading us eventually to buy the article described. This accounts in part for the number of people who use Ivory Soap and Bull Durham. The daily sight of the unanswered letter in the letter tray may finally call forth a reply. The ingenious torture that consisted in allowing a series of drops of water to fall on the bound victim produced a summation effect resulting in a greatly increased response.

Within certain limits the summation effect is increased as the length of the intervals between the subliminal stimuli is diminished. If the intervals are lengthened beyond a certain point, no summation effect occurs.

A response is sometimes given only after a number of diverse subliminal stimuli have been received, and may be the result not only of the last stimulus but of the entire series. Bringing about a response by a series of diverse subliminal stimuli is called the summation of diverse stimuli. The prospective purchaser of an automobile is led to visit the salesroom but remains irresolute in the presence of the machine. The salesman now initiates the process of 
summation. He calls the man's attention to various good features of the machine, and each of these stimuli brings the man nearer to parting with his money. The salesman appeals to his customer's vanity by reference to prominent men who own that make of machine. Finally a stimulus is given, such as the assurance that after this car is sold none will be available for several months, and the purchaser makes out his check.

To induce a child to take medicine, the summation of diverse stimuli is often effective. If a promise of candy or of money does not have results, we may try such bribery as offering to take him to the theater, or we may threaten to leave him at home. Finally, by petting or cajolery, the summation is completed. We often describe a person as being favorably disposed toward a certain course of action. This usually means that he has already received the first few of a series of diverse stimuli and all that we need do is to complete the series in order to bring about the response. For example, a man's child may have died recently and we realize that the time is auspicious for asking him to contribute to a children's charity. The acquaintance whom we would greet casually at home is welcomed effusively in a foreign country because we are already stimulated to friendliness by the internal changes that in part constitute homesickness.

The response to a series of stimuli varies according to the order in which the stimuli occur. A man 
standing beside a dark road responds differently to the sounds of approaching footsteps and to the sounds of retreating footsteps, which may be exactly the same sounds occurring in opposite order. Royce pointed out that it makes a difference whether a stranger first steps on a man's foot and then apologizes, or first apologizes and then steps on a man's foot.

\section{WEBER'S LAW}

Within certain limits the intensity of a stimulus may vary without modifying the nature of the response. If the stimulus is increased or decreased beyond these limits, the response alters its character or its energy. The amount by which a stimulus must be increased or decreased in intensity in order to alter the response is called the differential threshold. This term should not be confused with liminal threshold.

About 1825 it was suggested by Weber, a German investigator, that the ratio of the differential threshold to the amount of the stimulus is constant at all intensities for each class of stimuli. ${ }^{10}$ Although the law does not hold for very weak or for very intense stimuli, it has proven a demonstrable and valuable generalization. The ratio differs with different kinds of stimulation, being, for example, smaller in the case of light than in that of sound.

10 For a more detailed account of Weber's Law see Ladd and Woodworth, op. cit., pp. $361 \mathrm{ff}$ and $37 \mathrm{tff}$. 
The reflected light from a candle introduced into a sunlit room may not be noticed, but such an increase of illumination in twilight is at once apparent. It may be impossible to distinguish between a pitch of 512 vibrations and one of 513, but easy to hear the difference between pitches of 32 and 33 vibrations. A weight of 80 grams and one of 82 grams may be reported as being the same, but a weight of 20 grams and one of 22 will probably be recognized as different. It is evident that the apparent difference between two lights does not depend so much upon the absolute difference between the stimuli as upon the proportion of this difference to the intensity of the light. An absolute difference between two sound intensities does not insure our distinguishing between the two, for if the intensities are great this difference may be inadequate. The same is true of two weights, which stimulate us to different responses only if one is about three per cent heavier than the other. The just noticeable difference for light is about one per cent of the intensity of the stimuli. These differential thresholds vary greatly with different subjects and hold only within a limited range of intensities.

The Interaction of Stimulus-Response Mechanisms

As no animal is ever acted upon by just one stimulus at a time, but at any given moment is exposed to a great complexity of stimuli, its resulting be- 
havior is the interplay of many responses. The action of any stimulus depends on the other stimuli that occur along with it. A loud sound heard on the city streets causes a response different from that given to the same sound when the hearer is alone in the woods.

The combination of all the stimuli to which an animal responds at any moment is called a situation, and a combination of responses is called an act. ${ }^{11}$

If the situation that confronts the animal tends to arouse simultaneously two stimulus-response mechanisms, there may occur one of two results. One of the mechanisms, though not itself responding, may increase the tendency of the other to respond; or one may interfere with the action of the other.

The first of these results, where one system is an aid to the other, is called facilitation. This aid or reënforcement produces a more lively response in the system that is facilitated. Suppose a man, seeing a bear in the woods, responds by a dignified retreat. The bear now moves in the man's direction and he, previously walking, breaks into a run. Pigs eat more greedily when other pigs are sharing the meal, and almost any animal will partake more rapidly of the food that we threaten to remove. A toothache ends our delay in visiting the dentist, and a good appetite makes us respond promptly when summoned to dinner.

11 These definitions are proposed by Watson, Psychology from the Standpoint of a Behaviorist, p. 10. 
An increased tendency to act is to be expected when two stimuli lead to the same response, but this increased tendency may also occur in cases where the responses produced by the two stimuli are not the same.

The difference between facilitation and the summation of stimuli lies in this, that the stimuli combined in summation are all subliminal and occur serially, whereas the stimuli combined in facilitation may or may not be subliminal and if subliminal must occur simultaneously.

Contrasted with facilitation is the case of interference between two stimulus-response mechanisms. As a result of interference three things may happen; either both responses are given with lessened energy, or one response is given with lessened energy and the other is not given, or neither response occurs. The hampering effect that one system has upon another is called distraction. The preventing effect that one system has upon another is called inhibition. If a trap is baited and an animal is led by the odor of the bait to approach the trap, and if there is no odor of man about the trap, the animal will seize the bait and be caught. If, however, the body odor of the trapper adheres to the trap, the animal will either take the bait less readily or will entirely disregard it. If the bait is taken reluctantly, the body odor is a distracting stimulus; and if it is not taken at all, the body odor is an inhibiting stimulus. 
The reason one response prevails over the other is either that there is more resistance in the conduction path of one system than in that of the other, or that the relative strength of the two stimuli in terms of their thresholds is different. ${ }^{12}$

When interference so raises the threshold of both responses that neither is given, we have mutual inhibition. In this case a third stimulus may bring about a response that removes the animal from the first two stimuli, and the interference disappears. This may be seen in the case of a man who is addressed by someone while he is reading. He pauses in his reading and it is now doubtful whether he will answer the questioner or resume his book. One of these responses will eventually be given unless a third stimulus, such as the ringing of the telephone, causes him to disregard both book and questioner. Ordinarily man is acted upon not by two but by a multiplicity of stimuli, and his responses are determined by facilitating stimuli, inhibiting stimuli, distracting stimuli, and by the stimuli that primarily elicit the response.

\section{Compromise Responses}

When a spinal dog is simultaneously stimulated at a point on the shoulder and at a point several inches farther back, he scratches a spot somewhere

12 For a discussion of the neural basis of interference, see Sherrington, op, cit., pp. 55, 115-149, 223. 
between the two. His response is in the nature of a compromise. Man, as well, when stimulated to two distinct responses, often acts in a way that is a resultant of the two response tendencies. When playing ball with a stone, we tend to throw it as if it were a ball to the person who is about to catch it, and we tend to refrain from throwing it because we are in the habit of not stoning our friends. The resultant act consists in throwing the rock gently.

Compromise in emotional responses is the rule rather than the exception. If a child's mischief annoys us, we respond to him both as to a child to be treated kindly and as to a nuisance to be abated. The resultant response is remonstrance with sad good humor. When a puppy is scolded, his behavior is a compromise between affection and fear, and is somewhat suggestive of the politeness of human beings in the presence of strangers. 


\section{CHAPTER II}

\section{INSTINCT}

If we know the structure of a machine, we can predict what it will do whenever it is acted upon in a familiar way. Man is no exception to the rule, and we find that in so far as men are alike in structure they respond in the same way whenever their sense organs are acted upon in a like manner. Babies all show a great similarity of structure at birth before they begin to learn, and, to a considerable extent, this similarity of structure persists when they become adults, and even after each has taken on individual peculiarities due to the particular influences to which he has been exposed.

In addition to this partial persistence of the baby's original nature, there is a closely related factor that helps to make all men somewhat alike. This is that the structures of all of us tend to change in the same way as we grow older. This change we call maturation.

Acts that are due to original structure, or due to a structure resulting from simple maturation, we call instincts. Such a definition as this makes it possible to describe all behavior as either instinctive or learned. 


\section{REFLeXes}

Spinal reflexes have been described in Chapter I. Man's original structure includes most spinal reflex arcs, and, in addition to these, many neural ares of greater complexity whose pathways involve connecting fibres in the medulla and brain. All these natural pathways through the brain are usually called reflex arcs of higher level. The fixation of a light that has fallen on the periphery of the retina, and the grimacing due to a bitter substance on the tongue are examples of such higher level reflexes.

A baby that is just born is almost wholly lacking in experience. Although for some time before birth the sense organs, the nervous system, and the muscles are sufficiently mature to function, a conclusion that is proved by the behavior of premature infants, the child's isolation and confinement prevent any very elaborate responses.

At birth the infant enters a world rich in situations, and a world permitting freedom of movement. Then for the first time he experiences light, odor, temperature, and cutaneous pain stimuli. He then draws his first breath, cries, swallows, coughs, sneezes, nurses, and fixates objects with his eyes. He is still a creature of reflexes, although some of these reflexes, such as the movements of nursing, occur in fairly predictable series.

Many careful observations and experiments have been made upon babies from birth in order to dis- 
cover the nature of their reflex responses. ${ }^{1}$ The maternity hospital affords excellent opportunity for this work during the first few weeks of the baby's life. Movements made by an infant at birth may be regarded as natural tendencies unaffected by habit formation. In the case of responses made after a baby is several weeks old, even though they are then performed for the first time, there is always a possibility that they are a product of training, although often it seems more plausible to regard them as natural tendencies that are the outcome of simple maturation. The ability of a baby to reach out and grasp an object that he sees, usually appears when he is four or five months old. It is uncertain whether this act is due wholly to the maturation of his nervous system or is the result of trial and error learning. Before this so-called eye-hand coordination is attained, he has grasped many objects that come in contact with the palm of his hand and has fixated these objects with his eyes. Whether or not this act is instinctive could be decided only by placing the child in such restraint that no experience in casual grasping would be possible. If, on being given his freedom at the proper time, the eye-hand coördination at once occurred, we could assign it with certainty to the category of reflex. The suddenness with which this and other coördinated movements appear, however, lends plausibility

\footnotetext{
1 Watson, Psychology from the Standpoint of a Behaviorist, chap. 6 and 7.
} 
to the assumption that such acts are dependent upon late maturation and are to some extent independent of training.

Just after a baby is born, and when he begins to breathe, a vocalization known as the birth cry occurs. This cry is elicited by asphyxia and the customary slapping. Yawning has been observed five minutes after birth, and sneezing sometimes occurs as soon as the baby is born. Blanton" describes the "colic cry" as being high pitched and different in this respect from the general crying due to hunger, pain, and fatigue. Crying in response to a cold plunge may be inspiratory in character. Drawing down the corners of the mouth while crying has been observed 30 minutes after delivery, and the transverse crease between the eyes may occur at birth. Being picked up may cause the baby to cry, and a surgical operation will at any time cause this response.

Blanton reports the following sounds during the first month: $m, n, n g, h, w, r, y$, ow as in owl, $e e$ as in feel, oo as in pool, $a$ as in an, and $a$ as in father.

The enteric responses given the first day are swallowing, hiccoughing, regurgitation, spitting out, sucking, licking, and defecation.

Binocular accommodation and fixation of a light are often to be observed during the first hour. Fixation is most easily elicited when the light is placed

2 Blanton, "Behavior of the Human Infant," Psychological Revieno, 1017, pp. 456-483. 
directly in front of the child. Blanton reports that the eyes of many babies follow a slow moving hand at birth. Watson observed no blinking in response to a threatening gesture prior to the fifty-fifth day. The head may be rotated toward the source of light during the first few days. Tears may be present from birth.

Smiling has been observed in babies as young as four days old and may result from tickling on the face, stroking other parts of the body, rocking, or being turned on the abdomen across the nurse's knee.

In response to sound, the child may start, squirm, cry, or awaken from sleep any time after birth.

If placed face down upon a flat surface, the baby may rotate the head a half hour after birth. According to Blanton practically all babies three days of age will raise the head when the face is buried in a pillow. When held in a sitting posture, the baby may hold its head in equilibrium after the second or third day.

Finger movements may be observed at birth, and the grasping reflex is sufficiently strong from this time on to make it possible for the infant to support its body weight when holding to a rod. This muscular contraction is due to cutaneous stimulation of the palms, and to stretching of the tendons. The response is most energetic in the case of a crying child.

At any time after birth, when the child is dropped, the arms are thrown up toward the head. When the 
head is being scrubbed shortly after birth, the interference of the baby's hand sometimes interrupts the process. Watson, on taking hold of the nose of a three-day old baby, found that the child's hands almost immediately engaged his fingers. Avoidance movements of the arms may be elicited in very young infants by gentle pricking of the wrist. Kicking is commonly aroused by the clamping and tying of the umbilical cord.

Blanton found that dropping alcohol on either side of the abdomen elicited a leg movement on the side stimulated. She reports that when the big toe is pricked to secure a specimen of blood, the other foot is drawn up and pressed against the ankle of the pricked side. Watson found that when an infant at five days of age is pinched on the inner surface of the knee, the other heel will be brought up to this spot.

Stretching and arching in response to removal of clothing has been observed on the twenty-fifth day. Shivering may occur shortly after birth and the toes may be curled when the feet are exposed to the warmth of a fire when the child is a few days old.

If a baby is suddenly lowered, in addition to the upward movement of the arms, there is elicited grasping and holding the breath. Another coördinated movement that may occur during the first few days is turning over after being placed face down. Creeping backward may occur during the second week, but the change of position is very slight. Blanton records in the case of one baby two hours old the 
repeated act of placing the hand in the mouth. The youth of the child would indicate this to be an instinctive mechanism.

Watson found no tendency on the part of a baby of 169 days to wipe its hands when given a ball of library paste. If hand wiping is an instinct, which may be doubted, it matures at a later period. The same experimenter could elicit no swimming movements from young infants, which contradicts the accounts of the recapitulationists.

Some of Watson's observations of emotional responses may be stated here. Blinking and an upward movement of the hands were elicited at 100 days in response to a threatening gesture. Crying followed loud sounds or the jerking of the baby's blanket. No fear responses were given by the 165day old baby to the sight or handling of a cat, a rabbit, or a pigeon. Rage responses, consisting of stiffening the body, holding the breath, thrashing with arms and legs, and screaming, were produced by hampering the infant's movements or by simply holding the arms or head.

\section{Instincts are Chain Reflexes}

No response is ever given that does not in turn cause the stimulation of some sense organ. The contraction of a muscle stimulates the muscle spindles that are contained in it. The secretion of saliva or tears stimulates adjacent touch organs. Vocaliza- 
tion stimulates the ear of the person who makes the sound as well as the proprioceptors in the contracting muscles. Scratching, clenching the fist, sneezing, winking, swallowing, breathing, or a response of any sort whatever, produces its characteristic stimulus. Stimuli furnished by responses are called movement-produced stimuli.

Many responses cause new stimuli from the external world to act upon us. If we open our eyes, turn our head, touch the stove, walk from place to place, open a book, light a cigar, or call to a passerby, the act itself is productive of new stimuli. These stimuli from the external world that result from responses are also called movement-produced stimuli.

Movement-produced stimuli in their turn result in movements, and these movements cause further stimulation. In this way a chain of reflexes once begun may maintain itself by its own movement-produced stimuli. When the chain of stimuli are within the body, the order of the responses is highly predictable. This is because the structure of the body is fairly stable. A person who begins to yawn always finishes because the muscle strain of the first part of the act causes the movements that complete the series. No one stops with an open mouth and fails to finish his yawn. (See Figure 13.)

When movements bring stimuli from the external world to bear upon us, the chain of reflexes that results is predictable if the external situation is familiar and common. Man is strikingly adjusted to 
any of these commonly recurring situations in that his responses cause changes in the external world necessary to his preservation.

Suckling is a chain of reflexes, each reflex being called out by the stimulus that the preceding response produces. If a baby is gently tickled on the side of the mouth or on the cheek, its head is moved so as to engage the stimulating object with its mouth.

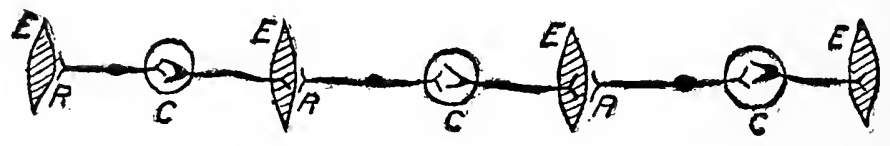

Figure 13. Diagramiatio Representation of the chanN Reflex MECHANISM (AFTER HERRICK). C, SYNAPSES IN NERVE CENTERS. E, EFFECTORS. R, RECEPTORS. THE ACTION OF EACH EFFECTOR RESULTS IN THE STIMULATION OF AN ADJACENT RECEPTOR. THE STIMULATION OF EACH RECEPTOR RESULTS IN THE ACTION OF AN EFFECTOR

This is a reflex. In finding the breast the baby is thus guided by the erectile mamilla. The mamilla in his mouth is the stimulus to reflex movements of the neck, jaws, tongue, and lips that cause close contact with the breast and produce suction. These movements result in milk's entering the mouth. When milk is taken into the mouth, it is the stimulus to reflex swallowing.

It will be seen that each step in the series of nursing movements is an act of intervention that brings about the stimulus for the next movement. Each step may, however, be elicited independently by the proper stimulus. Any touch on the cheek may cause 
the mouth to engage the stimulating object. Anything placed between the lips may cause reflex sucking. Any fluid in the mouth may cause swallowing. That these acts are called forth in the proper series depends upon the presence of a nursing mother. She is the ubiquitous situation to which all babies are adjusted.

If movement-produced stimuli alone caused the baby's next reaction, he would lose his way in the world and perish. Fortunately, however, he is guided by a world of orderly events. Converseiy, if the baby had no original organization to determine in part the sequence of reactions, the baby, by trial and error learning, would have to establish the order of the minute parts of all the serial responses necessary for his survival from birth. Otherwise he could live only in situations that would call out in the proper order the parts of each response. That one response may lead to another without learning, and guided chiefly by movement-produced stimuli, is well illustrated in some of the coordinated movements of newborn animals.

The baby's endowment consists of relatively simple mechanisms, with fewer instinctive responses to movement-produced stimuli than are found in most of the lower animals. Compared with the wasp, which flies, stings, and secures its own food from the time it leaves its cell, the baby has much to learn. It is here that the child's capacity for learning compensates for his early helplessness, and secures for 
him in the end an integration of behavior much more elaborate than that of an insect. The number as well as the simplicity of the responses that are ready to be attached to the child's private environment and to the stimuli that his own movements provide, contributes to this ultimate superiority.

Whereas the lower animals, in response to any one of a number of stimuli, make the same elaborately coördinated movement involving many effectors, the baby responds to each stimulus with a simpler bodily movement, but with a movement more particularly reserved for that element of the situation. In this way the behavior of the human infant exhibits frequent incongruities and combinations of reaction that interfere with one another. Gradually his responses are coördinated and adjusted to his world in a fashion that will be described under the heading Shortening of a Trial and Error Series.

Thus the instincts of babies are more numerous and less complex than are the instincts of the young of other species. Human beings are not endowed with ready-formed tendencies to fight, hunt, swim, or build shelter. These elaborate instincts in lower animals are due to many definite reflex responses to movement-produced stimuli. All such acts in man are learned. Even putting out the hand and grasping an object may be an art acquired by trial and error. Suckling and the emotional responses are the most elaborate of man's instinctive chain reflexes. The movements involved in these acts are stereo- 
typed in order and in kind, and these action patterns maintain in large part their integrity throughout life.

Mr. and Mrs. Peckham have described an interesting chain reflex (instinct) of a solitary wasp, as follows : ${ }^{3}$

She worked for an hour, first filling the neck of the burrow with fine earth which was jammed down with much energy - this part of the work being accompanied by a loud and cheerful (sic) humming-and next arranging the surface of the ground with scrupulous care, and sweeping every particle of dust to a distance. Even then she was not satisfied, but went scampering around, hunting for some fitting object to crown the whole. First she tried to drag a withered leaf to the spot, but the long stem stuck in the ground and embarrassed her. Relinquishing this, she ran along a branch of the plant under which she was working and, leaning over, picked up from the ground below a good-sized stone; but the effort was too much for her, and she turned a somersault on to the ground. She then started to bring a large lump of earth; but this evidently did not come up to her ideal, for she dropped it after a moment, and seizing another dry leaf carried it successfully to the spot and placed it directly over the nest.

An important fact in the behavior of any animal is that it persists in what it is doing up to a certain point and then turns to something else. The wasp responds to the various small objects in the neighborhood by attempting to drag them to the hole, 1905.

3 G. W. and E. G. Peckham, Wasps, Social and Solitary, Boston, 
and then desists when the hole is covered. The baby responds by well established reflexes to objects touching his cheek, to anything inserted between his lips, and to fluid in his mouth, until his hunger is dissipated. In these cases, covering the hole and filling the stomach are called consummatory responses.

Although reflexes may be classified according to the stimuli that call them forth, or according to the responses that result, such a classification is impossible when we deal with an instinct that is a chain of reflexes. This is because the chain of reflexes does not always follow a fixed order, excepting in that it is terminated by a characteristic response. It is in terms of these final responses that instincts are classified.

\section{Precurrent and Consummatory Responses}

When we attempt to describe what an animal is doing, we find that we can distinguish between certain responses that mark the end of a series of acts and those that lead up to this final response. We may see a dog running about in a field, occasionally picking up a scent and following it, losing the scent, ranging about until it is recovered, and barking, all with evident excitement. We explain his behavior by saying that he is after a rabbit, although it is evident that the rabbit itself is not acting as a visual stimulus. One of the important stimuli for the dog's activity is the scent the rabbit leaves behind it. The 
odor prompts the dog to follow the trail with his nose to the ground, and arouses energetic emotional responses. A part of the movements that would be involved in seizing the rabbit are also present, but the act of seizing can not be entirely carried out because there is no rabbit near enough to be seized. That the stimuli that cause the $\operatorname{dog}$ to hunt are in part internal stimuli, is shown by the fact that this behavior appears whenever the dog has been for a time without food.

The response that puts an end to this activity is killing and devouring the rabbit. The reason that the activity ends is that the internal stimuli that prompted the animal to range about have been removed by the act of eating.

Many responses are of such a nature that they bring to an end the stimuli that caused them. Often, when a response is prevented, emotional reënforcement ensues, so that, when the stimulus is persistent or recurrent, negative adaptation toward it does not occur. This emotional reënforcement makes probable the occurrence of the response as soon as a change in the situation allows it. Such a stimulus may act throughout a long period, during which it interferes with responses to many other stimuli. Persistent or recurring stimuli whose responses are blocked with a resulting emotional reënforcement will be called maintaining stimuli. Maintaining stimuli are ultimately removed by the responses they themselves provoke. 
The final response that removes these maintaining stimuli, by altering either the external situation or the internal state of the animal, is called a consummatory response. The series of responses leading up to this final response are called precurrent responses.

Precurrent responses are governed, for the most part, by the external situation. When a dog is hungry, the details of his behavior are his responses, instinctive or learned, to the circumstances in which he finds himself. The odor of rabbit causes ranging about, and in the case of a dog that has once caught a rabbit, the odor arouses eating movements in so far as they may be given in the absence of food.

These eating movements, a part of the consummatory response, are interestingly shown by a dog or a horse when inaccessible food is displayed. Probably a part of the consummatory response is always given throughout the period of preparatory acts, and this maintains a low threshold for the consummatory response until the opportunity for giving it in its entirety arrives. The organs of response involved in a consummatory reaction are thus in a state suitable for use, and the stimuli produced by this making ready for action serve, after repeated experience, to bring about or to facilitate the precurrent responses. This state of readiness in effectors may be observed throughout the interval between arousal and consummation in such acts as mating, hunting, nest-building, quarreling, or search- 
ing for a lost article. It is this that makes the dog range about when he has lost the scent, with the result that the scent is again picked up.

When the trail is lost, the dog is left with an abortive tendency to respond to an odor stimulus. This results in an emotional reaction that reënforces the trial and error behavior by which the scent is recovered.

The blocking of any consummatory response tendency results in emotion, and this resulting emotion is in a considerable degree proportional to the strength of the blocked tendency. When the swimmer finds his efforts to reach shore interfered with by the current, he is overtaken by panic. If you tell a child that you have something in your pocket that you have decided not to show him, he immediately becomes excited. Anyone whose efforts to catch a train are interfered with becomes emotionally wrought up. When Shakespeare's Anthony told the people that he held in his hand a document that he did not intend to read, their apathy changed to interest. Any object whose price renders our possessing it impossible becomes by that fact more desirable. Hampering anyone's movements results in his showing rage. Hunting is interesting only if the game is difficult to secure. This emotional reënforcement derived from the postponement of the consummatory response serves to facilitate the precurrent responses and so to hasten the consummation. 
The final or consummatory response in any ehain reflex is a convenient basis for classifying instincts.

Mating behavior is always terminated when copulation occurs. Food-seeking is always terminated by eating. Nest-building ceases when the nest is finished. Flight continues until a place of security is reached. Combat ends when the foe is killed or routed. The body is scratched until the parasite is removed. The behavior that leads up to these consummatory responses varies greatly according to the situation, but the consummatory responses themselves are highly predictable and so serve as a basis for the classification of instincts. Under each of the following important consummatory responses will be listed a number of chain reflexes to illustrate the variety of ways in which diverse precurrent responses lead to the same ultimate result. Probably few of these response series are purely instinctive. Certainly, in the case of man, these utilities are served for the most part by learned acts.

\section{Swallowing Food}

Suckling

Following while suckling Mouth gaping by young birds

Crying and whining of young

Licking

Scratching the ground

Restlessness due to hunger

Following a scent
Striking by snakes

Striking by fish

Diving by birds

Stinging and sucking by insects

Grasping

Constriction by snakes

Biting

Pecking

Stalking 
Tongue movements of liz- Springing

ards and frogs

Chasing

Creating water currents

Seizure due to contact

Hunting ery of owls and lions

Web building

Carrying home food

Migration

Crouching

Lying in ambush
Lapping

Chewing

Grazing

Rumination

Fighting and intimidating possible competitors

Threatening wing movements of pigeons while eating

Hunting in packs

\section{Copulation}

Preliminary restlessness

Mating calls

Drumming by partridge

Strutting, showing off, and dancing

Coyness of females

Fighting among males
Nuptial flight of some insects

Migration

Courtship

Affectionate behavior toward permanent mate

\section{Securing Shelter}

Restlessness in the open

Stereotropisms

Retirement to shelter in response to darkness

Seeking a roost high above ground

Burrowing and excavating

Cocoon spinning and the use of secretions in building

Caterpillar's use of leaves in building

Collecting building materials such as mud, sticks, leaves, hair

Rearranging these into nests and dens, in trees, on ground, in burrows

Plucking fur and down from breast for lining nest

Dam building by beavers

Yarding by moose

Huddling by cattle

Coöperative nest building of insects 


\section{Defeating Antagonists}

Restlessness when alone and seeking company of fellows, resulting in herds and colonies

Secretions of skunk

Discharge of nematocysts

Taking up posture which makes the animal seem more formidable

Snarling, growling, screaming (often in defense of food)
Cries that summon aid

Responding to cries for aid Flexion of porcupine Defensive grouping of herd Attack with bill

Fighting with wings

Resisting forcible manipulation

Struggling, squirming, biting when held

Retaliatory aggression

\section{Cleanliness}

Licking the body

Dusting plumage

Preening

Scratching

Biting parasites
Picking at foreign objects on surface of body

Cleaning of eggs by ants Rolling Shaking

Shaking of wet paw by kit- Scratching dirt over filth tens

Careful observation of animals will disclose the fact that practically none of the items in the above list refers to an act that is always executed in the same way. An act of flight, for example, is never twice the same. The movements depend upon the contour of the ground, upon the position of the enemy, and upon previously formed habits of all sorts. Such "instincts" as these are nothing more 
than the continuance of behavior of many sorts until a consummatory response has been given. A frightened partridge uses many means of escape, struggling, running, or flying, until the consummatory response of reaching concealment terminates its activity.

\section{The Effect of Varying Situations upon Preparatory Responses}

Greater uniformity in the order of the parts of an elaborate "instinct" is seen when each component act changes the situation in a set and characteristic way. Nest-building is a case in point. A shelf under the eaves is a stimulus that may start a mated bird in its search for building materials. Its return to this spot with material in its mouth initiates laying the foundation of the nest. Its empty bill starts it off again on a search for more materials. Return is delayed until its mouth is again filled. Its next nest-building movement is determined by finding the nest already begun, and so each step in the building is governed by the degree of completion of the nest at the time. This may be demonstrated by partially demolishing a nest which has been almost completed. The bird will act then much as it did when the nest first reached this stage of completion.

A solitary wasp usually leaves her prey just outside the hole, into which she goes before returning 
to drag the food into the nest. Fabre demonstrated that if the food is removed some distance from the nest, the returning wasp will again drag it close to the hole, leave it, and again enter the nest. If the food is repeatedly moved back, the wasp will behave time and again in precisely the same way. This nicely illustrates the way in which each act in the series is determined by the arrangement of stimuli.

Because of the diversity of conditions from time to time, no wasp would repeat exactly its original movements in bringing grasshoppers to its hole, and no bird would duplicate its original behavior in building a second nest. The bird's precurrent responses depend upon the nature of available building materials and the places where these materials are found. A cat prowling about the locality will greatly alter the bird's reactions, the sight of food may temporarily distract it from its building, but eventually the nest is completed after some combination or another of precurrent acts.

The wasp observed by the Peckhams was led to one preparatory response after another as it came by chance upon the small objects surrounding the hole. Although its tendency to move small objects to the hole is set going by the sight of the open hole and the presence of the small objects, the particular way in which it behaves is determined by the nature and the position of these objects. The sight of the stone initiates the effort to move it, but its resist- 
ance causes the wasp to relinquish it. It will then turn to any other material that may catch its eye until an easily moved object is found, whereupon the open hole is covered and ceases to exist as a stimulus to this sort of behavior. Successful covering of the hole is the consummatory response that does away with the maintaining stimulus, which remained unabated by the precurrent responses.

There is always a persistence of some maintaining stimulus if there is a persistence of the consummatory response tendency. Courtship is continued only as long as some internal or external stimulus for copulation is present. Fighting ceases in the absence of an antagonist or when rage subsides. The terrified person no longer flees when the pursuer is distanced, if the characteristic emotional state has passed.

Instincts, then, are seen to be chain reflexes whose serial arrangement is determined by movement-produced stimuli. The nervous mechanisms involved are established by growth and are not the result of training. When the movement-produced stimuli are external to the body, the order of responses is more variable than when the stimuli reside in the body itself. As the common element in so many diverse chain reflexes is the particular consummatory response to which they lead, the consummatory response is a valuable basis for the classification of instincts when a classification is demanded. 


\section{Individual Differences}

Everyone recognizes the fact that in a group of horses or cows or chickens one individual differs from another. Some horses are naturally faster, and some are naturally slower. One cow is a good milker and another cow gives but little milk, even though both have had the same care and feeding. Chickens vary in size and in the number of eggs they will lay. Even in the case of men we recognize differences in height and in pigmentation that are due to endowment and not to education.

It is a tendency of our own times to be less willing to admit that from birth one man differs from another in intellectual ability. To a very great extent, however, we are born and not made. Some men are gifted with brains, and some are handicapped by a natural inferiority for which no amount of training will compensate. The great majority of people in the world could never graduate from college, because of their inadequate intellectual endowment.

There are very few college students who can run a hundred yards in 10 seconds, more who can do it in 11, still more who can do it in 12, and probably about an equal number who can do it in 13. From this point on we find fewer and fewer students whose fastest time is $14,15,16$, or more seconds. If an unselected group of students were to start together to run the length of a football field, they would be 
strung out at the finish in some such way as shown in Figure 14.

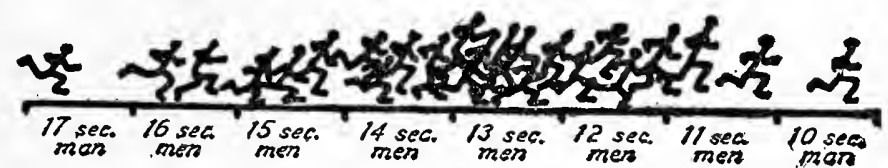

Figure 14. Distribution OF ONSELECTED GBoup OF RUNNERS

Their distribution according to speed might be represented graphically as in Figure 15.

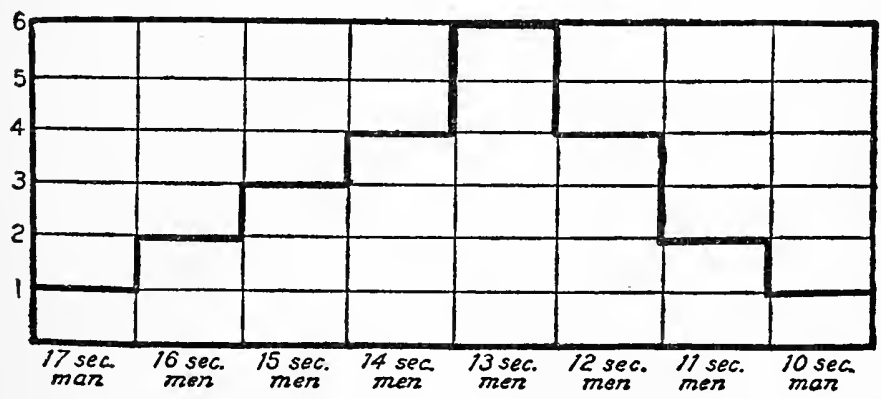

FIGURE 15. SURFACE OF FREQUENCY SHOWING THE DISTRIBUTION OF THE BUNNERS OF FIGURE 14 ACCORDING TO THEIR TIME IN SECONDS

It is possible by the use of mental tests to measure with but slight error the amount of a man's innate intellectual ability, and to compare the amount of this natural endowment with that of people in general. If we were to give our group of students mental tests, we would find a few of them to be conspicuously bright, more of them to be a little less intelligent, a great many of them bunched about the point 
of average performance, and fewer and fewer at points lower and lower in the scale. Such a measurement of the intelligence of a number of groups is represented in the graphs on page 73 .

In general, bright parents have bright children, mediocre parents have mediocre children, and dull parents have dull children. Striking exceptions to this rule should not be given undue weight. The handicap of ill health, poverty, or lack of educational opportunity, or the advantage of excellent training have some effect upon the score that an individual makes in intelligence tests. Tests are designed to minimize this effect.

There is no evidence for the common supposition that the neurological habits of parents are passed on to their children in the form of instincts. There are, however, many experimental results that suggest that certain of the parents' acquired characteristics are passed on to the offspring. All these transmitted bodily modifications, such as congenital syphilis or malnutrition, are of a sort quite distinct from the neurological changes involved in habit formation, and offer no evidence for the belief that education is inherited. Children descended from generations of English-speaking ancestors are probably no quicker in learning English than are babies of foreign extraction.

It is not unusual for people untrained in biology to think they see contradiction in the two statements that "bright parents are likely to have bright chil- 


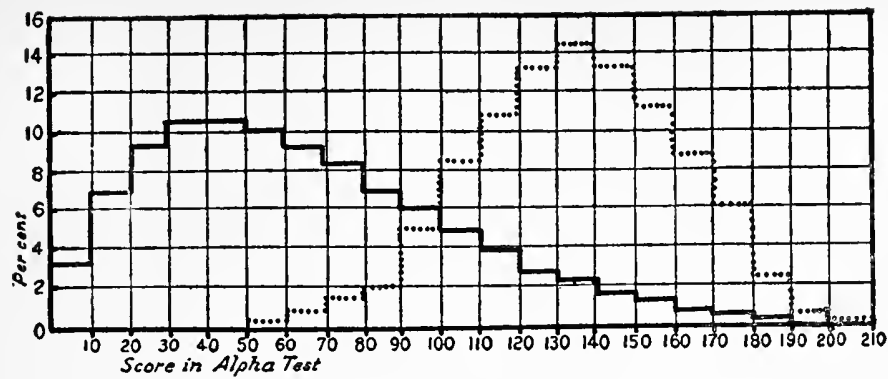

Figure 16. Distribution of alpha test scores for college stuDENTS AND FOR THE DRAFT ARMY (EQUAL AREAS)

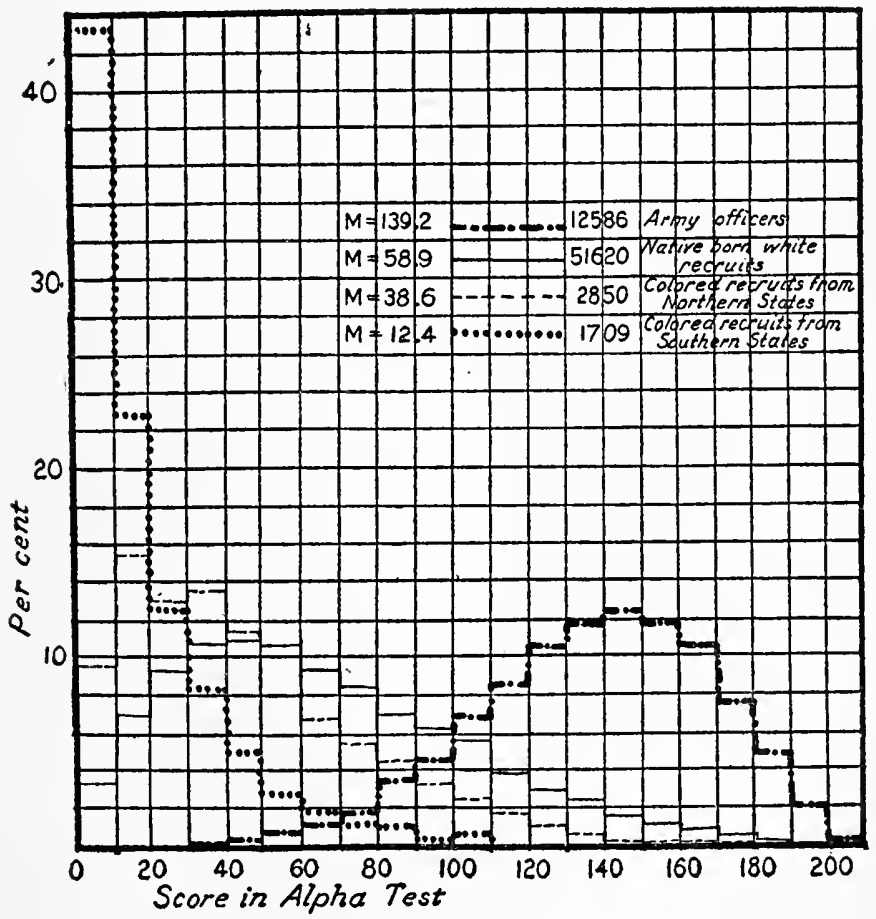

Frgure 17. DIstrLuUtion OF ALPHA test scores FOB VARIOUS GBOUPS IN THE DRAFT ARMY (EQUAI. AREAS) 
dren" and that "the results of schooling are probably not inherited." This is because they suppose that individual differences are all due to training, a supposition that is, of course, untrue. 


\section{CHAPTER III}

\section{LEARNING}

Although all babies start life with the same kinds of capacities, we find them as adults displaying various individual abilities that have been gained through practice and education. They have become judges, farmers, carpenters, editors, burglars, and politicians. Each has developed skill along certain lines. Psychology must explain how these diverse habits are developed.

We seldom observe in adults an elaborate act that is a pure instinct, and this is because the original structure of the nervous system changes as a result of use. We must not, however, fall into the error of supposing that when any response is modified by learning, it thereupon ceases to be instinctive. The instinctive components of any act may be discerned, no matter how greatly it has been transformed by training.

The modifications of instinctive behavior that result from use are of two sorts. One sort of learning results in the attachment of a response to a stimulus that did not provoke it originally. This is illustrated by such a common act as reaching for the telephone receiver when the bell rings. A baby or a 
savage does not respond in such a way to this stimulus. Another sort of learning is a modification of the ease with which a response may be elicited. Under certain conditions a person may develop a ready anger toward interruptions when at work, and under other conditions he may develop toward the same occurrences an increasing toleration.

All habits, no matter how complex, are the results of these easily understood changes in stimulus-response mechanisms. We shall first consider the modifications in the ease with which responses are brought about, and later, under the heading "The Conditioned Response," we shall discuss the attachment of responses to new stimuli.

\section{Positive Adaptation}

Repeated working of a stimulus-response mechanism, especially if the stimulus is just above the threshold of response, results in lowering the threshold, in decreasing the reaction time, and in increasing the vigor with which the response is given. This effect of repeated working is called positive adaptation.

Because of practice, the lookout on board ship is able to signal the approach of a vessel more readily than is the landsman who stands beside him. If the situation is such that we always get up when the alarm clock rings, the clock may be moved farther and farther from the bed on successive nights, un- 
til we are finally aroused by a sound much too faint to have gotten us out of bed on the first morning. A physician may develop a positive adaptation to the telephone at night, while his wife sleeps through the disturbance. His wife, on the other hand, is often the one who responds to the crying of the baby. The suburbanite develops a sensitive ear to the whistle of the early train; the bank teller is quick to detect counterfeit money; the woodsman notices signs that escape the city dweller; and all of us turn when a dime is dropped even on a noisy street. If we were to see two signboards side by side and lettered in the same type, one bearing the words BULL DURHAM and the other the nonsense words RAHD LULBUM, and if these were just near enough to enable us to read the first of these signs, we would not be able to decipher the second, though the same letters occur on the two signs. We do not develop positive adaptation to all stimuli that act upon sense organs, but only to those that provoke a response.

When we first learn to perform an act in response to a new stimulus, the time involved in giving the response is much longer than it is at a later period, after practice. This shortening of reaction time is best studied where a large number of stimuli are responded to in novel ways, as in learning to typewrite, to send or receive telegraphic messages, to translate a foreign text, or to take dictation in shorthand. By measuring the performance of any of these acts during successive practice periods, and 
by plotting these measurements, we get what is called a practice curve. An illustration is given in Figure 18.

In telegraphy the practice curve for either sending or receiving shows that more and more words

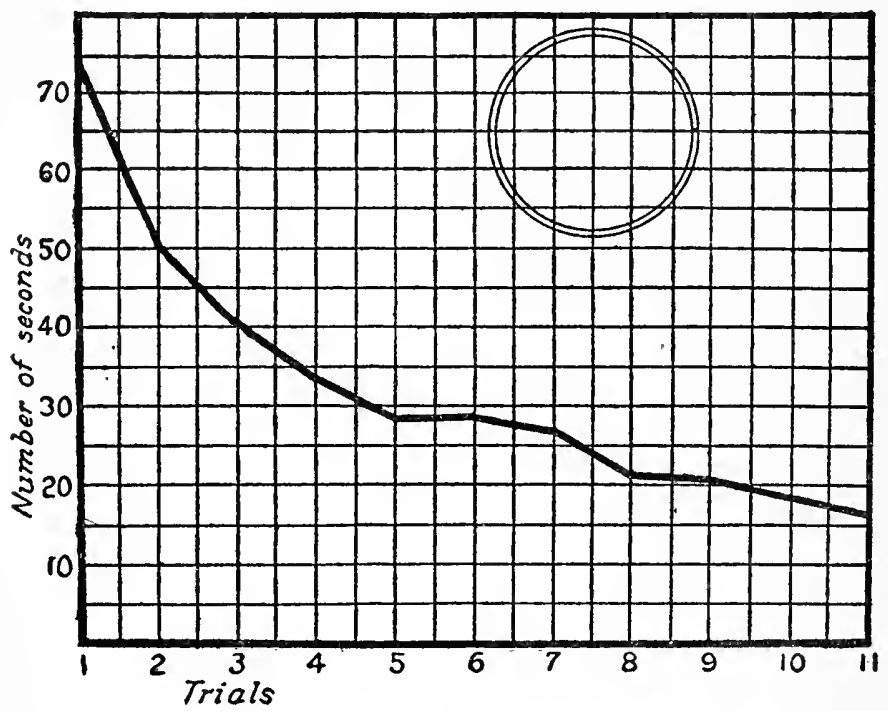

Figure 18. curte of practice in mirror Drawing. each ordinate REPRESENTS THE AVERAGE TIME OF 50 SUBJECTS. THE FUNCTION PRACTISED WAS DRAWING A CIRCLE BETWEeN THE DOUBLE LINES. THE FIGURE WAS SCREENED FROM THE SUBJECTS AND VISIBLE ONLY IN A MIRROR. THE OUTER CIRCLE WAS FOUR INCHES IN DIAMETER. THE TRAOK BETWEEN THE TWO CIRCLES WAS AN EIGHTH OF AN IKCH WIDE

may be handled in a given time as practice continues. There is, of course, a limit to such improvement, and the telegrapher finally approximates his maximum speed. As this limit is approached the curve flat- 
tens out. Thus the first part of practice is relatively more fruitful than the last part. ${ }^{2}$

Through use, the tendency of a response to follow its stimulus becomes better established. This greater tendency to sequence is shown not only in a lowered threshold and a shortened reaction time, but in an increased resistance to distraction. The practised act is performed in the face of altered conditions and in spite of internal variations that would have prevented the reaction originally.

Positive adaptation is gradually lost after practice has been discontinued. This slow disappearance of positive adaptation is called forgetting, and may be measured just as the appearance of positive adaptation may be measured. The rate of forgetting, as graphically represented, is at first rapid. (See Figure 25.) As time passes, the loss of practice effects takes place at a slower rate, and even after years of disuse, a stimulus-response mechanism may still show traces of positive adaptation. Horse buyers determine whether a horse has ever had mange by stroking the horse's flank. A horse that has had mange, and has through practice developed positive adaptation of the natural skin-biting response, will respond years later by a quivering of the lip.

1 Thorndike, "Notes on Practice, Improvability, and the Curve of Work," American Journal Psychology, 1916, pp. 550-565. Hill, Rejall, and Thorndike, "Practice in the Case of Typewriting," Pedagogical Seminar, 1913, pp. 516-529. Lashley, "Tho Acquisition of Skill in Archery," Carnegie Institute, 1915. 
Anyone who has narrowly escaped being struck by lightning shows a greater fear response than before to the distant thunder storm. If we have been provoked to anger by another's outrageous act, he may arouse our anger again by the most trivial discourtesy. At first this might seem to be evidence that positive adaptation results best from responses to intense stimuli but this is probably not so.

It requires a very intense stimulus to call out an extensive, diffuse, and complete emotional response, although parts of the response may be given to a weak stimulus. Once the response has been called out in its entirety, the elements originally having high thresholds are more easily elicited and the act as a whole is bound together by what we shall later call conditioning. This explains why a child who has been thoroughly frightened shows cowardice on slight provocation. His entire fear mechanism has been called into action, and the partial fear response, which is ordinarily given by children who have never known abject fear, gives place to a more complete expression upon insignificant occasion. The child who has often been teased to a point of rage, shows positive adaptation of those parts of the rage response that are naturally more difficult to elicit, and thus develops a bad temper toward small grievances.

\section{Negative Adaptation}

If a subliminal stimulus is repeated with gradually increasing intensity, the response may not oc- 
cur when the stimulus reaches or even passes the usual threshold point, and in this way, especially if the response is never given, the threshold of response will be raised. This is called negative adaptation.

If the temperature of the room falls gradually, we fail to notice it, but if, for any reason, it suddenly becomes cold, we react to the change. If the cost of living were to double over-night, there would be public disorder the next day, but, because the doubling is a gradual process occupying several years, the situation remains below the threshold for rioting. The physician is inured to the suffering of others by witnessing it repeatedly, and by the necessary inhibition of any useless expression of sympathy. A child who is afraid to sleep without a light may become adapted to sleeping in entire darkness by a gradual reduction of the intensity of the light on successive nights. The practised person while using a microscope, shows negative adaptation for stimuli affecting his left eye. The disobedient child is indifferent to his parent's call because he has failed, on many occasions, to respond. In order to train a dog to come when called, the expert dog trainer never uses the dog's name except in summoning him. The visitor in a household is disturbed by the children's noise, while the parents may have become adapted to it. Many parents also become negatively adapted to their children's questions and are surprised when their attention is called to this. 
James thought it unfortunate that man is endowed with a fear response, the severity of which often renders him helpless in the face of danger. ${ }^{2}$ Nearly anyone, if he were compelled to walk an I-beam high above the street, would be seized by panic and would fall. But James overlooked the fact that this original over-supply of fear is of value when it is ultimately decreased by negative adaptation to the dangerous situation. If fear were not found in excess in the ingenuous man, the dangeradapted man would often die of foolhardiness. Excessive embarrassment handicaps the adolescent in the presence of strangers, but we all dislike the adult in whom negative adaptation has been so thoroughgoing as to leave no traces of reticence.

A man is saved from feeling distaste for his ageing wife because wives grow old gradually, and he becomes negatively adapted to characteristics that, were they to occur suddenly, would discourage his affection. The proper way to break a horse to the saddle is to accustom him first to a blanket, next to blanket and surcingle, then to the saddle in addition. Later, to adapt him to the pressure of the rider, a bag of feed of gradually increased weight may be strapped across the saddle. Successful breaking depends upon keeping the stimuli within the horse's growing toleration. A disliked food taken in quantities sufficiently small to excite no disgust, may be eaten in gradually increasing

2 James, Principles of Psychology, vol. ii., p. 419. 
amounts on successive occasions until a large portion does not cause aversion. Crowding the threshold for intolerance of a stimulus, without reaching the breaking point, makes for increased tolerance.

Another way in which negative adaptation may result is by the failure of the response, though given, to rid the animal of the stimulus. In such a case, the stimulus-response mechanism becomes fatigued, and the response is given less and less energetically to the persistent stimulus, until all response ceases. The horse that is broken by the cow-puncher method becomes accustomed to the saddle when his efforts to dislodge it repeatedly fail, and so, while he may always make slight movements of resistance while being saddled, the threshold of resistance is permanently raised.

We have said that negative adaptation may be brought about in two ways. The repetition of a subliminal stimulus may cause it; or it may result when a stimulus persists in spite of the animal's responses, after fatigue has raised the threshold. There is a third kind of situation that results in negative adaptation. An eliciting stimulus may be rendered ineffective by the presence of an inhibiting stimulus, and, the threshold of response being thus raised, negative adaptation results. In this way children become negatively adapted to temptingly accessible food by the inhibiting threat of punishment. In Triplett's experiments, perch were separated from minnows, which are their natural food, by a glass 
partition in the aquarium. A perch would at first dart toward a minnow, but would strike its head against the glass. In time the big fish became negatively adapted to the presence of the minnows. The partition was then removed and the minnows mixed safely with their natural enemies. This case, though an example of negative adaptation, involves a conditioned response, and this will be discussed below.

Both negative adaptation and summation follow upon the repetition of subliminal stimuli, though they are quite different results of such repetition. It is the length of the intervals between the stimuli that determines which one of these two effects will occur. A series that will have a summation effect, and finally bring about a response, may lose that effect if the length of the intervals between stimuli is increased, in which case negative adaptation, or the permanent raising of the threshold, takes place. These alternative possibilities are seen not only in behavior but in the physiological responses of the body to drugs. If one dose rapidly follows another, a cumulative effect results, but if gradually increasing doses are given at widely separated intervals, negative adaptation results, so that the patient may come to tolerate amounts of the drug that would have been fatal at the outset.

3 Triplett, "The Educability of the Perch," American Journal of Psychology, vol. 12, p. 354 . 
Transitory Changes of Threshold During a Single Practice Period

If a considerable time has passed since an act was last performed, the threshold of response is found to be unusually high and the reaction time to be unusually long. When a ball player begins his day's practice, he is less sensitive to situations and slower to respond than he is after fifteen minutes of warming up. In golf we take a few practice strokes before driving from the first tee in order to pass this period of sluggish reaction. The slowness and the weakness of response and the high threshold that characterize the beginning of any activity we shall call initial torpor. ${ }^{4}$

Initial torpor is seen in simplest form in the contractility of the muscle-nerve preparation or in a spinal reflex. When it is exhibited in such a complex act as game playing or factory work, other elements enter in to make it appear greater than it really is. When work has first begun, negative adaptation to distraction has not yet occurred. Passers-by, noises, and room temperature, all disturb us at first, but later, through negative adaptation, are disregarded.

Another obscuring factor is the hangover of responses recently given. Conversation just engaged in leaves the talker for some time afterward still

4 Thorndike, Educational Psychology, vol. ii. 
talking to himself. If we turn from chess to letter writing, a tendency to make chess moves hampers the composition of our first paragraph. The student who has hurried to avoid being late at class is agitated for some time after taking his seat. This hangover of recent movements is due partly to the persistence of emotional reënforcement.

A complex habit is made up of many parts and involves many action systems. Initial torpor attaches to each part and to each emotional reënforcement. It is dissipated in the parts of lowest threshold before it disappears in others. As one part after another of the entire act is brought into play by tentative beginnings, and by the stimuli that these beginnings bring to bear upon us, the several parts of the act successively lose their sluggishness and combine into the act as a whole. After such warming up the entire habit has a lowered threshold.

Every time work is begun after a long period of rest, initial torpor is found to be present. If the practice curve is still rising and has not reached a plateau, the absolute amount of initial torpor to be overcome is less at the beginning of each successive practice period. There is no difference in kind between the positive adaptation shown in overcoming initial torpor and the positive adaptation that is the gradually decreased reaction time and lowered threshold of an act practised at intervals for many days and graphically represented by the practice curve as a whole. 
Toward the end of the doubleheader the ball player again becomes less sensitive to situations and slower in response, and this we call fatigue. Toward the end of the shift in the factory the number of ac-

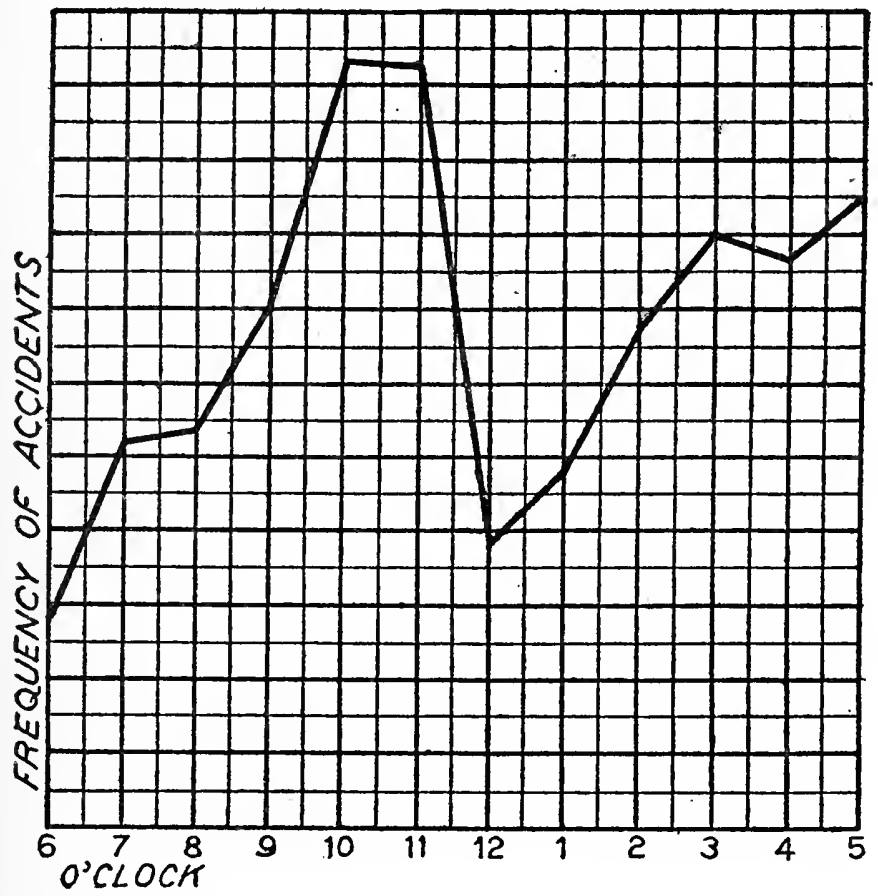

FigURE 19. DISTRTBUTION OF GERMAN INDUSTRIAL ACCIDENTS THBOUGHOUT THE WORKING DAY, IN PART THE RESULT OF FATIGUE (AFTER GOLDMARK)

cidents increases. ${ }^{5}$ The third time around the links we make a poor score. Fatigue is the slowness of response, the weakness of response, and the high

5Goldmark, "Fatigue and Efficiency," Russell Sage Foundation, 1912, p. 71 . 
threshold of response that finally occur if any activity is continued long and vigorously. It is a temporary effect of repeated action, and a period of rest causes it to vanish. ${ }^{\circ}$

Variations in response threshold may result either from variations in the conductivity of synapses, or from variations in the contractility of muscles. The high threshold that characterizes initial torpor seems mainly the result of resistance at synapses, a condition that is reduced by practice. The high response threshold in fatigue is the result chiefly of a reduced contractility in the muscle, which is brought about by exercise.

\section{The Conditioned Response}

How may a response be provoked by a new stimulus? Let us take the case of a dog that sees a cat. On seeing the cat he barks. Suppose that while looking at the cat he hears his master say the word "cats", and that these two stimuli occur together several times. Later if he hears the word "cats", although there is no cat present, he will bark. This response first called forth by the sight of a cat is now provoked by a new stimulus, namely, the sound of a word. When a response is elicited by a new stimulus, because of the fact that the new stimulus has occurred along with the old, it is called a conditioned response.

"Thorndike, "Fatigue in a Complex Function," Psychological Review, 1914, pp. 402-407. 
If a percussion hammer falls upon the patellar tendon, a spinal reflex is elicited involving the contraction of the quadriceps muscle. This is called the knee-jerk. In 1902, Twitmyer demonstrated that if a bell was sounded each time that a hammer fell on the patellar tendon, it was possible, after considerable practice had occurred, to elicit the knee-jerk by the auditory stimulus alone. ${ }^{7}$ To-day a reflex response to a substituted stimulus is called a conditioned reflex, because the substituted stimulus is one of the conditions accompanying the original stimulus. Pavlow discovered that a conditioned salivary reflex could be secured from dogs. Certain foods, when eaten, cause a copious secretion of the salivary glands. He found that, if some visual or auditory stimulus is made the invariable accompaniment of the saliva-exciting food, the accompanying condition will provoke the salivary flow in the absence of the original food stimulus. Watson and Lashley demonstrated the conditioned salivary reflex in man as well as other conditioned reflexes in both dogs and human beings. ${ }^{8}$

The principle that one of the accompanying conditions of a stimulus responded to may later become a substituted stimulus for the response, applies to all associative learning. If a bell is attached to a dog's tail and the dog is petted in a way to make him wag: his tail, the sound of the bell will be an ever present

7 Twitmyer, "A Study of the Knee-jerk," Philadelphia, 1902.

8 Watson, Psychology from the Standpoint of a Behaviorist, pp. 29-38. 
condition under which the caudal response is elicited. After considerable wagging of the belled tail the bell may be removed and the wagging produced without petting when the dog hears the bell rung. In order to make a dog respond to his name when called, the trainer secures this response first to food and then, while the dog is coming, speaks his name. In time the sound of the name becomes the substituted stimulus for approach.

If a number of photographs is presented to a subject each one being named by the experimenter and then by the subject as he looks at the photograph, a conditioned response will be established in time toward each picture, so that the subject will call it by the proper name. The previous stimulus for this response was the word spoken by the experimenter, and the substituted stimulus is the accompanying visual representation. In like manner probably any response may be conditioned by accompanying stimuli in the absence of the original stimulus. Nausea may occur at the mere sight or odor of food in which a nauseating medicine was once taken or that was eaten during a storm at sea. This fact was made use of in curing the whiskey habit. Mark Twain found it difficult to speak on serious matters in public because he himself constituted a conditioning stimulus that always provoked laughter in his audience.

- Interesting examples of conditioned emotional responses are described by Locke in his Essay Concerning Human Understanding, Book 2, Chapter 33. 


\section{Conditioned Emotional Responses}

An interesting example of a conditioned response is seen in the attachment of an emotional expression to some situation that originally had no power to bring out the emotion. Probably each emotion is originally provoked by a very limited number of situations. Tickling is the adequate stimulus for causing the baby to smile, but the baby may learn to smile at sight of the person who has tickled him because he has been exposed simultaneously to the tickling and to the sight of the tickler. He is not originally afraid of the sight of a dog and indeed will ordinarily reach toward it, but once frightened by its bark or knocked down by its rush the subsequent sight of the dog is sufficient to cause the expression of fear. ${ }^{10}$ The dog once kicked by the milkman will fly into a rage at sight of him, his rage response being originally provoked by the kick, but conditioned by the appearance of the man.

It is in this way that we learn to show anger, joy, fear, love, disgust, and other emotions in response to those occurrences of life that are apt to be followed by events that make these responses appropriate. Thus we anticipate the attack of a familiar foe, or by an early withdrawal avoid too close proximity to the frightful object. Many of our fears, likes, or

10 An experiment in establishing conditioned emotional responses in an infant is described by Watson and Rayner, "Conditioned Emotional Reactions," Journal of Experimental Psychology, 1920, pp. 1-14. 
dislikes are conditioned responses to stimuli that have only a chance temporal connection with their natural provocation. A celluloid collar in itself is neither alluring nor repulsive, and our dislike of such an article of dress is dependent upon the fact that we have always experienced it in connection with a wearer who is not too scrupulous as to his personal cleanliness. Everyone builds up a set of emotional tendencies through this process of association, so that his adult attitude toward the experiences of life is fitted to the culture into which he has been born.

Particular melodies become associated with the words of songs and with emotional expressions that have been called out by these words. Although at first only the words may have had the power to arouse the emotions in question, the music itself, in the absence of the words, will later have the same effect. Easter and Christmas music, the melody to which sentimental words were sung, patriotic airs, the words of which originally excited patriotic emotions, or the music sung at the funeral of a friend, will long afterward revive the emotional expression of which they were at first the incidental accompaniment. Conversely, music itself may directly arouse emotional responses, and this fact is made use of to reënforce the conviction that the attending words but partly establish. The stirring airs of the camp meeting or the patriotic rally bring many to the mourner's bench or the recruiting office 
who would remain sinners or slackers if appealed to by words alone.

Emotional expressions as a whole may be attached to new stimuli, and in inappropriate situations constitute many of the psychoneuroses. If in the process of courtship a person is placed in a position to arouse great fear, the emotion of fear may become attached to all erotic stimuli, and what is known as an anxiety neurosis may develop. Cases have been reported in which an aversion for small rooms can be attributed to the subject's having fainted at one time in a small close room; in which a fear of buzzing insects followed a child's being frightened by a humming bird that entered a window and flew rapidly about the child's head; in which a horror of bells was caused by a church bell's ringing at a time when great depression, resulting from her mother's death, possessed the subject, who believed herself responsible for her mother's illness. Such conditions often call for treatment at the hands of a psychologist.11

The way in which these bad habits of emotional response are cured is to attach a rival response to the stimulus that arouses them. If, for example, a person shows a morbid aversion towards touching absorbent cotton, the psychoanalyst attempts to discover the origin of this response by delving into the subject's past. It may be found that as a child the subject once handled some dirty cotton that had been 1920.

11 Hollingworth, The Psychology of Functional Neuroses, New York, 
used as a surgical dressing, and that he was at that time scolded by a disgusted parent. For practical purposes it probably does not matter whether this event was the occasion of the subject's original distaste for cotton, provided the subject himself is convinced that this was the real cause. With this start, the psychoanalyst proceeds to lower the threshold for the recollection of this childhood event, and so makes certain that the subject will always think of the event when cotton is seen. The subject is then told that little children can not be held responsible for failure to avoid unsanitary acts, that the subject himself was in no way to be blamed for what he did, that certainly no harm resulted from his act, and that, indeed, the whole matter is very ludicrous as we look back upon it.

In this way there becomes attached to the sight of cotton the tendency to discuss the childhood event and for such discussion to be accompanied by selfsatisfaction and amusement. If this line of response is sufficiently practised and sufficiently reënforced by verbal rationalization, it develops a threshold that is lower than that of the aversion response; and thus the aversion habit is cured.

\section{The Substitution of Srmitar Stimuli}

An act may be learned in response to one situation and later given to another that is partially identical, even though the common elements in the two situa- 
tions are wholly incidental and irrelevant. This substitution does not involve the process of conditioning. It is nicely illustrated by many false moves in everyday life. The following cases have been observed recently. A person was about to make tea. Instead of turning on the gas for the Bunsen burner, lighting it with a match, turning on the water faucet, filling the kettle, and placing the kettle over the burner, he made the mistake of turning on the water, lighting the match, and placing the match under the faucet. The mistake, of course, was due to the similarity of proprioceptive stimulation involved in turning the gas cock and opening the water faucet, the false response being practically the same as the gas-lighting response. Another example of the substitution of one stimulus for another, because of partial identity, was found in the case of a man who entered a shop to purchase a newspaper and who dropped his money on the floor. He picked up the money and left the shop without securing the paper, and did not appreciate his mistake until he was some distance away. Here the responses of picking up the coin and of picking up the newspaper are almost identical, and the mere act of picking something up was the usual stimulus for leaving the shop.

\section{Facilitating Effect of Conditioning Stimulu}

If a dog that has been trained to respond to the word "cats" sees a cat at such a distance that the 
stimulus is below the threshold for chasing, his master may urge him on by using the word and he may at once start in pursuit. In this way the sound of the word "cats", although not now the sole cause of the response, facilitates the response, because it occurs in conjunction with the actuating stimulus.

Illustrations of these conditioning stimuli and their resulting facilitation are plentiful in everyday life. The literary man accustomed to writing while smoking a pipe finds it difficult to work without the pipe in his mouth. The clergyman is moved to greater eloquence when wearing his cassock, and would find it difficult to preach a sermon on the street corner. The college instructor, because he frequently uses chalk during lectures, finds facilitation to his speech through holding a piece of chalk in his hand. Our familiar surroundings increase our personal efficiency, and this law gives a psychological justification to the so-called right of personal property.

A man sleeps best in his own bed, not only because he is negatively adapted to the distracting stimuli of his neighborhood, but because he has gone to sleep many times in these surroundings and they have a facilitating effect in producing slumber. A child often refuses to sleep unless covered by a familiar blanket, or allowed to suck his thumb, or permitted to take a certain doll to bed with him. 


\section{Neural Basis of Learning}

Conditioned responses involve the formation of new pathways and the possibility for this is best afforded by the intricate association fibres of the cortex. When a neural arc is acting, impulses received from sense organs not previously connected with this neural arc are likely to be drained into its outgoing motor pathway. This drainage establishes new synapses and thus connects new sense organs with the responding muscle or gland. This is the neural basis of the conditioned response. It may be best understood by consulting the diagram in Figure 20 .

Impulses aroused by accompanying conditioning stimuli are drained into the motor system that is active at the time. Thus when the original stimulus and the conditioning stimulus act together, the combined energy from the two is drained into a single motor system. For this reason the conditioning stimulus facilitates the action of the original mechanism and this mechanism may act with a stimulation less intense than was first required.

The changes in the nervous system that account for positive adaptation are presumably an increase in conductivity at synapses. Resistance at a synapse is decreased each time a nervous impulse passes through it, and an improvement in conductivity of the synapse results from use. A lessened resistance 

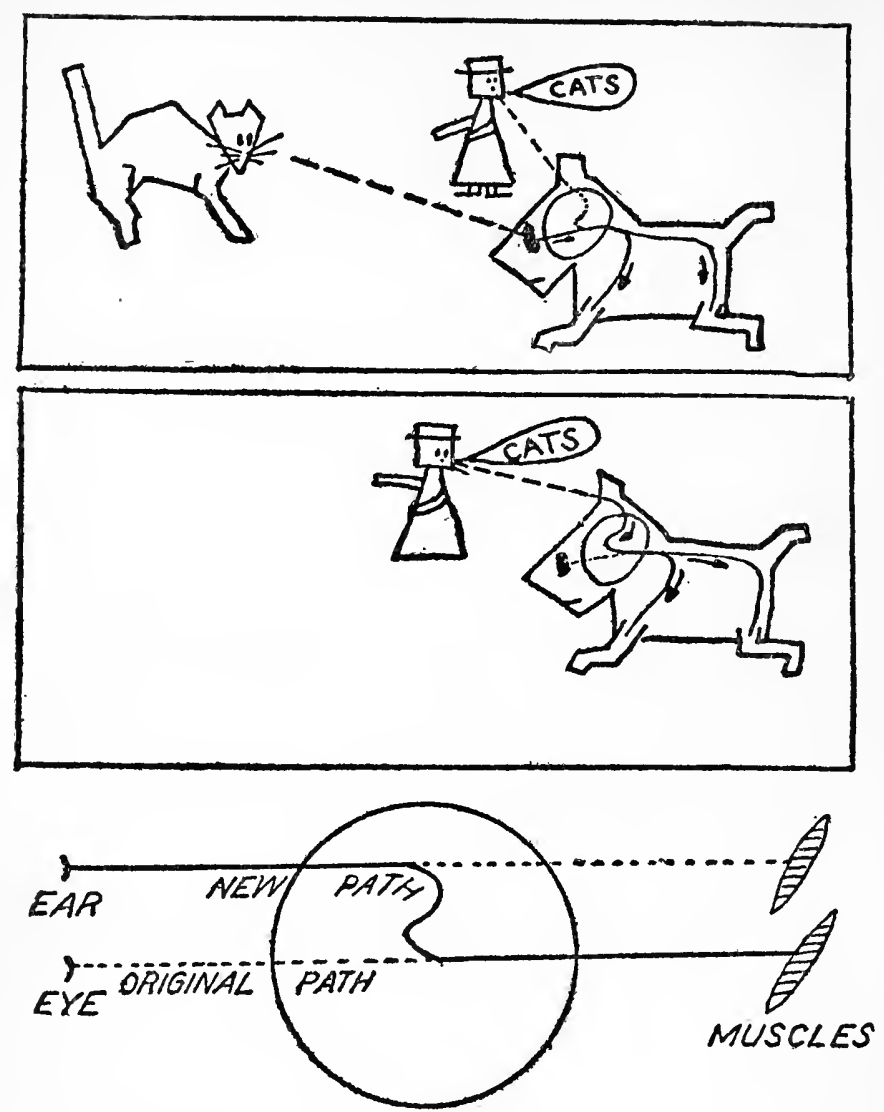

Figure 20. establishing a condtioned response. The first STIMULUS THAT SETS THE DOG TO RUNNING AND BARKING IS THE SIGHT OF THE CAT. IF, AT THE SAME TIME, HE IS STIMULATED BY TIIE WORD "CATS" PRONOUNCED BY HIS MASTER, THE IMPULSES RESULTING ARE DRAINED INTO THE SYSTEM THAT IS ACTING, AND A NEW PATHWAY IS ESTABIISHED. AFTER PRACTICE, THIS SOUND BECOMES THE CONDITIONING STIMULUS THAT MAY SET THE DOG INTO ACTIVITY IN THE ABSENCE OF ANY CAT 
in the synapses of a neural arc means a reduced threshold of response.

The nervous changes underlying negative adaptation are rather more hypothetical. We may suppose, however, that an impulse that starts to traverse a neural arc, but which does not reach the terminal effector, must of necessity drain into other pathways. Any motor pathway, when active, may drain to itself afferent impulses from other neural arcs. With use, drainage pathways become better established, with the result that later impulses show a lessened tendency to traverse the original neural arc and an increased tendency to traverse the new drainage pathway. Thus negative adaptation of one response always means the substitution of another response. This substitution is brought about when drainage establishes new association pathways. In this way impulses from the stimulus that is apparently disregarded actually reënforce some routine activity. The drained impulses may reënforce respiration, or any system that is active, or they may occasion emotional responses. Thus they establish a habit of doing something other than the act to which negative adaptation has been developed.

\section{Associative Inhibition}

If, while reading aloud, we encounter a word that we have been in the habit of pronouncing in either of two ways, a pause in reading can be noticed. 
This is because there are two pathways of discharge available for the afferent impulse. The two responses, being incompatible, can not both be given, and mutual inhibition from a single stimulus is the result. This interference is an event in the central nervous system, and may occur without causing a contraction of the muscles involved in either of the incompatible responses. Practice of an incorrect performance of any act makes later learning of the act in its correct form more difficult than if the incorrect performance had not occurred. If a part of the multiplication table is wrongly learned, more practice of the correct form is required than is required for attaining equal facility in a part of the multiplication table that has never been attempted. The attachment of two incompatible responses to a single stimulus, which results in their mutual inhibition, is called associative inhibition.

\section{The Serial Response}

Each movement a man makes is likely to bring him into new relations with his surroundings and thus cause new stimuli to act upon him. In this way a stimulus produces a response, this response a new stimulus, this stimulus a new response, and so on until there are no more stimuli that cause movement. If such a series is repeated many times, the man's responses show positive adaptation to each of the several stimuli, so that the time required for going 
through the series of responses is shortened. Entering our own house is an act we all perform smoothly and quickly. The first time we entered the house, however, we were less quick in opening the gate and in closing it after us, slower in mounting the unfamiliar steps, finding the key, and unlocking the front door. As we repeat the act day after day our entrance takes less and less time. This increase in speed is in part a simple positive adaptation of response to the successive stimuli of gate, steps, key, and lock.

In addition to the stimuli that affect our eyes and to which our responses are given, there is another series of stimuli that the responses themselves cause and that accompany the visual stimuli. These are stimuli to the proprioceptors in the muscles and tendons caused by the movements of manipulation and walking, and the stimuli to the end organs of touch that these movements occasion. These movementproduced stimuli play a rôle similar to that of all other stimuli that are incidental to the actuating stimulus, in that they serve to condition the response when the actuating stimulus is absent, or to facilitate the response when they occur time after time along with the actuating stimulus. This facilitation is a cause for the increased speed of the serial reaction in addition to the positive adaptation mentioned above.

In like fashion a person learns his way about the house, at first depending upon his eyes to avoid ob- 
stacles and to find the easiest route from place to place. As all movements are accompanied by proprioceptive stimulation, in time he is able to dispense with visual stimuli and to find his way about in the dark. Tying a cravat or lacing a shoe is at first dependent upon visual stimuli, but later each component movement becomes almost wholly conditioned by the kinaesthetic and touch stimuli occasioned by the preceding movement. A pianist while learning a musical composition depends upon his score as a guide in making each movement. Later, because each movement becomes the cue to the next, because of its stimulation of sense organs in the muscles, and because of its producing sounds that stimulate the ear, the musician may throw away his score. If a printed page is read aloud many times, the book may be closed and the passage spoken from memory. This is in part the result of the sound of each word becoming the conditioning stimulus for the movements producing the next word, and in part the result of the accompanying kinaesthetic stimulation playing a similar rôle. In learning to write we first depend upon copy books, but later, in addition to the conditioning proprioceptive stimulation, the sight of the first letter of the familiar word that the pen forms becomes a conditioning stimulus for writing the second letter, and this a conditioning stimulus for the third, and so on. ${ }^{12}$

12 Concerning the neural basis of chain reflexes and serial resyonses see Herrick, Introduction to Neurology, and Sherrington, Integrative Action of the Nervous System, p. $181 \mathrm{ff}$. 
When a person is learning to dance, he makes one movement after another in response to each verbal direction of his instructor. While one movement is being made the instructor gives directions for the next, so a proprioceptive stimulation caused by the preceding movement accompanies the instructor's verbal stimulus. With repetition of the stimulusresponse series, these proprioceptive stimuli become conditioning stimuli and serve to link together the responses in the absence of verbal direction. When this dependence of each movement upon the muscle stimulation of the preceding movement occurs, we say the person has learned to dance. The way in which this substitution of movement-produced stimuli for the original exteroceptive stimuli comes about. is illustrated in Figure 21.

The facilitating effect of accompanying conditioning stimuli is seen in what might appear at first sight to be cases of simple positive adaptation. Thus positive adaptation to the alarm clock is shown by the conscientious person who, always responding, is eventually stimulated to rise by the faintest tinkle. $\mathrm{He}$ is aided in rising, however, by the fact that his first start of surprise has been followed by the movement of his arm in throwing off the covers, and this in turn by sitting up, feeling for his slippers, putting them on, and rising to his feet. When this series of movements is made, the proprioceptive stimuli occur in a certain order and become conditioning stimuli that serve to fix the sequence of responses. 
Positive adaptation plays its part in speeding up each step in the chain reaction, but the most important factor in maintaining the response as a whole is the series of conditioning proprioceptive stimuli.

Such conditioning stimuli as are mentioned above are involved in the movements themselves, and are not subject to the vagaries of the external environ-

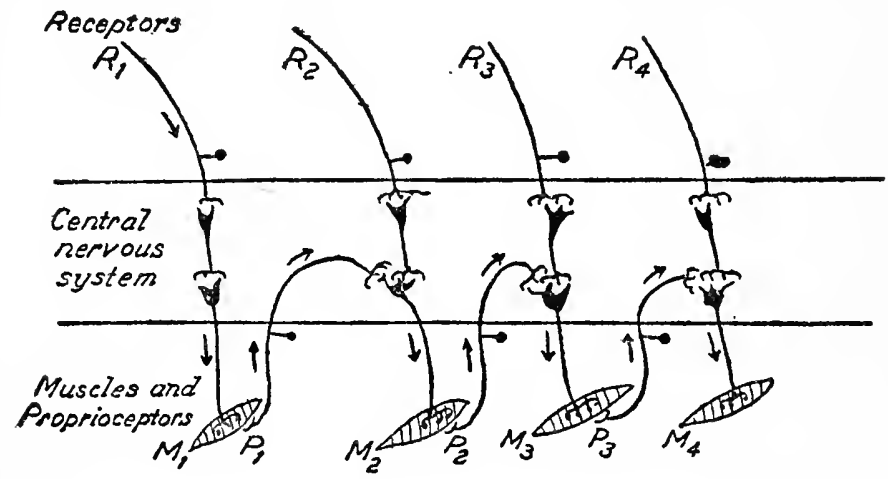

Frgure 21. Diagramatic representation of the formation of a SERIAL-RESPONSE HABIT (AFTER DUNLAP). THE SERIES OF RESPONSES IS AT FIRST THE RESULT OF THE SUCCESSIVE STIMULATION OF THE DISTANCE RECEPTORS SHOWN AT THE TOP OF THE FIGURE. DURING PRACTIOE THIS STIMULATION IS ACCOMPANIED BY THE STIMULATION OF PROPRIOCEPTORS IN THE ACTING MUSClES. THIS PROPRIOCEPTIVE STIMULATION GIVES RISE TO NERVOUS IMPULSES THAT ARE DRAINED AS INDICATED BY THE ARROWS INTO THE ACTING SYSTEM AND IN TIME THE SERIES OF RESPONSES MAY BE ELICITED BY THESE MOVEMENTPRODUCED STIMULI, ONLY THE FIRST OF THE DISTANCE RECEPTOR STIMULT BEING NECESSARY

ment. Hence they serve to stereotype the response as a whole in a way that would not be possible if the organism had to depend for guidance wholly on external situations whose regular occurrence is uncer- 
tain. These orderly response series, now partly independent of the environment, constitute most of our skilled acts and enable man with his aptitude for such habit formation to dispense with the fixed instinctive order of responses characteristic of the behavior of the lower animals. This is not because man has more proprioceptors or other sense organs than have lower animals, but because in man these sense organs have more extensive connections in the central nervous system. The resulting plasticity enables man to adjust himself to various cultures, occupations, and environments.

The Effects of Practice on the Serial Response

The effects of practice in establishing a serial response have been measured by Ebbinghaus, who determined the number of repetitions necessary for learning a series of nonsense syllables so that it might be reproduced once without error. By a nonsense syllable is meant such a sound combination as nis, geg, fof, gol, nen, or kev. ${ }^{13}$

The longer the series, the greater is the number of repetitions required for learning. Ebbinghaus could repeat a series of seven syllables after having said it once, whereas a series of 12 syllables required about 16 repetitions, a series of 16 syllables required 30 repetitions, one of 24 syllables, 44 repetitions, and

13 See: Lyon, Memory and the Learning Process; Meumann, Psychology of Learning; and Ebbinghaus, Memory. 
one of 36 syllables, 55 repetitions. These are represented in Figure 22.

These results may be stated in another way, namely, in terms of the actual amount of work done to learn each series. Repeating 12 syllables 16.6

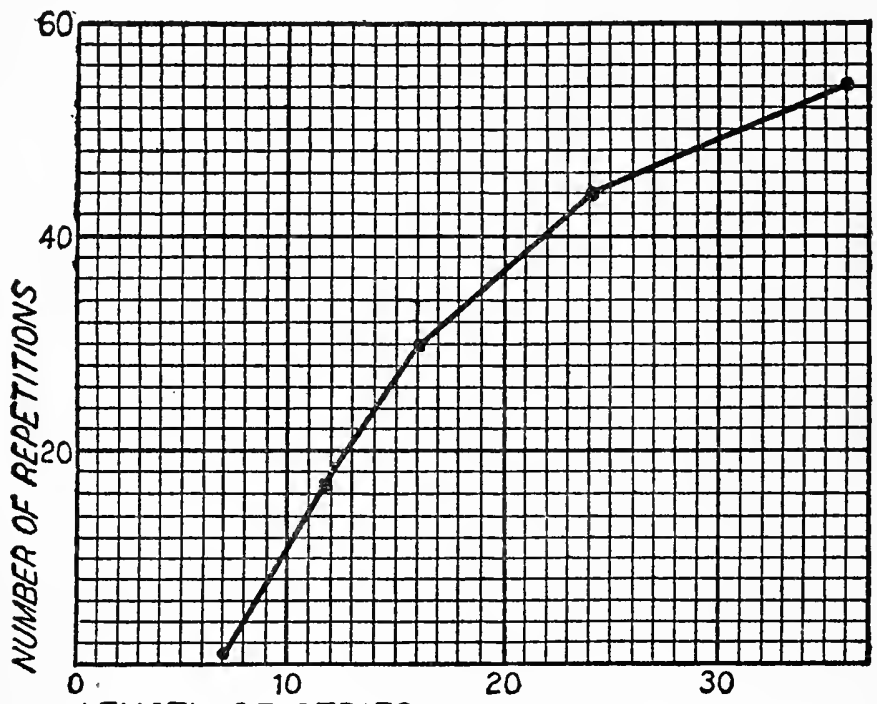

Figure 22. THE NUMBER OF REPETITIONS REQUTRED fOR ESTABLISHING SERIAL RESPONSES OF VARIOUS LENGTHS. THE MATERIAL LEARNED CONSISTED OF SERIES OF NONSENSE SYLLABLES. A REPETITION CONSISTS OF SAYING ANY SERIES ONCE, IRRESPECTIVE OF THE IENGTH OF THE SERIES. THE SYLLABLES WERE SPOKEN AT THE RATE OF 150 A MINUTE (AFTER EBBINGHAUS)

times involves pronouncing 199 syllables; repeating 16 syllables 30 times involves pronouncing 480 syllables; repeating 24 syllables 44 times involves pronouncing 1,056 syllables; and repeating 36 syllables 
55 times involves pronouncing 1,980 syllables. If we plot these values graphically, we find they lie approximately on a straight line. (Figure 23).

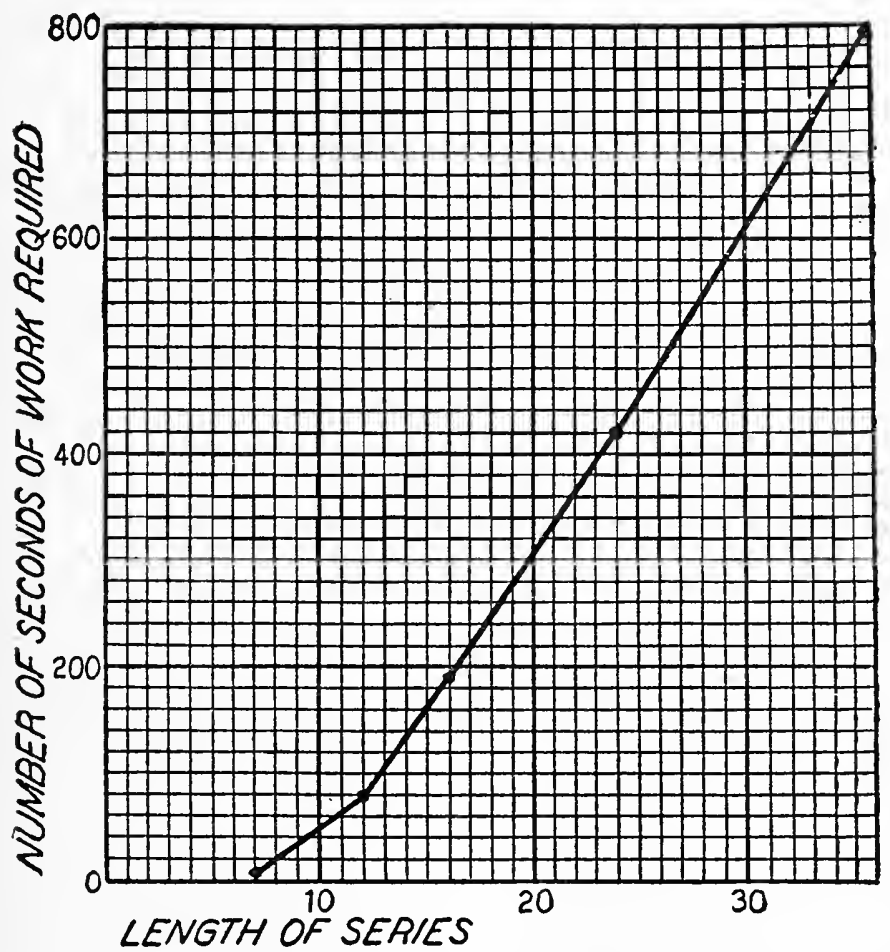

FigURE 23. THE SAME RESULTS ARE SHOWN AS IN FIGURE 22, BUT ARE BEPRESENTED IN TERMS OF THE ACTUAL AMOUNT OF WORK DONE IN ORDER TO LEARN THE SERIES OF VARIOUS LENGTHS, EXCEPT FOR SERIES OF LESS THAN 12 SYLLABLES, THE WORK REQUIRED IS A LINEAB FUNCTION OF THE LENGTH OF THE SERIES

This means that as we pass from one series to another, the difference in the work required for 
learning is proportional to the difference in the lengths of the series learned. If the syllables are repeated at intervals of .4 seconds, or in other constant rhythm, the time consumed will be proportional to the number of syllables spoken. If we prepare series of nonsense syllables of totally different material and of different lengths, containing 16, 17, 18, 19, etc., syllables respectively, and find that 16 syllables are learned in 3 minutes and 17 in $31 / 2$ minutes, then the series of 18 syllables will be learned in 4 minutes, the series of 19 syllables in $4 \frac{1}{2}$ minutes, the series of 20 in 5 minutes, and so on. It will then take $13 \mathrm{~min}-$ utes to learn a series of 36 syllables.

Even though it may be impossible to remember to-morrow what we have learned to-day, to-day's learning makes to-morrow's relearning easier. The amount of positive adaptation remaining from previous practice may be measured by the number of repetitions saved when material is learned over again. This method of measuring retention has become known as the saving method.

Ebbinghaus, using a number of different 16-syllable series, repeated some 8 times, some 16 , some 24 , some 32 , some 42, some 53, and some 64 times. Twenty-four hours after each one was practised he found the number of repetitions necessary for relearning it. In this way he discovered that each one of any number of repetitions produced the same amount of retention as any other. It happened that, for the length of series used, each of the original 
repetitions saved the next day one per cent of the time that would have been required if there had been no previous practice. Thus 8 repetitions saved 8.1 per cent of the next day's work, 32 repetitions saved 32 per cent of the next day's work, and 53 repetitions saved 53.9 per cent. The fatigue resulting from many repetitions made it impossible to carry the experiment beyond the point of 64 repetitions. Except for this, 100 repetitions would probably have made it possible to reproduce the series the next day without any review. It will be remembered that to learn a series of 16 syllables, so that it may be repeated once without error immediately after the learning, requires about 30 repetitions. Figure 24 shows the relation between the first day's practice and the next day's relearning.

\section{Forgetting}

If a given amount of material is memorized, we may measure the amount retained in memory at any later time by finding the length of time that is required to relearn the material. The time saved in relearning, compared with the time required for the original learning, gives us a quotient that stands for the proportion retained in memory. By this method it is shown that the memory deteriorates as time goes on, and that the rate of deterioration is most rapid at the outset. This rate of forgetting as measured by Ebbinghaus is shown in Figure 25 . 
Meumann and others report what they take to be a slight recovery of memory at the end of 24 hours. ${ }^{14}$ This anomaly was not shown in the careful work of

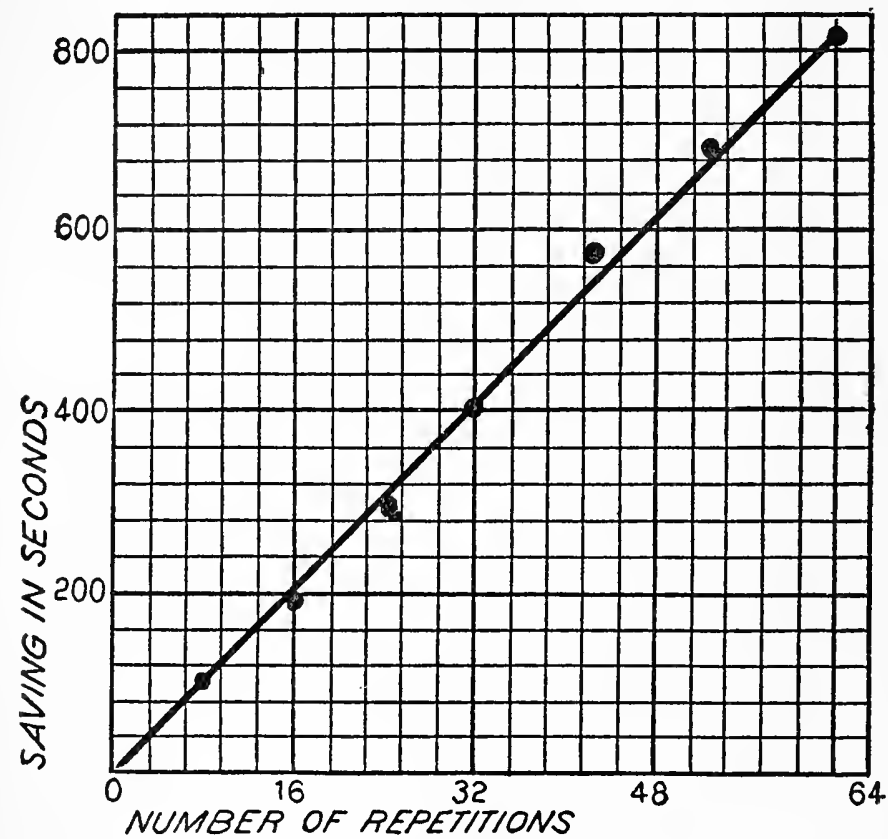

Figure 24. The time saved in relearning a serial response of 16 NONSENSE SYLLABLES SHOWN AS A FUNCTION OF THE AMOUNT OF YESTERDAY'S PRACTIOE. THE AMOUNT OF POSITIVE ADAPTATION FOUND AT THE TIME OF RELEARNING IS A LINEAR FUNCTION OF THE AMOUNT OF WORK DONE 24 HOURS EARLIER (AFTER EBBINGHAUS)

Ebbinghaus though a tendency to such recovery may be noticed in Figure 25. Meumann's subjects were unable to recall as much 9 hours after practice as they could recall 13 hours later. Graphically rep-

14 Meumann, op. cit., Chapter 7, Sec. 6. 
resented, there was a rise in the forgetting curve between the 9 - and the 24-hour points. Many suppo-

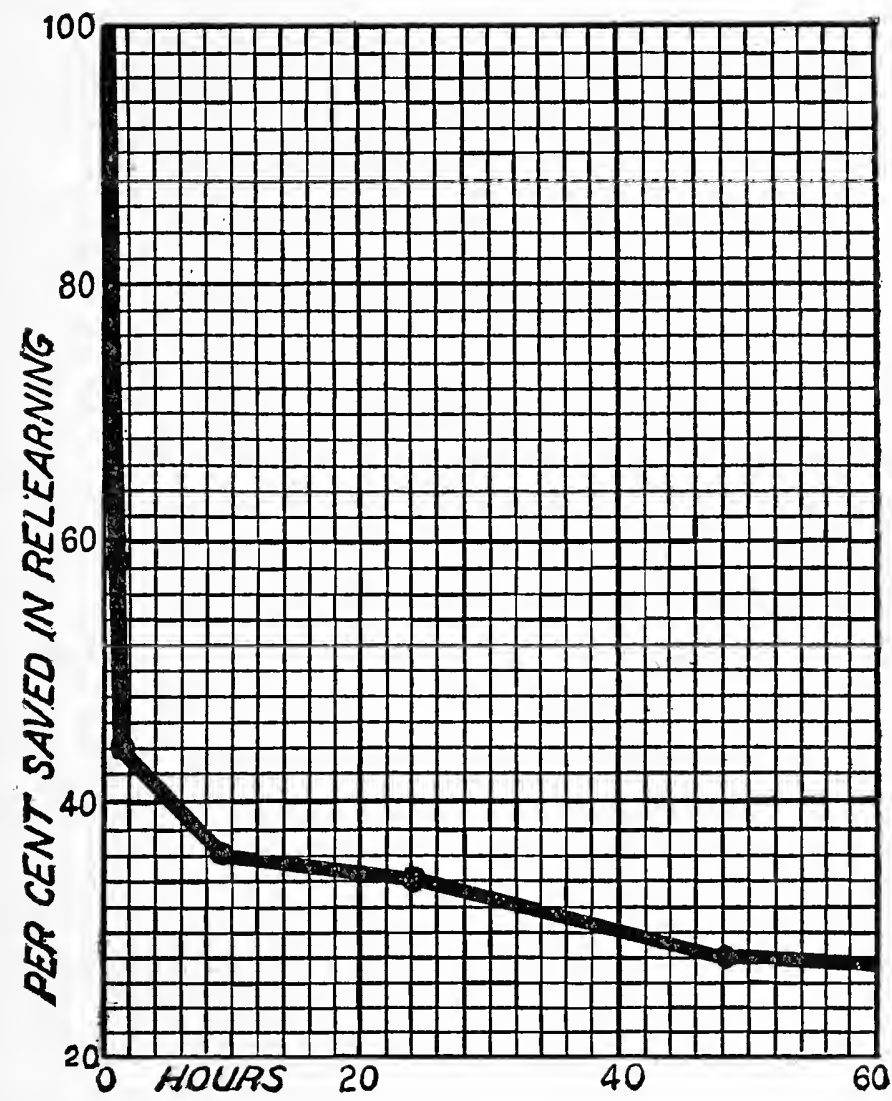

Figure 25. the rate of forgetting a nonsense series (after ebBINGHAUS). THE AMOUNT OF POSITIVE ADAPTATION REMAINING AT ANY TIME IS MEASURED BY THE SAVING METHOD

sitions have been made on the basis of these results. Colvin says "this improvement in memory seems to 
be due to the fact that the original impressions have had an opportunity to become associated with permanent elements in consciousness, and, therefore, are capable of revival more readily after a certain lapse of time." 15

From the following experiments by W. R. Wilson in the local laboratory an interpretation of Meumann's results in terms of the facilitating action of conditioning stimuli is suggested. Ten subjects learned lists of ten nonsense syllables, and 72 hours later relearned the same lists sometimes in the same surroundings, and sometimes in different surroundings. Each subject learned one list in the laboratory and relearned in the laboratory, learned a second list in the laboratory and relearned out of doors, learned a third list out of doors and relearned in the laboratory, and learned a fourth list out of doors and relearned out of doors. In eight of the ten subjects there was greater saving in each case where relearning occurred in the same surroundings in which the first learning had taken place. Two subjects showed in one of their four series a greater saving where relearning had occurred under dissimilar conditions. An average of 11.4 per cent fewer repetitions were required to relearn in similar surroundings.

In another experiment the subject was seated in a room and copied a list of letters on a typewriter whose keys had been arranged in a random order.

15 Colvin, The Learning Process, p. 140. 
He copied the same list 24 hours later and the times were compared. A variable condition consisting of the presence or absence of the odor of oil of peppermint was used. Each subject practised a list with the odor present and repeated the same list with the odor absent; he then practised a list with the odor present and repeated the list 24 hours later with the odor present. He then practised the list without the odor and repeated with the odor; and last practised without the odor and repeated without the odor. Thirteen subjects were used, and the average saving in the time required to repeat the list was 9.4 per cent greater when the repetition took place under the condition of the first practice.

It is highly probable that the greater retention shown by Meumann's subjects at the end of 24 hours depended upon the daily recurrence of conditioning stimuli. There is a diurnal rhythm of experience that results in a characteristic internal state at each hour of the day. We sleep, eat, work, and play according to a fairly rigid schedule. The resulting periodic bodily states, present at the original learning, contribute familiar stimuli to anyone who is engaged in relearning after a 24 -hour period. These stimuli come to condition the responses and facilitate the relearning.

\section{Whole and Part Learning}

One of the practical questions that arise when we have something to commit to memory is whether the 
material should be rehearsed from beginning to end, or broken up into parts so that each part can be learned separately and the parts later combined. If the law represented by Figure 23 held for short series as well as for long, it would take approximately twice the time to learn any series as to learn a series half that length. Part learning would then evidently be wasteful, because it would take the same time to learn by parts as to learn by wholes, and after the parts were learned the order of the parts would have to be learned also. The law (Figure 23) holds, however, only for lengths somewhat greater than the memory span. This memory span is the amount that can be accurately reproduced after a single reading. Because very small parts are memorized with relatively greater ease than large parts, we have no way of determining in advance of experiment whether the easy learning of small parts compensates for the necessity of linking these parts together after each has been committed to memory.

Ebbinghaus has shown that when two series of different lengths are memorized to the point of one perfect reproduction, the longer series is better retained after 24 hours than is the shorter series. Thus, 33 per cent of a 12-syllable series is shown by the saving method to persist after the lapse of one day, whereas 48 per cent of a 24-syllable series is retained. This fact, taken in conjunction with the law (Figure 23) that an increase in the length of the series demands a corresponding increase in the 
amount of work required for learning, gives us reason to expect that experimental results will show a saving when the method of learning by wholes is employed.

Experimental results demonstrate conclusively that part learning is wasteful and whole learning most efficient. The whole method requires less work for a single accurate reproduction, and for a given amount of work done results in fewer errors and better retention. This holds true for both nonsense material and for meaningful material. ${ }^{10}$

The word "learning" is here used in the sense of verbatim memorizing where only serial responses are practised. In such a subject as geometry, the laws of whole and part memorizing do not apply. This kind of learning will be considered in the chapter on perception.

\section{Results of the Distribution of Practice}

If we have a certain amount of time to spend in memorizing, it is found advantageous to distribute this time over several days rather than to utilize it all at one sitting. Ebbinghaus found that a 12-syllable series repeated 68 times consecutively required 7 repetitions for relearning 24 hours later. Series of the same length repeated on an average of 17.5 times

16 Lyon, op. cit.; Pechstein, Whole vs. Part Methods in Motor Learning, Psychological Monographs, 1917; Pyle, "Economical Learning," Journal of Educational Psychology, 1913, pp. 148-158; Pyle and Snyder, "The Most Economical Unit for Committing to Memory," ibid., 1911, pp. 133-142. 
the first day, 12 times the second day, and 8.5 times the third day (38 in all as against 68) needed but 5 repetitions for relearning on the fourth day. It is evident from this, and from similar results that have been found for meaningful material, that economy of learning demands distributed repetitions.

Lashley has shown that, in training white rats to choose the path leading to food, using two trials a day saved 69 per cent of the work that would have been necessary if ten trials a day had been used. ${ }^{17}$

\section{Learning Meaningful Material}

Learning a prose passage verbatim, committing verse to memory, or learning to say a set of nonsense syllables as in Ebbinghaus' experiments, is the acquisition of serial response habits. When the practice begins, each printed symbol is the stimulus for a response that has been already attached to this symbol by conditioning. As the stimuli occur in a given order, the reactions follow each other in a given order, and with a sufficient number of repetitions the serial response is established independent of visual stimuli but dependent upon proprioceptive and auditory stimuli.

In learning nonsense syllables the learner is wholly unaccustomed to the order of the responses, and the whole of the series must be learned. In deal.

17 Lashley, "A Simple Maze; with data on the relation of the distributien of practice to the rate of learning," Psychobiology, 1918, pp. 353-367. 
ing with words, on the other hand, the learner is seldom without some previous experience of their sequence, and when committing to memory ordinary prose he relies very largely upon already formed serial response habits. Familiarity makes relatively easy his remembering combinations of "sensible" words. The meaningfulness of language is a further aid to prose learning. This aid is partly composed of gesture and characteristic emotional expression, of customary pitch, speed, and intensity variations of the voice. The response tendencies that are touched off by each of the spoken words also play their part in the reënforcement.

Some prose is easy to commit to memory, whereas other prose is difficult. Easy prose contains sterotypisms and familiar word combinations. Less stupid and more original texts combine words in a less predictable order, and so are more difficult to memorize or even to read. Verse is easy to learn on account of its set rhythm and its predictable end rhymes.

\section{Trial and Error}

Certain organisms, such as paramoecium, have for the most part but a single manner of response. This is given to every harmful situation the animal meets in its forward swimming and consists in backing, turning to one side, and then proceeding in a new direction. If this response brings it again into 
harmful conditions, the response is repeated until the animal is progressing through a medium that contains no stimuli for this avoidance reaction. When an animal makes many trials, any one of which may or may not be specially fitted to remove the animal from harm or bring it into better surroundings, and when as a result of these trials it finally stumbles upon the suitable response, its behavior is called trial and error. ${ }^{18}$

Trial and error enters into the behavior of all animals. When hungry, they are likely to range about until, after many fruitless reactions, they come at last by chance upon food or the signs of food. In the same way mates are discovered, new shelter is found, or building materials secured. The trial and error behavior of most higher animals differs from that of the lowest forms in exhibiting not one but many different kinds of response. If we place a cat in a "puzzle box," the door of which opens only when the cat pulls a string or turns a knob, the cat will make many kinds of unsuccessful movement before it accidentally hits upon the proper means of escape.

Most inventions and discoveries are the result of happy accidents. Charles Lamb's hypothesis of the origin of roast pig is not wholly fanciful. We may be certain that the discovery of intoxicating beverages was due to the carelessness of some primitive

18 Thorndike, Animal Intelligence, p. 35ff; Jennings, Behavior of Lower Organisms. 
housewife who allowed her fruit to spoil but whose frugality prompted a reluctant use of a concoction whose hidden possibilities must soon have had a wide publicity.

A series of trial and error responses may become a habit in certain cases through the agency of conditioning stimuli in the manner described in the discussion of serial responses. It is very seldom, however, that the series of trial and error responses as a whole becomes fixed as a habit. Usually the series is shortened in the process of habit formation, the final response being given but many of the futile responses that preceded it being eliminated. We may now ask the question how this shortening of the series is accomplished.

The Shortening of a Trial and Error Series into a Final Habit Response

When considering the subject of threshold of response we found that a stimulus may be too weak to elicit any movement. When a stimulus is above the threshold, the kind of reaction it causes may depend upon its intensity. It is a general principle that most stimuli, which when weak cause an approach reaction, cause avoidance when they become very intense. This is illustrated by taste stimuli. The sourness of lemonade and the bitterness of coffee can be increased to a point where these drinks are avoided. A limited amount of salt is necessary 
to make eggs palatable, but when exceeded causes avoidance. Children instinctively seek sweet food, but food may be so sweet as to become disgusting. The resistance that a little child shows to rough handling may be replaced by acquiescence to gentle manipulation. The baby accepts more readily the nipple of his nursing bottle when it is gently placed in his mouth than when it is forcibly inserted.

The response that a new-born baby gives to a stimulus is definitely determined by the innate structure of his nervous system, although there may be minor fluctuations of response in the same infant at different times due to such physiological changes as hunger or fatigue. His response tendencies are in large part predictable. He naturally responds by grasping, looking, withdrawing, or other movements according to the nature of the stimulus. Thus approach and avoidance are not chance behavior, and the fact that all people learn in much the same way is due to their being equipped to respond to a given stimulus by the same reaction. Many of these reactions are simple reflexes.

The more remote an object is, the less intense is its stimulation, and approach to the object gradually increases the intensity of this stimulation. In certain cases an intensity may be reached that causes a turning away. Thus the increasing stimulation of a single sense organ often results successively in opposite orientations.

Another frequent result of approaching an object 
is to bring stimuli to bear upon sense organs not at first affected. A single object may be the source of stimuli first to distance receptors, such as eyes, ears, or nose, and later to the sense organs in the skin, muscles, and tendons. When a deer approaches at the sight of a man, not only does the visual stimulus increase in intensity, thus tending to make the deer take flight, but its greater proximity to the man brings into play odor stimuli, in response to which the deer turns away. This succession of approach and avoidance is characteristic of most trial and error behavior. ${ }^{19}$

The incompatibility between approach and avoidance is for the most part an incompatibility of orientations. The movements of locomotion made by the deer are not fundamentally different in approach and in retreat. The difference lies in the direction in which the deer is turned. This makes evident the importance of the analysis of movement groups into their component parts.

There is a classical example of the baby and the candle. The baby seeing the flame approaches his finger, and on feeling the flame withdraws his finger. If charged wires are placed before the opening of a rat's food box, so that the animal in stepping upon them receives a mild punishment, his approach is followed by avoidance. If a bird takes a bite of a cinnabar caterpillar, the taste makes it reject the

19 Holmes, Studies in Animal Behavior, Chapter VII; Watson, op. cit., Chapter 8. 
food. A master who does not enjoy the friendly greeting of the dog that places his dirty forepaws on clean clothing, causes the dog to desist by stepping on the hind feet of the animal. In all these cases while the approach stimulus is still present, the avoidance reaction has been called forth. The result is that the avoidance reaction is now conditioned by the approach stimulus, so that on the next occasion the avoidance response tends to be given as soon as the approach stimulus is received. The sight of the flame has become the conditioning stimulus for withdrawing the finger. The sight of the door of the food box has become the conditioning stimulus for turning away. The sight of the caterpillar has become the conditioning stimulus for rejecting the food. The sight of the master has become the conditioning stimulus for returning to all fours. In addition to the conditioning visual stimuli involved in these responses, the proprioceptive stimuli brought about by the approach movements serve to condition the movements of withdrawal.

It is obviously impossible for the baby to extend and withdraw its hand at the same time, for the rat simultaneously to approach and retreat from the door, for the bird to eat its caterpillar while rejecting it, or for the dog to paw his master while backing away. The interference of these opposed movements may not, on the second occurrence of the approach stimulus, prevent the succession of approach and avoidance, but eventually repetition establishes 
the conditioned response more firmly, so that in the end, provided the avoidance stimulus is sufficiently strong, the approach response ceases to be given. This is due to the gradual lowering of threshold of the avoidance response as elicited by the approach stimulus and the resulting mutual inhibition of the two opposed response tendencies. When this occurs, we say the baby is trained to avoid the candle, the rat to avoid the door, the bird to let the caterpillar alone, and the dog to proper conduct.

Emotional reënforcement is usually associated instinctively with avoidance responses. Running away is accompanied by fear; rejecting food, by nausea; averting the eyes, by disgust or shame; withdrawing the burnt hand, by grief; turning away from insuperable obstacles, by annoyance. The responses to all pain stimuli are emotionally facilitated. This emotional reënforcement makes avoidance relatively more energetic than approach, and so in the rivalry of two incompatible responses it is likely to prevail.

The approach responses in mating and food-getting have strong emotional reënforcements. Thus, because of appetite, these approach movements are often carried out to the disregard of stimuli that would otherwise cause withdrawal. Negative adaptation to the disregarded avoidance stimuli then occurs. Within certain limits, the longer the period of fasting or continence, the greater is the emotional reënforcement and the more aggressive the approach movements. This, along with the fact that abortive 
behavior of this sort calls out further emotional reenforcement, assures the final success of food-getting and mating.

Let us consider again the case of a cat placed in the puzzle box. After many fruitless movements he is attracted by the button, the turning of which opens the door. After the cat has been placed repeatedly in the box, the time required for escape becomes gradually less, and the fruitless movements grow fewer, until finally the cat's being placed in the box may be followed at once by the successful response of turning the button.

The cat when in confinement is instinctively organized to respond to the sight of bars, cracks, corners, and even solid walls by approaching and pulling and pushing with paws, claws, nose, and teeth. If any part of the box is loose, the cat has a tendency to continue his manipulation. He is also instinctively organized to turn away from these same objects when they offer more than a certain amount of resistance to his attack.

The situations the cat faces in the puzzle box are composed, for the most part, of visual stimuli that attract him, followed by stimuli to his proprioceptors and sense organs of touch that repel him, and these two classes of stimuli are given by the same object. He is instinctively attracted by the sight of the bars, but on reaching them, especially if they are rigid, he is instinctively impelled to turn away. This turning away is due to the resistance of 
the bars to his attempted manipulation and to his efforts to force his way between them. Approach and retreat are here original tendencies called forth by a single object.

With repetition the sight of the bars becomes the conditioning stimulus for retreat, so that the conditioned response inhibits the original response. One by one the movements of approach to the various confining surfaces of the box are inhibited by the conditioned responses of retreating, until at last the animal is attracted by the door-opening device. The reason that this last movement is not inhibited is that the device itself never serves as the source of a stimulus that is instinctively avoided. Although the cat turns away from the button in response to the open door, he does so not because the button repels him but because the open door attracts him. Approaching the button and approaching the open door are the only approach responses that are uninhibited by conditioned avoidance responses, and, while the door is closed, the button alone calls forth an uninhibited response.

When the cat is but partially trained, he makes useless responses to various parts of the box. He always ends, however, by making the successful response and by escaping. As some useless responses are given on some occasions and others on other occasions, depending upon the cat's chance position in the box, the successful response, always occurring, is likely to be the one most practised. This may be 
another factor in lowering the threshold of response to the door-opening device. ${ }^{20}$

Mutual inhibition of two incompatible response tendencies may result from other kinds of situations than one in which the same object furnishes both approach and avoidance stimuli. If a dog is tickled on both sides simultaneously, the usual scratch reflex may be elicited from neither side. ${ }^{21}$

Here two approach responses serve to inhibit each other because the tickling of each side produces a contralateral extension of the hind leg, as well as the oscillatory scratching movements of the leg on the side stimulated. As both legs are actuated both to scratch and to support by the bilateral stimulation, and as these movements are incompatible, there may result either no movement at all or, because of the unstable equilibrium of this system, an alternation of scratching on the two sides. It is only this unstable equilibrium that makes incredible the case of Buridan's ass, who, the victim of balanced approach tendencies, starved while standing between two stacks of hay.

A more stable equilibrium is found where an animal is hemmed in by avoidance stimuli. The cat hesitates to take to the water when pursued by a dog. The victim in a burning building is repelled by both the fire and the long drop to the street. In

20 Smith, "The Limits of Educability in Paramoecium," Journal of Comparative Neurology and Psychology, 1908, p. 503.

21 Sherrington, op cit., p. 143. 
daily life we are often placed between the devil and the deep sea.

When trial and error behavior does not involve avoidance responses, many fruitless movements may be retained in the resulting habit. The self-educated bricklayer is likely to preserve many superfluous motions that are the results of the chance arrangement of his materials at the time he first began to learn the trade. If an inconveniently placed brick, or an awkward manner of handling his trowel, had always been the stimulus for an avoidance response, as of course it occasionally is, he would not have developed his unskillful and costly habit. The instruction a bricklayer receives consists in verbal directions and criticisms that compensate for the absence of innate avoidance stimuli. The same is true of learning a golf stroke, learning to play a violin, or learning to sing. In social behavior the moral code in the absence of avoidance stimuli serves to inhibit acts that endanger common welfare, leaving free from interference only acts of virtue.

The reason that such habitual serial responses as signing one's name, whistling a melody, or reciting a poem, undergo no shortening by the omission of responses is that these acts do not bring avoidance stimuli into play.

It has been pointed out before that many act's are made up of movements of orientation, locomotion, and intervention. It is not necessary that orientation should be complete before locomotion begins, or 
that locomotion should be finished before movements preparatory to intervention are commenced. In such a practised act as picking up a book from the floor, we do not first turn toward the book, then walk to the spot, bend the body, extend the arm, and grasp the book, all separately. We are more likely to start walking as we turn, bend the body and extend the arm as we walk, and, while grasping the book, turn the body preparatory to walking away.

When a number of acts form a serial response, one act is seldom completed before the next is begun. In this way there is an overlapping of compatible movements, orientation for the next act occurring while the movements of intervention of the last act are still in progress. This telescoping of one act with another is one of the factors in shortening the time of a serial response.

Where overlapping of acts occurs, more movements are made at the same time, and so more movement-produced conditioning stimuli are available to knit together the parts of the series.

As a series of acts is repeated time and again, the degree of overlapping of the individual acts increases more and more, until limited by the anatomical structure of the animal or by the requirements of the situation. This overlapping is made possible by the fact that many conditioning stimuli have been acting for some time before the response that they have come to condition has occurred. As 
we approach a door and finally see the keyhole we reach for our keys. Later, because we saw the door while reaching for the keys, we take out our keys when we first come in sight of the door. Reaching for one's keys having been established as a response to the sight of the door, may occur while opening the gate, provided the door is in view. Thus the response may next be conditioned by the gate opening, and later still by the sight of the gate in the distance.

In the same way, because of the overlapping of the parts of situations, a dog first responds to the sight of members of the family, then to their footsteps, then to the sound of the train on which they regularly arrive.

Ease, grace of movement, or the facile performance of a difficult act does not come with maturity alone, but requires practice. Coördinated movements are guided by stimuli in the external situation, or by stimuli that are movement-produced. Each movement is attached to its stimulus by original nature or by conditioning, and the proper energy of each movement is learned by trial and error. In picking up a brick we grip it sufficiently to keep it from slipping out of the hand, take up a posture that prevents our being overbalanced by the weight, and lift with sufficient force to raise the brick from the ground. In the process of learning, the brick and each antecedent movement furnish the conditioning stimuli for each part of the act. We employ a very different prehension, posture, and lift in picking up 
a sponge. We are not conscious of this difference in behavior unless the object we pick up has a deceptive appearance.

Awkwardness is eliminated by trial and error, and by the dropping out of incompatible movements that constitute mistakes. We adjust the force of muscular contractions to the work that is to be done. Such adjustments, together with the elimination of false moves and the telescoping of successive acts, results in a maximum simplicity of the effective response, and this we call coördination, or eusynergia.

The nervous structure that governs many coördinated acts is a matter of original nature alone. Birds and insects fly without practice; the baby balances on his two feet by means of a neural mechanism that, though it improves with use, is an endowment of great effectiveness; nursing movements occur in an orderly combination and sequence. The extent to which the cerebral cortex is involved in learned coördination where the sequence of movements is independent of stimuli remains somewhat a matter of conjecture. It is not probable, however, that an elaborate series of movements may be coördinated by cortical processes independent of movement-produced stimuli.

\section{IMITATION}

When a response resembles its stimulus, we call the response imitation. We laugh on hearing others 
laugh. A fright response spreads from individual to individual in the herd. One sheep jumps the fence because the preceding sheep jumped it. The barking of one dog causes all the dogs of the neighborhood to join in. On seeing a person studying the sky we stop and do likewise. When a cage of pigeons is supplied with water, the water may not be noticed for some time, but when one pigeon begins to drink, several others will usually perform the same act. Smoking, yawning, whistling, throwing stones at a target, rising and going home, hissing and applauding, are stimuli that readily call out imitation in others.

Tickling is probably the original stimulus that causes a baby to smile. He does not at first smile by imitation, but in order to learn to imitate he must have someone present to smile back at him. If the sight of a smiling face accompanies the baby's act of smiling, it thereby conditions his response and will later cause him to smile in the absence of tickling.

Practically all imitative behavior is made up of conditioned responses, there being very few cases of instinctive imitation. These few cases are probably limited to the tendency of lower animals to run, swim, and fly together, to orient themselves in the same direction, and to follow one another. The instinct of following is very often the act of approaching something that is moving away. This analysis applies rather to the following of fawns, 
kittens, and puppies than to the following of chicks. In the case of the fawn that follows its mother in her flight the approach response is very evident, for when the mother stops, the fawn nestles against her.

The dependence of imitation on learning is well illustrated by language acquisition. The baby is at first moved to make a great variety of vowel and consonant sounds by such stimuli as he receives from a moderately full stomach, a soft bed, and a warm, well lighted room. The sounds he makes accompany the movements that produce them and, because the vowels are sustained and the consonants either sustained or repeated, these sounds also precede the movements that continue or reiterate them. They thus become the conditioning stimuli for their own production, so that when uttered by others they are imitated by the baby. A period of practice, during which the baby plays with these sounds, is necessary before imitation is possible, and by this practice the baby is prepared to imitate the particular sounds of any language.

Imitation is seldom an exact replica of the act that is imitated. The imitator's response is that habitual act of his that most nearly resembles the act he observes. As a person grows older, his reaction tendencies become less variable and more stereotyped. Thus a child is in many ways a better mimio than is an adult. If, for example, in his playing with sounds, a baby has familiarized himself with a 
certain French vowel, he is likely to imitate it with considerable accuracy, whereas an adult, whose language responses, throughout a lifetime of practice, have been confined to English sounds, will imitate the French vowel by its nearest approximation in his native tongue.

In New England the invocation, "O mihi beate Martine," is found in degenerate form as the exclamation, "Oh my eyes and Betty Martin." The baseball player in his first attempts at golf imitates a golf stroke inaccurately because of his familiarity with a bat. One of the reasons that it is hard to learn to dive is because we have learned so well to jump feet foremost The motion picture actor's failure to imitate the behavior of a social class to which he does not belong is the product of a life spent in acquiring a manner of quite another sort. The plasticity of children lies in their relative freedom from stereotyped habits. The behavior of an adult falls into ruts from which he extricates himself only with great difficulty. 


\section{CHAPTER IV}

\section{COENOTROPES}

Watson performed an experiment in which a baby was shown a white rat. The baby looked at the rat without displaying any fear. The rat was exhibited again, and, while the baby was looking at it, an iron bar was struck. The resulting noise caused the characteristic and instinctive fear response. When the rat was exhibited a third time, the sight of the animal called out the fear reaction. In this way the experimenter secured a conditioned response to the substituted visual stimulus. The baby had become afraid of rats. In similar fashion, fear could be attached to toy balloons, chrysanthemums, the experimenter, or to any object whose visual appearance had originally no power to cause the emotion of fear.

No movements, except eye movements, are instinctively elicited by a visual stimulus. The baby is surrounded by the world of things seen, and all these visual stimuli are available for substitution. By conditioning, the sight of an object prompts the baby to do again what he was doing when he saw. the object, and in time many complicated and elaborate responses are determined by what he sees.

The avoidance movements of fear, the attack 
movements of rage, and the approach movements of love are given to visual stimuli only through the process of conditioning. We must learn to keep our distance from charged wires, dangerous animals, stoves, falling objects, and people who sneeze. We must acquire the habit of striking out at aggressors who have not yet touched us, and to cry when dangerous objects are seen approaching. Without previous bodily contact, probably no sex responses would be given to visual stimuli.

Babies are instinctively afraid of thunder, but not of lightning. When lightning accompanies the thunder, it takes on the power to make the baby afraid. Objects acquire frightfulness by being present during fear.

Few people are afraid of toy balloons, but many are afraid of the sight of dogs. This is because few people have been frightened in the presence of a balloon, but many have been barked at or bitten while looking at a dog. Where loud sounds or pain . stimuli are naturally inherent in a situation, the accompanying stimuli that the situation offers to eyes, nose, or organs of touch compel in all men some fear as a conditioned response. Thus there are fears, likes, or irritations that are shared by the world at large. But this is usually true only when the situations include a natural stimulus, either present or impending, to these emotional responses. We all show fear when confronted with a precipice or a wild cat, although this is not an in- 
stinctive response. We share with oúr fellows an ideal of feminine beauty, which is a matter of common training. Anyone is ammoyed when he sees that he has missed his train, although the sight of a departing train is not an original stimulus for anger.

Equipped with fairly definite response tendencies, a baby is born into an orderly world. He is exposed to a systematic routine and a fixed sequence of situations. Above all, the combination of stimuli resident in such objects as his bed, his clothing, his tub, his mother, and his own body is almost invariable. The original nature common to all babies, together with the inevitable environment they all share, develops similar habits in all children. That all people have not identical habits is due to individual differences in endowment and to the peculiarities of the world that each lives in. These neurological and environmental differences are more likely to be noticed than the commonality of endowment and the universality of the world order, which latter are so commonplace that their importance is often underestimated.

The habits that are produced and called out by common situations that everyone experiences, are frequently given such names as fighting instinct, mating instinct, hunting instinct, hoarding instinct, shelter-seeking instinct, maternal instinct, gregarious instinct, or instincts of curiosity, approval, scorn, mastery, and submission. Even in the behavior of lower animals the acts described by these 
terms may owe something to learning. When performed by man, they are always acquired reaction tendencies, though we all possess them by virtue of our having a common human nature that is trained in a common world. The extent of man's capacity for forming conditioned responses, which distinguishes him from lower animals, is the outstanding attribute of human nature.

Habits that men universally share are obviously to be distinguished from the private habits of typewriting, piano playing, vocations, hobbies, personal idiosyncrasies, and the like. There is no adequate term for these common habits in psychology. They might be called instinct-habits, common action patterns, vulgarities, primary acquirements, or common acquisitions, but all these terms are either ambiguous or cumbersome and none of them is sufficiently concise to describe so important a class of acts. For lack of a better word we shall employ the term coenotropes to describe common modes of learned response that are the product of original nature and commonly shared environment. ${ }^{1}$ Further experiment may discover the integration of these coenotropes to be more dependent upon the slow maturation of innate nervous structures than we now have reason to suppose.

A group of learned acts may be given a common name because of the similarity of the situations that

1 The word coenotrope, pronounced seenotrope, is derived from

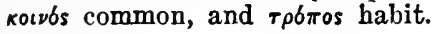


cause them or because of the similarity of their results, and thus very dissimilar acts may be classed together. The common mode of behavior known as "collecting" is made up of diverse acts whose results show a greater resemblance than do the acts themselves. Head hunting and stamp collecting are very different, but both acts result in possessing a collection. The common mode of behavior known as "curiosity" may be illustrated by acts so dissimilar as peeping through a hole in a high board fence and buying a newspaper. All acts of curiosity, however, are excited by situations that are similar in their make-up, so that the situation serves here as a basis for classification.

Such a class name as "shaving", denotes a specific act that is a part of the learned equipment of many individuals. The characteristic use of many objects, such as a razor or an umbrella, constitutes a common mode of behavior that is not made up of diverse acts.

\section{Common Habits}

The original tendencies mentioned in the chapter on "Instinct" are fairly simple responses. It is possible that there are more elaborate acts that properly may be considered a part of original human nature.

A baby, however, may acquire conditioned responses immediately after birth, and the older observers did not distinguish carefully between habit 
and instinct in reporting the behavior of babies. As any normal child grows older we find him creeping, walking, balancing without support and with stationary feet, climbing, hitting, throwing, running in pursuit of moving objects, avoiding obstacles in his path, and making many other movements that the young of lower animals make as a result of neurological endowment. To what extent these acts in the human child are instinctive is largely a matter of surmise. The child's opportunity for establishing many of these stereotyped responses by trial and error learning is certainly great, and the uniformity of conditions under which all children live makes tenable the assumption that learning is here an important factor.

Spalding demonstrated that birds fly without preliminary trials, and that their awkward first attempts at flying are due to the immature condition of an instinctive flying mechanism. His experiment was to confine one set of birds so that they could not fly and to leave unrestrained a control group of the same age. When the control group had "learned" to fly successfully, the confined birds were liberated and were found to fly at once with all the precision of the others. ${ }^{2}$

It would be unjustified to infer by analogy that the child's first blundering efforts at walking are similarly the responses of an immature walking mechanism. It has been pointed out already that

2 Preyer, Mind of the Child, Part 1, p. 239; Spalding, in Nature, vol. 12 , p. 507 . 
man lacks in large part the elaborate instinctive tendencies of the lower animals. Spalding's results, however, should make us cautious of denying in the case of the baby a natural ability to walk. There is some evidence that this ability is a chain reflex. Spontaneous walking without preliminary trials has been occasionally reported of babies under the observation of psychologists.

Balancing on the feet is almost certainly an instinctive endowment, just as is balancing the head. Stair climbing, and many other forms of locomotion involving the surmounting of obstacles, are in part habits.

In the absence of experimental work we must be content with conjecture as to how a child learns to throw. Grasping and releasing an object are instinctive, as are also patting movements of the arms. The combination of these movements may result in throwing any object that is held in the hand. The serial response so established by trial and error may be the beginning of a throwing habit. Skillful manipulation of objects and the stereotyped movements involved in transporting objects from place to place can not be regarded as instinctive.

More than 95 per cent of adults are right-handed. It may be asked whether this is an acquisition or a natural tendency. Most children are trained by their parents to use the right hand in holding and manipulating such articles as cups, spoons, or pencils. Doll reports that among the feeble-minded about half 
are right-handed and half are left-handed. ${ }^{3}$ This, together with the facts that the feeble-minded are characteristically apathetic toward instruction and that they often occur in families where but little instruction is offered, suggests the possibility that dextrality is the result of training. Among babies up to the age of three weeks Watson found no preferential use of either hand in supporting the body weight.

The absence of any isolated society of left-lianded people opposes the hypothesis that right-handedness is wholly an acquisition. In anthropological museums a left-hand weapon is an anomaly, although the Australian boomerang is usually thrown with the left hand. There is some evidence for the belief that among left-handed persons the regions of Broca and Wernicke are, contrary to the rule, commonly found in the right hemisphere. If this is so, it might argue for an instinctive right- or left-handedness.

Original responses of spitting out, grimacing, and head-turning seem to follow gustatory stimulation by bitter and sour substances. When sugar solution is placed on the lips, sucking and licking result. Refusal to nurse when the nipple has been smeared with oil of amber or petroleum is reported by Kroner. ${ }^{4}$ It is doubtful whether this is a tactile or an

3 Doll, "Anthropometry as an Aid to Mental Diagnosis," Research Publication 8, Training School, Vineland, New Jersey, 1916.

4 Peterson and Rainey, "Beginnings of Mind in the New Born," in the Bulletin of the Lying-in Hospital of the City of New York, 1910. 
odor response. Peterson and Rainey attribute grimacing, sucking movements, and restlessness to olfactory stimulation.

Natural tendencies of approach and of avoidance are thus organized about situations of direct vital importance. Avoidance responses are provoked by noxious stimuli and by stimuli that are distinctively characteristic of harmful situations. Instinctive reactions to restraint, loud noises, and bodily injury have already been described. Approach or quiescence is called out by stimuli that are commonly associated with the presence of food or with safe and beneficial conditions. This ambivalent equipment gives direction to all habit formation, and with it the new-born infant is ready to enter upon trial and error learning with considerable security. No visual stimulus, unless intense enough to cause injury, will elicit original movements of avoidance or attack. A baby soon learns, however, to retreat, struggle, or cry at sight of those objects whose contact has on previous occasions aroused avoidance. Conditioned responses of this sort soon modify the baby's original nature.

When instinctive avoidance is unsuccessful in freeing the child from noxious stimuli, movements of attack are generally the instinctive result. Thus resistance to the intention of others is early developed and bad temper follows upon teasing or upon the rough handling sometimes involved in dressing, bathing, or in any abrupt manipulation. 
The attainment of coenotropes and of instinctive chain reflexes does not occur until some time after birth. If a ten-day old chick has never seen a hen, it will not follow a hen. James argues from this, and from similar examples, that "many instincts ripen at a certain age and then fade away." $\mathrm{He}$ cites Spalding's account of a chick that was kept away from its mother for the first ten days and then, being replaced, showed no tendency to follow. It did, however, follow any person of whom it caught sight, having acquired this habit during the first few days.

This fact should not be interpreted to mean that an instinct had faded away. There is, of course, no following-the-hen instinct. The young chick will follow anything, a handkerchief dragged along the floor, or a retreating man, dog, or hen. The young and inexperienced chick follows either man or hen to the disregard of stationary objects. The original tendency to follow is probably stronger than the original tendency to approach anything that is at rest. If the threshold for following a man has been lowered by practice, even though the tendency to approach the still object is similarly lowered, manfollowing may prevail over the tendency to approach the motionless object. As no practice has lowered the threshold of the hen-following response, the chick may well disregard the hen and busy itself

5 James, Principles of Psychology, vol. ii p. 398. 
with other stimuli, the responses to which have been well practised.

The response tendencies present in the new-born, being uninhibited by incompatible habits, may become attached to any one of a multitude of objects. Distracting habits once formed, however, inhibit the relatively sluggish instinctive response to a novel object, although this response might have been given before such incompatible habits stood in the way.

The oft rehearsed man-following habit of Spalding's chick was well enough grounded to compete successfully with the tendencies to scratch, peck, or make off toward moving bugs. There being no henfollowing habit, we may suppose that the hen, when later introduced, was merely powerless to compete for the chick's attention in the face of these distractions. This seems more reasonable than the hypothesis of transiency of instinct.

As with the chick, so with the child. At first one wet-nurse will be accepted about as readily as another, but later, when the infant has formed the nursing habit toward his mother, she alone is able to elicit energetic and contented suckling. Something in his mouth is not the only stimulus that calls forth the nursing response in the practised baby. His mother's way of holding and talking to him, the shape of her breast and her general appearance are all conditioning stimuli that facilitate the child's nursing. In the case of the strange nurse, the ab- 
sence of these conditioning stimuli permits the success of rival movements of resistance and crying that tend to follow manipulation. Such movements are inhibited by the behavior called out by the mother. Once the movements of resistance and crying have been elicited by the strange nurse, the characteristics in which she differs from the mother may condition these movements, so that the baby will struggle in her arms the next time, unless she has succeeded in getting him to nurse on the first occasion. We have no ground for supposing that mere strangeness causes resistance, except in so far as a strange situation may have the effect of breaking up an habitual response series.

Instincts ripen but do they fade? With his law of transiency of instinct in mind, James says, "There is a happy moment for fixing skill in drawing, for making boys collectors in natural history, and presently dissectors and botanists; then for initiating them into the harmonies of mechanics and the wonders of physical and chemical law." There is certainly a "happy moment" for teaching a child any habit. This, however, is probably not a "nascent period" but rather a time before antagonistic, incompatible, or distracting habits have been formed.

Both Instincts and Coenotropes Are Common Modes of Behavtor

An uncritical description of instinct as the behavior that is common to all men was popularized 
by the contemporaries of Darwin. Although all men are fundamentally alike in their original structure, there are individual differences in instinctive endowment, and this individuality is no less instinctive than commonality or universally shared traits. Furthermore, a great deal of the behavior that is common to all men is undoubtedly learned. Everybody knows how to use a stick as a weapon, but no one does so instinctively. Wearing clothing is as universal as many of the elaborate instincts of lower animals, but is, of course, a learned act. The behavior that is characteristic of any particular culture, and that is not found elsewhere, can not be attributed to original structure, but should be regarded as the effect of environment.

The nest building of birds and insects, the web building of spiders, and the cocoon spinning of larvae are striking examples of complicated and elaborate instincts. These acts may be futile if the normal course of events is interfered with, but the lower animals are not deterred by minor irregularities of situation. Elaborate and serially combined responses are characteristic of their instinctive behavior. On the other hand, the instinctive acts of man are relatively simple, but in the process of learning, these simple responses take on many and varied combinations. The more we investigate man's original nature the less intricate his instinctive reactions appear to be. We ought probably to regard the elaborate instincts attributed to man by 
the school of William James as being for the most part learned acts.

To call pugnacity, or constructiveness, or acquisitiveness, or self-preservation, or mating, an instinct is a dangerous concession to popular usage. Each component act as elicited by a particular situation might better be so called, always bearing in mind that this series of acts is terminated by a consummatory response. A complete understanding of behavior always involves an analysis in terms of stimulus-response mechanisms, and to name, for example, all the behavior of carnivorous animals that results in securing food "the" hunting instinct serves little purpose but to end prematurely the student's scientific curiosity. If we rest content with the description of the hunting instinct as the unlearned behavior of a carnivorous animal that results in his securing food, we certainly add nothing to anyone's information when we say that animals secure food by means of the hunting instinct. Such an explanation is of the sort given by Molière's physician when he says that opium puts one to sleep because it possesses a soporific property. If we are going to make use of "instinct" in the description of behavior, the terms must apply to specific reaction tendencies. 


\section{Play}

One of the most conspicuous instances of the unconsidered explanation of conduct in terms of a so-called instinctive tendency is the popular explanation of play. For a century past many writers have accounted for the whole range of play activities in terms of a general "play impulse," or "instinct to play," or "a disinclination to remain unoccupied." This resembles the attempted explanation of acts so various as a snowball contest and the writing of a hostile editorial as manifestations of an "instinct of pugnacity."

A short examination of play will serve to illustrate the method of analysis of all coenotropic tendencies. When this has been done, the student will be less likely to consider pugnacity, curiosity, or piety as simple instincts. He should then not rest satisfied when told that men fight because of a combative instinct, that they investigate because of instinctive curiosity, or that they are religious because of an innate religiosity.

Compared with practical conduct, play is an incomplete act given in response to an incomplete situation. It will be remembered that a situation is made up of many stimuli and that an act is composed of many combined responses. The situations to which the young are exposed are almost always lacking in stimuli that are present in the situations 
that confront the adult. The puppy's antagonist does not tear the puppy's flesh, and is otherwise less aggressive than the opponent of the large dog. The child's doll-house lacks stairways, plumbing, and many of the necessary parts of a real house. The doll itself may be so elaborated as to close its eyes or squeak, but it is grossly lacking in the characteristics of a real baby. You sit down on the rug and say, "Let's play that this is a boat." For play purposes the absence of naval architecture is as unimportant as the absence of surrounding water. The next door neighbor is an Indian if he has feathers and a tomahawk, even though he lacks the bloodthirstiness of the actual redskin.

Just as the play situations are limited, so are the acts of play correspondingly limited. The puppy is actuated to gentle aggression and limited retreat, whereas a richer situation with more intense stimuli would have resulted in either real fighting or flight. The child's doll-housekeeping is very sketchy, and her care of the doll is thoroughgoing only in such matters as hugging and spanking. The child's skill in handling the rug-boat would never qualify him as a real navigator. His assault upon the Indian next door is fortunately abortive, and may even be limited to saying the word "bang."

We are apt to say that the child fills in the gaps in the situation by imagination. This is often an unjustified interpretation by, the adult, who is more likely than the child to notice the gaps and to inter- 
pret the fairy story or to people the mud pie with apples.

Not only is the local situation incomplete, but there is an incomplete appreheusion of the larger situation. The cues to distant but related situations that occur in the limited play environment are overlooked. For this reason play is characterized by the low stimulus thresholds that are present within the smaller situation and that are due to the absence of inhibiting and facilitating effects of more distant situations. There is involved a disregard of incongruities, as in the theater when the background is a canvas drop instead of a prison wall, and when the orchestra pit would offer a way of easy escape for a real prisoner. Children at play have a high threshold for the summons of parents but a very low one for the behavior of their playmates. Thus play situations are more or less isolated from the world as a whole. The player is detached, irresponsible, carefree. Although this same isolation may at times seem to characterize serious work as well, this is really never so, work always being controlled by remote situations more or less suggested by present stimuli. Freedom from this kind of facilitating and inhibiting stimuli accounts for the frequent description of play as activity without external compulsion, or as aimless or purposeless activity. Such a description tacitly assumes that work requires reenforcement from associated situations.

In the nature of things children play more than 
do adults. If they react at all to a limited environment, it must be with a limited response. Play, however, is not lacking in adult behavior. It is, of course, often deliberately planned. In athletic contests and games, conventional restrictions inhibit certain of the responses of participants, and so limit the situation to which the others respond. On the track we are not tripped up or pushed, although under more grim conditions this would be a part of the situation. Our opponent at tennis does not attack us with his racquet and our boxing partner attacks us only with his gloves.

Not only is an act of play incomplete when compared with the movements involved in serious work, but the play act contains many movements not found in practical life. Probably the most conspicuous of these superfluous play movements is the talking that is nearly always a part of make-believe behavior. In playing "horse" with a broomstick a child will speak to the object in a way that would be useless if the plaything were real. He will explain to the onlookers imaginary characteristics of his mount. Moreover he substitutes his own loeomotion for that of the supposititious animal. The horse's life is crowded with a wealth of dramatic incident that no actual horse would tolerate.

The origin of the extra movements of play is to be looked for first in the necessity the child faces of compensating for the sketchiness of his playthings. If the horse is unable to pull the child, the child 
must pull the horse. The absence of temper in the wooden animal is made up for by much jerking, shaking, and clinging on the part of the rider. Other sources of superfluous movement are emotional expression, the traditional way of playing such and such a game, and the habits the child has formed in somewhat similar situations.

Just as play acts contain superfluous movements, so the play situations contain many elements not found in the practical world. This is so because the child is obliged to use make-shift toys and to look for adventure under restricting circumstances. The tail of the broomstick horse is made of straw. Its travels carry it over rugs, through hallways, and up the stairs. Its existence is spent in an incongruous world and may at any time come to an end when sweeping begins.

In play consummatory responses are never successfully expressed. Tea is drunk from empty cups. The slaughtered enemy is soon back in the fight. Kissing games are supervised by adult chaperones. In short, play is the prolongation of preparatory responses, the consummatory response never being sufficiently complete to terminate the behavior. Partial responses to incomplete sex situations occur from earliest infancy. Before the baby is able to carry on a successful fight he shows anger, and fear is manifest before he has developed the movements necessary to flight. The incompleteness of consummatory responses in play maintains the pre- 
current responses and produces a high pitch of emotional excitement.

The energy with which play activities are carried on suggests at once their reënforcement from internal responses such as are present in the preparatory acts of hunger, love, rage, and fear. With the beginning of play any lassitude that may have been evident disappears. In dancing, boxing, and the game of hide-and-seek the complete response is aborted. With the proper additions to the situations the excitement of play may be increased to the point of actual love, rage, or fear.

It follows from what has been said that play can not be described as a specific instinct, nor is there any group of original response tendencies that in themselves constitute play. Play is almost as much dependent on learning, the fixation of habits, and the organization of responses about objects and situations as are the serious activities of adult life.

\section{Other Examples of Common Modes of Behavior}

It is not practicable to undertake a discussion of all coenotropes because of their great number, and because many of them are relatively unimportant. The student must acquire the ability to analyze the many common modes of action that have class names in common speech, and to distinguish the parts played by original nature and by learning. Fear of strangers, homesickness, fear of the dark, and 
curiosity will serve as representatives of the many coenotropes that are ordinarily recognized.

No baby shows a fear of strangers until he has developed many habitual responses toward his family. These habitual responses are called out in fairly definite order by such stimuli as his mother's appearance and the way in which she acts. $\mathrm{He}$ comes to adjust his responses to his mother's next move, and if she behaves in an unusual way, his serial response is disrupted, with the result that he is likely to cry. Since the performance of any serial habit response depends upon receiving the proper stimulus for each step in the series, the absence of any one of these usual stimuli, or the presence of any stimulus provoking an incompatible response, will result in blocking the serial reaction. The blocking of any habit series results in emotional arousal.

When a stranger holds out his arms to a baby, the baby may respond to this familiar situation by "going" to the stranger. Further intercourse with the stranger, however, does not yield those stimuli on which the baby's intercourse with his mother is based. His chain responses are thus disrupted and he cries. If his mother is standing by, the sight of her will cause him to reach out toward her and thus be taken from the stranger's arms. If the stranger wears unfamiliar glasses, beard, or clothing, other strangers of like appearance will be feared when met. If the mother is by custom more 
polite to strangers than she is to members of her immediate family, her manner toward guests may become the cue to shyness in the child.

Homesickness is similarly the result of the disrupting of serial response tendencies caused by the absence of necessary and familiar stimuli. The child in a strange situation is prompted to begin many acts that can not be carried out. Anyone is ill at ease when his habits do not run smoothly. In a foreign country his speech fails to alter his environment in the way that is compatible with his habits, and homesickness results. A letter from home starts behavior that can not be consummated in strange surroundings, and he shows depression. People whose routine involves the presence of others are subject to loneliness when in solitude.

Darkness is not an original stimulus to fear, but there are many factors that contribute toward the commonality of fear of darkness. One of these factor's is the disruption of responses dependent upon visual stimuli. Our progress across the room is ordinarily determined by what we see. In the dark, the serial response is disorganized. Moreover, previous injuries from violent contact with objects in a dark room have left us with conditioned responses of avoidance and grief to darkness as a substituted stimulus. The likelihood of fear is further increased by the fact that when the light is turmed out, we are no longer distracted by what we see, and there is less interference with the instiuctive tendency 
to be frightened at the many sounds that are everywhere present. To these direct causes for the development of a common fear of darkness is added the observed effect of darkness upon our fellows.

Curiosity is not a specific act, but acts of curiosity may be distinguished as a class. All such acts are the result of a blocking of responses that are called out by partly unfamiliar situations, and such behavior is always accompanied by emotional drive. Our tendency to enter the dark cave is blocked by fear of the wild animal that might inhabit it. If the interior of the cave is familiar to us, we feel no curiosity. Conversely, no unfamiliar object arouses curiosity unless some element of the situation hinders further acquaintance. Zest is added to the performance of any act by reason of its being prohibited. The scientific curiosity of a generation ago concerning biology was in part brought about by the condemnation of the theory of evolution. Sex curiosity is much enhanced by social taboo. The emotional drive present in curiosity is often the ordinary accompaniment of the act that is blocked, but is always augmented by the difficulty of carrying out the act. Fear, love, anger, or various mixtures of exciting emotion may always be recognized in curiosity. The classification of acts as instances of curiosity is based upon the presence of this emotional drive, upon the hindrance in the face of which the act must be carried out, and upon the novelty of the situation receiving attention. Ex- 


\section{COENOTROPES}

cept in this setting, no specific act is an example of curiosity.

No matter how much man modifies his conditions of life, the human nature of babies remains the same; and though man may build up elaborate machinery of law and custom for controlling his natural tendencies, in the race these original tendencies remain the constant and fundamental determiners of behavior. 


\section{CHAPTER V}

\section{PERCEPTION}

A single object, such as a banana, may furnish stimuli to eyes, ears, nose, tongue, skin, muscles, or to sense organs in the enteric tract, but not all these stimuli affect us at the same time.

A watch lies on the table. On receiving visual stimuli from a portion of the surface of the watch, we may pick it up and receive cutaneous and kinaesthetic stimuli, turn it over and see the other side, or carry it to the ear and hear it tick. It is in the nature of objects that they embody this assemblage of diverse stimuli.

In the beginning, our responses to watches or to bananas are merely reflexes to the separate stimuli those objects furnish. While we respond to contact with the object, other stimuli from the same object frequently act upon us. While seeing an object, we may also smell it. While smelling it, we may also hear it. Thus, each stimulus may finally call forth, by conditioning, any of the responses that any of the other stimuli would naturally provoke. In this sense we may say that an adult responds to an object as a whole. After experiencing together the various stimuli emanating from an ob- 
ject, we react in a way that anticipates stimuli that the object is likely soon to furnish.

A baby finally learns to avoid bodily contact with fire, barking dogs, whirling machinery, and wet paint merely upon seeing them at a distance, although the visual appearance of these objects calls forth no original avoidance responses. He learns to smile at sight of, his mother who has cuddled him, to cry at the touch of a lifting rod, and to support his nursing bottle with his two hands when the nipple is placed in his mouth. All these acts are conditioned responses to substituted stimuli, and the formation of such conditioned responses constitutes acquaintance with the objects.

When, by this process of conditioning, any stimulus from the object furnishes a cue for the early occurrence of responses that were originally given only as the result of further acquaintance, the baby is said to perceive the object.

It is in the process of manipulating or merely observing a thing that the baby receives simultaneously the various stimuli that are resident in it. His response to any one of these stimuli may then become attached to any other. In his behavior towards any object such as a chair, a pin, a stick of candy, or his own hand, some of these responses tend to become dominant and are attached by conditioning to many of the minor stimuli with which the object provides the baby.

Thus objects come to "look" heavy, hot, smooth, 
wet, or soft. Things "sound" large, thin, distant, or as though in rapid motion. By touch or odor objects may be identified.

The stimuli offered by an object may be materially altered as a result of the baby's intervention, locomotion, or orientation. If he tears or crumples paper, it makes a noise and takes on a different visual appearance. If he grasps a pin, it may prick his finger. If he inverts the inkstand, the ink is spilled. If he pushes a tumbler off the table, it falls and crashes. If he releases his rattle, it may tumble off the bed. These changes in the form or the position of the objects occasion new responses, which, by conditioning, are later called out by any cue the object furnishes.

A part of our environment is always changing. We must learn to look out for danger and to take advantage of fortunate opportunities. Moving objects alter the stimulation they give us although we remain quiet. Animals, guns, matches, and engines have their own peculiar ways of behaving in response to our manipulations, and the baby's growing perception of such objects as these includes many anticipating responses dependent on past encounters. A firecracker never looks the same to the baby after one has exploded in his fingers. The baby ceases to use the cat's tail as a handle after he has once picked up an aggressive cat in this way. He learns to bounce his ball, to tease his parents, and to coerce younger children. When this learn- 
ing has occurred, we say that he perceives the ball as something that bounces, parents and companions as individuals who may be imposed upon.

Situations recur time after time in orderly grouping and sequence. The frequent reiteration of responses to these recurring events enables us to perceive a situation as one that is about to be followed by its familiar consequences. Our ability to do this is dependent upon the overlapping of the parts of situations, which permits the formation of conditioned responses. The change from one situation to the next is always a partial change, and any two successive events have elements in common.

There is then, on the one hand, perception of objects with their groupings of available stimuli, and, on the other hand, the perception of events with their temporal sequence of stimuli. Perceptions can not be sharply divided into these two classes, but any perception may be characterized as a perception chiefly of things or chiefly of occurrences.

Perception is always a reaction tendency more or less completely expressed. When less complete, the expression is often limited to an orientation of receptors and effectors, but the neurological changes that go unobserved are often far reaching. Thus a perception that is apparently limited to orientation may be a very extensive process in the central nervous system. As a result of our observing a thing, the thresholds of many other responses are raised or lowered. When we glance at the articles 
in a shop window or hear it said that the bank closes to-day at twelve o'clock, delayed reactions are initiated that are brought to pass only upon further stimulation, or in conjunction with other responses not yet aroused. In this way reaction tendencies are altered by stimuli that are merely observed, and to which at the time we give no overt response. We may sit inertly on the shore and watch people swimming, and it may seem to an onlooker that but few responses are involved in our perception. The next day, however, we bring a swimming suit to the beach and it is then evident that many changes occurred in our nervous structure as a result of the situation that, when operating, was only "observed." An immediate overt reaction to objects is much less frequent than is the act of observation.

\section{Perception and Speech}

Perceptions involving a verbal response constitute a most important class, and such responses often serve to drain much of the energy that situations arouse. Our interest in a distant object is often terminated as soon as we are able to name it.

The expression of word perceptions is usually subvocal. Verbal symbols serve as cues for many subsequent acts. An object named is often an object with which we are in a better position to deal, because much appropriate behavior is attached to words by conditioning. Once we have said "Good- 
by" there is little to do but to go away. Before we call a man a thief we are less aggressive in our antagonism toward him than we are after the word has been used.

The subvocal expression of word response tendencies is an essential part of thinking. Perception in verbal terms initiates new word reactions, and by the series of word responses our conduct is guided.

Such subvocal responses consist in slight contraction of muscles which, if stimulation were more intense or inhibitions were absent, would result in actual speech. We may often see fellow passengers on the street-car moving their lips in a manner appropriate to the words they are reading, and we can readily observe slight movements of our own vocal apparatus that are minimal movements of speech, even though these could not be detected by others.

Such minimal responses are not confined to speech. Many of the onlookers at a boxing contest may be seen to follow the contest with minimal defense and attack movements, and in the theater audience there are many who shrug their shoulders with the heroine and become stern when the villain is confronted by the hero. These movements are sometimes mimetic, but that they are not regularly so is shown by the fact that they often anticipate the movement of the boxer or of the actor, and are the onlooker's response to the antagonist's threatened blow or to the villain's advances. 
These minimal movements constitute in part the perception of situations, and, since they themselves offer proprioceptive stimulation, such movements may be the cues for further responses. The clenched fist as well as the muttered epithet plays a part in determining subsequent action.

Talking is a serial response. Many of our sentences are faithfully reproduced habits that have been uttered in the same form hundreds of times. These stereotyped sentences are often imitation of other people's speech. In spite of stereotypisms, we frequently use a novel combination of words. This is made possible by the fact that any word, when spoken, is a stimulus that arouses a number of word reaction tendencies, because nearly any word has in previous speech been followed now by one word and now by another. Although various sequences of words are available, the response thresholds at the moment determine what sequence shall occur.

When we use the word "abate," there is little doubt but that this will be followed by the word "nuisance." But such words as "eat," "carry," "push," or "find" have been followed in the past by so great a variety of word responses that it is hard to predict which of the reaction tendencies present will prevail.

The low threshold of the word that does prevail is determined by many things. First of all there is the influence of words uttered shortly before by either speaker or listener. Many of the words we 
use when talking about football have been used on previous occasions after the term "football" has been introduced.

An intelligent person in good health holds to the topic of conversation. One of the symptoms in insanity is an undirected verbosity in which the tendency to adhere to the topic of conversation is lost, and in which the words occur without regard to context. This sort of speech has been well called "word salad." It is often approximated by simple-minded and excitable people.

In addition to the influence of verbal context there is the influence of non-verbal situations in determining our choice of words. The facial expression of our hearer, the fact that he is a man rather than a woman, being in another's house rather than in our own, and having a good appetite instead of having just satisfied it, are matters that determine the words we say.

Among the topies most tenaciously adhered to in conversation are diet, romance, and adventure. The drive toward this form of conversation is provided by the visceral organization of man, and needs but little stimulation from external conditions.

Most important of all in determining the form of our sentences is the previous non-verbal perception of the objects or of the events we discuss. Past events dictate the words we use in their description, as these words are in part delayed responses to the described events. 
The internal emotional responses play an important rôle in perception. Just as things may "look" hard, so they may "look" dangerous, disgusting, beautiful, or annoying. If the response threshold is high, or if the provocation is slight, the expression of the emotional response tendency may go no farther than these internal changes. As a result of stronger stimulation and reënforcement, overt emotional responses may result.

\section{At Different Times a Situation May Prompt Us to Different Perceptions}

The form of any perception is determined in part by the combination of stimuli that affects the sense organs at the time, and in part by the conditioned responses that the individual has previously associated with these stimuli. The threshold of these conditioned responses varies in a single individual according to the recency with which the responses have been performed, and according to the nature of the behavior in which he has just been engaged. The alignment of pieces on a chess board is perceived most thoroughly by a player who is in practice. A page of Virgil may be almost meaningless to a person who has for years neglected his Latin. Such a recent experience as reading a detective story may lower our threshold of perception of burglars. Having run out of gasoline the day before lowers the threshold of perception of the indicator of the gas 
tank. After an accident on the road the driver's perception of traffic is changed.

Due to the dependence of perception on habit, the same combination of stimuli will be perceived differently by two persons. The tea taster's perception of tea, the florist's perception of roses, the fancier's perception of dogs, and the entomologist's perception of bugs, differ from the corresponding perceptions of untrained persons. Each of us has his private equipment of habit and perceives any situation accordingly.

Because response thresholds vary from time to time, a combination of stimuli may be perceived now in one way and now in another. The words "time flies" may be perceived as a statement that time is fleeting or as a request to determine the rapidity with which flies fly. The staircase figure (Figure 26) may be perceived as a flight of steps seen either from above or from below. Stimuli that may lead to either of two radically different perceptions are called equivocal stimuli. Where two diverse situations have several elements in common, these several elements occurring alone as stimuli may lead to a perception of either situation.

Equivocal stimuli often give rise to false perceptions, which may be rectified by further acquaintance with the situation. Such a false perception is called an illusion. Reacting to a piece of tin foil seen on the street as though it were a coin, responding to a bit of floating dust in the air as though it were a 
house moth, running away from the sound of a falling object in the woods as though it were a wild animal, appropriating another person's umbrella under the impression that it is one's own, are all examples of illusion.

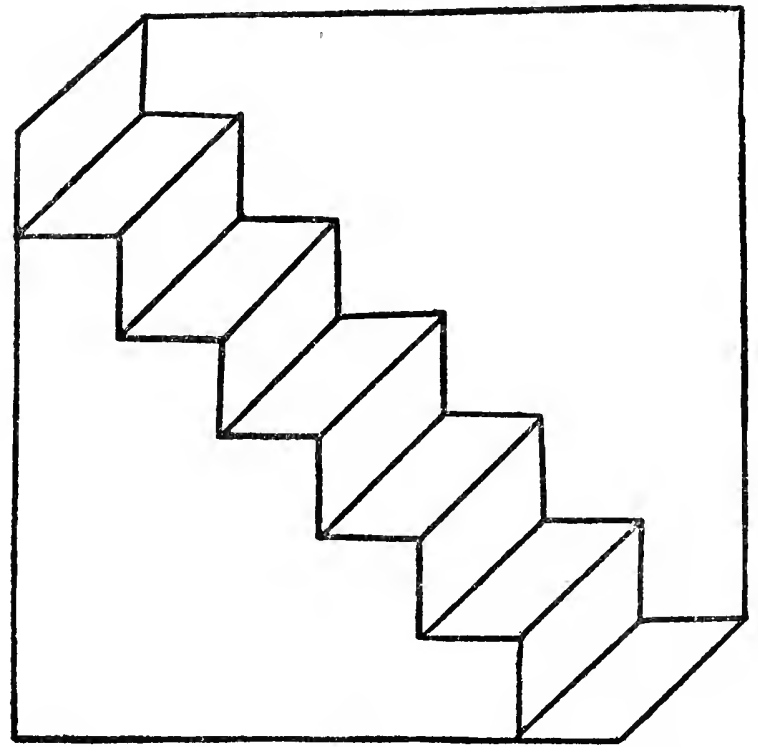

Figure 26. Staircase figure. This may be seen as a Flight of STAIRS VIEWED FROM ABOVE, OR AS A FLIGHT

VIEWED FROM BELOW

An hallucination is a response tendency, not initiated by sensory stimuli, which follows a sensory impulse originating in some part of the nervous system. It is often the result of degenerative processes accompanying nervous disease, but frequently occurs in healthy individuals. All hallucinations con- 
form to reaction tendencies of low threshold. The insane patient who reports that he hears voices wariing him of the treachery of an acquaintance must previously have acquired reaction tendencies of suspicion toward the person in question.

Changes in the sense organs themselves, incident upon circulation and upon metabolism in general, provide for the normal individual sufficient sensory cues for hallucinations of a simple sort. This is most likely to occur when he is in a half-waking state

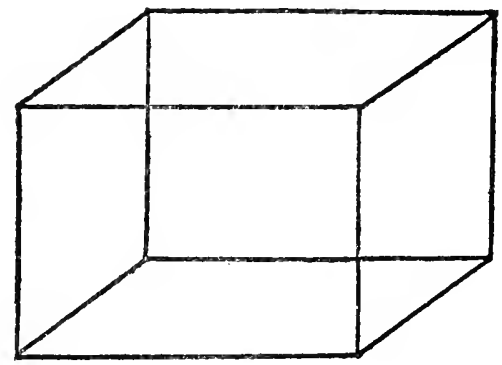

Figure 27. THE FACE THAT is PERCEIVEd AS NEAREST THE OBSERVER MAY ALSO BE PERCEIVED AS THE MOST DISTANT

and partially isolated from sensory stimuli. It is of common occurrence for a person to report that his name has been spoken just as he is about to go to sleep. Visions are most frequently seen in the dim light of bed rooms.

Our perceptions are determined not only by the habits we have acquired but also by the kind and by the intensity of the sensory stimulation to which we 
happen to be exposed. Stimuli may occur in combinations of practically unlimited diversity and no two situations are ever wholly identical. As two situations, but slightly different, may cause two very different perceptions, the number of possible perceptions is almost unlimited.

\section{Compromise Responses in Perception}

Compromise responses have already been described. As we walk through the woods the direction our footsteps take is a compromise of the many orientation tendencies that are aroused by rocks, trees, and the contour of the ground. The course of a bird flying through the forest is determined by the visual stimuli from all the obstacles it must avoid. There seldom occurs an isolated response. Most responses are somewhat distorted by the total behavior of the moment.

Objects and events are never perceived independently of their settings. My dollar is one thing and his dollar is quite another. Food at meal time furnishes a perception very different from that of food after dinner. Soap experienced together with towels and water and soap seen on a druggist's counter are not perceived merely as soap. A word has complete meaning only in its context, and we perceive short sentences as wholes and not as lists of words.

Man is undoubtedly of all animals the best en- 
dowed with neurological mechanisms for compromise responses. When an unfamiliar combination of stimuli produces a resultant reaction, the act so integrated may become a response habit. In this way perceptions shift their content and grow in fitness and complexity as a result of the successive occurrence of slightly different assemblages of stimuli. Each unusual occurrence in a situation leaves behind it a trace of compromise that becomes a part of later perceptions of events somewhat the same.

\section{Perceptions from Simultaneous Stimuli}

There is no one sense organ in the skin or muscles by which we perceive things as hard, soft, rough, smooth, wet, dry, greasy, or sticky. In comparison with a soft object, a hard object, when pressed upon, gives more intense stimulation to touch and pain organs and stimulates a smaller area of the skin. The muscles involved when we lean upon such an object, or when we grasp it, are often under greater tension than if the object were soft.

When we draw our finger along a surface that intermittently stimulates the sense organs of touch, we say that it is rough. When the movement stimulates the same organs in the muscles, but when the stimulation of the sense organs of touch is sustained and not intermittent, we call the surface smooth.

Perception of wetness results from the stimulation of cold organs along with the stimulation involved 
in the perception of smoothness. The perception of greasiness requires the absence of the fine vibration of the skin that is characteristic of drawing the hand over a surface free from grease. A silver spoon always feels more greasy than a varnished table top because the polished metal surface offers less friction. Objects seem sticky when, on releasing them, the skin adheres somewhat to the objects and is displaced outwardly. The perception of tickling necessitates the contraction of muscles, especially those adjacent to the area stimulated, and always contains an emotional component.

The identification of objects by skin contact and manipulation alone, is called stereognosis. If we reach behind a screen and feel an object, we can usually tell what it is. A watch is colder and heavier than a pencil. The surfaces of the two objects when rubbed afford different stimulation to sense organs in the skin and muscles. As the finger follows the contours, the position and movement of muscles and joints afford a characteristic stimulation. A lack of resistance in the loose parts of the watch and the pliability of the rubber end of the pencil furnish sensory cues to the respective perceptions.

\section{Space Perception}

The perception of distance or depth, and space perception in general, consist either of such responses as saying, "That house is about a mile away," 
or "This table is four feet long,", or of such responses as throwing a stone at a mark, jumping from one spot to another, setting out to walk to a certain objective, reaching for an object near at hand, sitting down on a chair that seems appropriately placed, or they may consist of such responses as inhibiting any overt reaction, or giving attention to objects or turning away from them according as their position causes one sort of stimulation or another.

\section{Visual Space Perception}

As a stimulating object changes its distance from the eye there is a change in the nature of its stimulation and a change in the character of the responses that are instinctively given. Visual perception of distance or depth depends ultimately upon these two facts. We shall consider first the instinctive responses of fixation, binocular accommodation, and monocular accommodation.

When a spot of light falls upon any part of the retina other than the fovea, there is an instinctive tendency so to move the eyeball, and possibly the head as well, that the light shall be brought to bear upon the fovea. This response is called fixation. It is effected by the contraction of muscles external to the eyeball. These muscles include the four recti muscles and the two oblique muscles of each eye. (Figure 2.) When the same object stimulates both 
eyes, each eye tends to fixate. This double fixation is called binocular accommodation.

A straight line extending outward from the center of the fovea and passing through the center of the lens is called the axis of vision. When binocular accommodation occurs for a distant object, the axes of vision of the two eyes are practically parallel. When we look at a near object, these lines of vision form a greater angle. The degree of convergence increases with the nearness of the stimulating object and produces muscle strain. This muscle strain affords movement-produced stimuli of varying degrees of intensity. The intensity and the distribution of this stimulation in the external eye muscles is one of the sensory cues to the perception of distance.

In order that the image of a near object may be clearly focused on the retina, the ciliary muscle and the iris muscle must be contracted (see the description of the eye in Chapter 1). The contraction necessary to accomplish this clearness of focus is called monocular accommodation. The eye at rest is accommodated for far vision. The nearer the object, the greater is the contraction in the circular fibres of the ciliary and the iris muscles, and the greater is the stimulation to the sense organs that are in these muscles and in their attachments. This varying stimulation serves as another sensory cue to the visual perception of distance. The stimulus that effects these instinctive movements of monocular accommodation is a blurred image. It is probable 
that the stimuli derived from movements of binocular accommodation also produce instinctive monocular adjustment.

Along with the varying degree of remoteness of an object there go changes of stimulation other than those that cause instinctive binocular and monocular accommodation. The nearer an object, the larger is its retinal image. This is a sensory cue for perceiving the distance of all objects of familiar pattern. As all the one-cent pieces we have ever seen have been uniformly about three-quarters of an inch in diameter, we have developed, through learning, different responses of approaching and reaching for pennies, according to the size of the image they cast on the retina. As a tuft of cotton has no uniform size, the size of the retinal image it casts is not very suggestive of its distance.

Near objects show a clearness of detail and a differentiation of shadows not seen in objects that are far away. This difference in stimulating effect we learn to interpret perceptually by appropriate responses. The indistinctness of things far away is due mainly to particles in the intervening atmosphere. In the clear air of Colorado distant mountains look deceptively near. Trees seen through a fog look larger than they really are because, being indistinct, they are wrongly perceived as farther away. Being perceived as farther away, they are consequently responded to as though they were larger trees, for larger trees farther away would 
cast visual images of the size the eye receives. This effect is utilized in the illusion of distance that is secured on the stage by interposing a fish net between the back drop and the audience.

Far away objects have a blue appearance due to the polarization of sunlight by atmospheric particles, and this provides another sensory cue for perception of depth.

Farther objects may be partially obscured by nearer objects, and when so seen are perceived as more remote. (See Figure 28.) Due to the fact that

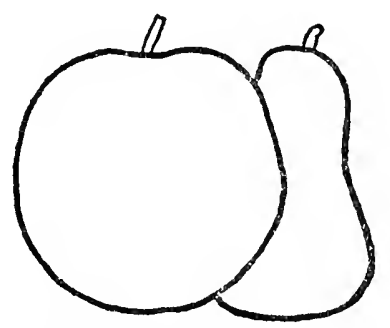

Figure 28. THE pear is perceived as behind the apple because it IS PARTIALLY IIIDDEN BY TIIE APPLE

most things extend upward from the ground, distant objects are ordinarily seen over the tops of objects near at hand. Thus the objects higher in the field of vision are likely to seem the more remote. (See Figure 29.)

If a far object is fixated and the head is moved from side to side, intervening objects in the field of vision appear to move in a direction opposite to that of the head movement. If a near object is fixated, 
movement of the head is accompanied by the apparent movement of more distant objects in the same direction. When the eye is at rest, the retinal image of an object passing in the foreground shifts more rapidly than that of the object moving at the same speed in the distance.

When walking or when riding in a train, the fixation of near objects in the landscape must be accomplished by more rapid eye movements than the fixation of distant objects. All these differences of

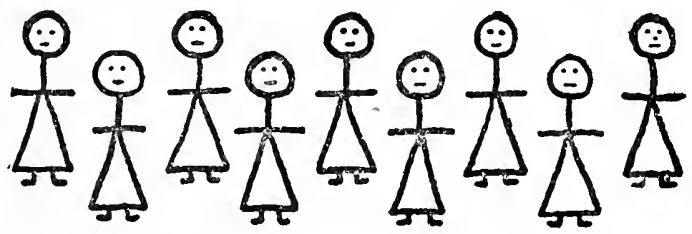

Figdre 29. obJEcts IMIGHER IN THE FIELD OF VISION TEND TO BE PERCEIVED AS MORE DISTANT

stimulation serve as sensory cues to the perception of depth.

An object seen both with the right eye and with the left eye is seen from the two different positions, so that each eye views a different part of the object's surface. Unless it is bi-laterally symmetrical and of a certain regular surface without shadows, the images it casts upon the two retinae will be dissimilar. The nearer an object is to the eye, and the greater the consequent binocular convergence, the more dissimilar are the two retinal images. Not only are the two images that are cast by the same 
object different, but these images are commonly seen by each eye against a different background. The degree of dissimilarity of these images, together with the unlikeness of their backgrounds, is another sensory cue to the perception of depth.

Visual space perception includes responses to objects seen above, below, to the right, or to the left. The difference in stimulation that serves to distinguish such perceptions from each other is twofold. The part of the retina stimulated is different, and, if fixation follows, the eye movements involved in fixating the stimulating object are different. These eye movements afford various movement-produced stimuli.

\section{Visual Perception of Objects}

Objects give not only such stimuli as elicit space perception, but furnish their own characteristic pattern and color stimulation. This printed page contains words of many different patterns and the corresponding image-patterns on the retina serve as the sensory cues for many different perceptions. As the page is moved away from the eye, the images become smaller, but we call the patterns the same.

It is probable that the similarity of our responses to an object seen at different distances is due to the fact that an object affords a continuous stimulation as it moves toward us or away from us. The pattern of the letter $\mathrm{H}$ is seen in all sizes as the letter ap- 
proaches the eye. His mother seen at a distance of three feet looks to the baby like his mother seen at a distance of ten feet because he has continuously fixated her and has maintained other responses toward her as she changes her position. If it were not for this gradual change of size of images cast by approaching and receding objects, it is probable that all visual patterns of dissimilar size would arouse wholly different perceptions. Due, however, to this sequence of stimulation, and to the overlapping of responses, patterns of different size often arouse practically the same perception.

Because of another sequence of stimulation, patterns of dissimilar form tend to arouse similar perceptions. As our friend turns his head, he casts upon our retina an image of gradually changing shape. All this time we are acting toward him in the same way. For this reason the full face and the profile photographs of our friend seem much more alike to us than the full face and the profile photographs of a stranger. As we handle a cylindrical tobacco can, the image of its top changes from a circular image to an elliptical image whose smaller axis gradually diminishes. The degree of resemblance of two patterns certainly depends in part on their relative position in such a temporal sequence of stimulation.

Retinal stimulation from objects differs in color, and various combinations of color may enter into the retinal pattern. Certain colors are characteris. 
tic of particular objects and substances, and the state of objects is often indicated by variations in color. We avoid picking up the poker by the red end; we cease cooking food when it is sufficiently brown; and we eat a red apple rather than a green one.

\section{Auditory Space Perception}

The direction of an object is roughly perceived by means of the ears, because when the object is not in the median plane, it stimulates one ear more than the other. The direction of a sounding object that is in this median plane, in front, above, or behind us, is perceived very inaccurately. The evidence of a person who testifies in court that he heard a revolver shot just ahead of him on a dark night should never be admitted, although his testimony that the shot came from the right may be of considerable value.

The direction of a continuous sound may be fairly well located by turning the head toward the side at first more strongly stimulated. When the sound is heard equally by the two ears, the face is directed toward the source of the sound. The shape of the external ear is responsible for slight differences in the intensity of a sound as it comes from one direction or another. For this reason we may have a meager perception of an object's being before or behind, even when we do not move the head.

If a familiar object emits a sound of fairly constant intensity, this intensity is a cue for perceiving 
how far away the object is. Telephone bells, fog horns, bumble bees, alarm clocks, automobiles, and even footsteps, human voices, rustling leaves, and falling objects arouse distance perceptions according to the intensity of the stimulation. The intensity of a wholly unfamiliar sound would be no cue to the remoteness of its source.

The echoes that are reflected from objects furnish a sensory aid to our perception of distance. These echoes are notably of assistance to the blind, who find it easier to avoid obstacles when they walk with heavy shoes on resounding pavements or when they tap the ground with a stick. If the reflecting surface is several feet away, not only the intensity and the direction of the echo, but the time interval between the original noise and its echo may assist in the distance perception.

\section{Auditory Perception of Objects}

The sounds we hear about us are combinations of simple tones, each tone having a different pitch. A tone is made up of simple vibrations of a single rate. Its pitch depends upon the rate or frequency of these vibrations. Rapid vibrations are high pitched and slow vibrations are low pitched. Any complex sound may be analyzed into its pure tone components. When a harp string is plucked, the resulting note has a fundamental tone, caused by the string's vibrating as a whole, and a great many tones 
of higher pitch (overtones) that are caused by the more rapid vibrations of parts of the string. A well made tuning fork has practically no overtones so that the sound it produces approximates a pure tone.

Any note, such as middle $\mathrm{C}$, is different when sounded on a piano, a, violin, a banjo, or a harp. This difference is called a difference of timbre, and is due to differences in the intensities of the various overtones that each instrument produces. Voices of men, women, and children differ in timbre and this is also true of the voices of individuals.

The overtones in a musical sound have vibration rates that are all multiples of the vibration rate of the fundamental tone. A noise is made up of a combination of tones whose vibration rates are in no simple ratio. The sounds of a passing locomotive, of paper being crumpled, and of a slamming door, are complexes of tones in disorderly confusion and are called noises.

The diversity of noises is due to the peculiar structure of the objects whose vibration causes them, and so each kind of object has its characteristic sound. These characteristic sounds serve as the cues for auditory perception of objects. The sounds of sawing, hammering, or extracting rusty nails can hardly be mistaken. We distinguish the passing automobile from the passing street car. The jingling of coins and the jingling of a bunch of keys are sufficiently different to afford different perceptions. 
Sounds may shift from one fundamental pitch, from one intensity, or from one timbre to another. This shifting, as well as a certain duration and rhythm, is characteristic of certain objects and events. Words, and vocalization in general, more than any other sounds, depend upon this change of tonal composition and this modulation of intensity for their effectiveness as sensory cues.

\section{Olfactory Perception}

Odor stimuli are of little use as sensory cues for perception of the direction of the odorous object. This is because a change of orientation changes but little the intensity of odor stimulation. The gases that emanate from an object and that are borne on the wind may affect our sense organs long after the source of the odor has been removed. Objects may be seen and heard only when present, and changes of position modify their stimulation. Because of this, light and sound are the best cues for direction perception.

Energetic emotional responses, many of them instinctive, are given to odor stimuli. This drive results in trial and error behavior until a more definite spatial perception of the object is obtained through other senses. There is a compensation for the absence of odor space perception in this drivearoused trial and error behavior. The odor of food starts the animal on its search, although it may have 
no perception of where the food is. As it nears the food, the odor becomes more intense and the animal's explorations more thorough at this spot.

A hound, crossing the trail of a fox, probably does not perceive by the use of his nose alone the direction in which the fox has gone. If he proceeds in the wrong direction, the trail becomes fainter, whereupon he is apt to turn about and follow a scent that becomes increasingly warmer. As he approaches the fox, his excitement increases and this keeps him from turning back once he is rightly headed. The ability of an ant to take the right direction when placed on a trail is probably due to its familiarity with the surface over which it has frequently walked, and not due to any mysterious odor mechanism for keeping its homeward course.

Different odors arouse different emotions and lower the thresholds of particular reactions. This is often the result of conditioning, but is sometimes instinctive. Kittens, before their eyes are opened, and without previous experience of puppies, will raise the head and "spit" when a puppy is introduced into their cage. The odor of a possible mate causes general restlessness among most lower animals and lowers the threshold of mating responses. The odor of food causes hunger and the odor of spoiled food causes nausea. The ant stimulated by a strange hive odor shows fear, and, when confronted with one of its own group that has been artificially perfumed with the odor of a strange hive, 
shows fight. The odor of a crowd probably has a quieting and depressing effect upon human beings.

The olfactory lobes in the human brain, as compared with those in the brains of most lower animals, are relatively small, and man's odor perceptions are relatively meager. Standing upon his hind legs, man has a wider visual horizon and less opportunity for bringing his nose in contact with objects. Thus his increasing dependence upon vision seems to have been accompanied by a lessened dependence on odor perceptions.

The poverty of man's odor perceptions is, however, not wholly due to the lack of an adequate mechanism. With careful practice a great improvement in odor perceptions is possible. Blind persons, tea and wine tasters, and connoisseurs in food often show an interesting superiority in odor discrimination.

The diversity of odor stimuli, their capacity for arousing dissimilar responses, and the many possible combinations of these stimuli enable us to distinguish objects with considerable accuracy by means of this sense. Not only individual objects but classes of objects as well have their characteristic odor. Things that are not seen may often be recognized by their scent as tobacco, cheese, frying bacon, coffee, or fresh bread. All marine animals smell somewhat alike. So do most flowers and most fruits.

The compromise reactions, which grow up about 
objects as a result of our responding to the various stimuli that they offer, become attached to the odor stimuli that the objects furnish, and in this way instinctive responses of one sort are often replaced by learned responses of quite another. The odors of whiskey, tobacco, cheese, and clams are distasteful to most children, but are popular among adults.

\section{Kinaesthetic and Static Perception}

The perception of objects from muscle-sense cues has already been considered. Nearly all bodily responses are determined in part by muscle and static sense stimulation that results from our position and our movement. Without movement-produced stimuli to the proprioceptors in the legs we would be unable to walk. Jar and displacement of muscles and viscera give us perceptions of being jolted, dropped, or carried about.

Our perception of rotary direction is not confined to instinctive responses of head turning and eye movements. Stimulation of the semicircular canals brings about many learned responses that maintain equilibrium in such acts as dancing, boxing, or tennis playing.

\section{Touch Perception}

The way we identify the part of the body that is touchea needs no elaborate explanation. A percep- 
tion is always a response and the stimulation of differently located sense organs naturally provokes different responses. To a touch on the palm of his left hand a baby responds by closing that hand. Pricked on the right toe, he flexes the right leg. Superimposed upon these instinctive movements are the learned responses given to objects that he sees in contact with his body, and that he feels in the process of manipulation.

\section{Time Perception}

The sequence and duration of events in the external world are as real as the objects that the world contains. The common sense justification for this view is the fact that events keep time with each other. Two objects that are dropped together from the same height strike the ground together. Every time they drop the same number of seconds is ticked off on the watch. Bodily functions are also synchronized with external events and with each other. Our intestinal tract is a not inaccurate time piece, and we know the lunch hour by our peristalsis as well as by the clock. Thus we have an orderliness of stimulation that determines an orderliness of perceptual responses.

The perception of duration involves some such response as saying to ourselves, "While we have been talking, the bank has probably closed for the day, the postman has come and gone, and the train 
on which our friends left has reached the city." We are assisted in this perception by knowing that the bank closes, the postman comes, and the train reaches its destination all at the same time. We would be much more certain that all these events have occurred if we were to look at our watch, but even in the absence of a watch we are likely to be correct in our perception.

Men have learned that of all the orderly changes in the external world, the series of changes in the position of the stars with reference to fixed points in an observatory is the most dependable. This simply means that from knowing the hour angle of a star we can infer more concerning other events than from knowing the stage of completion of any other orderly sequence found in nature. Because of this we call astronomical events the most regularly recurrent and accept them as a convenient standard of reference.

Our perception of time, though nearly always aided by periodic stimuli from orderly events in our environment, may be independent of these stimuli. It is by no means impossible to guess successfully the amount of time that has elapsed since we entered the room. The question how we do this may be partly answered by recalling the facts of forgetting.

When an act has been performed once and is then performed again, the ease of the second performance depends upon the amount of time that has elapsed since the first. This ease of performance, or degree 
of positive adaptation, attaches to reminiscences as well as to overt acts. When we ask ourselves how long we have been sitting here, we rehearse the events that occurred when we entered the room. This rehearsal involves looking at the door through which we entered, making minimal movements that correspond to such acts as entering, saying what was said at that time, or taking our seats. The amount of positive adaptation that exists in these acts of rehearsal after any lapse of time is a cue for our perception of the length of time that has passed. Cues of this sort are acknowledged in popular speech by such words as "I remember it as though it were yesterday" or "The boat has just whistled."

A yet more effective cue to our perception of duration is our recalling the acts or events that have filled the time in question. Recalling events is not possible unless there were perceptual responses when the events took place, and recall is a somewhat incomplete repetition of these responses.

All events that fill any period of time vary more or less in rate of occurrence when referred to the astronomical standard, but many of them are sufficiently periodic to be dependable as measures of time. Pulse, respiration, and the rhythm of walking, talking, or eating are sufficiently periodic to enable us to perceive time as long or short according as it contains more or fewer of these events. The recollection of many diverse events may also enter into our perception of time. 
The increasing fatigue that results from maintaining a bodily posture is significant of the time that has elapsed since the posture was taken up. So also is the increasing stimulation from holding the breath during short intervals of close attention. An interval seems longer when the muscles are tense and the respiration and pulse are rapid.

\section{JUDGMENT}

Even the simplest reflex is not given immediately following stimulation. There is a period of latency in both sense organ and muscle, and some time is required for the nervous impulse to traverse the reflex arc. Probably the shortest reflex time is .02 second.

If we are asked to respond to the sound of a bell by lifting the hand as quickly as possible, the interval between stimulus and response is found to be about .15 second. This is perception in its simplest form.

The perception of the more complex situation that involves speaking the name of a familiar object exposed to view requires about .5 second. More elaborate perceptual responses to complex situations require a still longer time.

Perceptions of situations that contain a novel combination of stimuli have a comparatively long reaction time, and these perceptions we call judgments. There is no sharp distinction between slow percep- 
tions and rapid judgments. The slowness that characterizes judgment may be due to any one of several causes.

The simplest cause for delay is the weakness or meagerness of the sensory stimulation. Music heard faintly in the distance may not at once be recognized as any particular melody. Objects seen in the twilight are identified with difficulty. An unfinished drawing may require a moment of study before we decide what it represents.

In the presence of equivocal stimuli the final perception is often delayed until facilitating habits are brought into play. We may waken from sleep to find the odor of smoke in the house. No elaborate perception may result until it dawns on us that we read in last night's paper of a forest fire in the neighborhood. In this way a perception may be completed as a result of the slow action of reënforcements that we already possess, and without further explanation of the objective situation.

A novel combination of stimuli brings about a compromise response, and this response is slower than one that has been practised. When we meet a friend who has removed his mustache, our perception is both slow and changed in character. If the objects surrounding the bee hive have been moved about, the returning bee shows excitement and takes a longer time to enter the hive. In driving an unfamiliar automobile our responses are less prompt and necessarily modified. These responses are 
changed in character because a different combination of neural mechanisms has been called into play by a new aggregation of stimuli. The lengthened time of responses is a result of the interference between the mechanisms involved. Probably no two responses are wholly compatible, and in extreme cases the interference may result in mutual inhibition.

A dog that is first trained to come when his master calls him may later respond to the call of a stranger, even though the stranger's appearance, tone of voice, and odor may differ from those of his master. The dog's response depends upon both the similarity and the differences between the new and the old. A baby that has learned to say "duck" while looking at the duck in his picture book is likely to disregard differences and to call any bird a duck. If a hat is sailed over the chicken yard, the chicks may run to cover, giving the response that is customary when a hawk appears. A hunting dog may be thrown into great excitement if his master leaves the house carrying a broomstick as though it were a gun. In all these cases the animals have responded to those stimuli in the new situations that are identical with stimuli occurring in the original situations. The new features may sometimes greatly modify the response and may sometimes be almost wholly disregarded. In man, and to some extent in lower animals, these new features commonly bring into play reaction tendencies that either inhibit or facilitate an habitual response, or that result in a compromise response. 
Counterfeit money is sufficiently different from real money to furnish a cue for its rejection. A stranger may look almost like an acquaintance, but a minor dissimilarity keeps us from speaking to him. We may be about to claim a trunk in the baggage room until we observe some strange characteristic about it that causes us to search further. In these ways response tendencies are prevented by our taking note of some detail in the new situation that was absent when the response was learned.

One of the laboratory guinea-pigs had in its cage a paste-board nest-box with an entrance on the side. One day it gnawed a small hole in the top of the nestbox and immediately afterwards, on being given a piece of carrot, sat down beside this hole to eat. The food accidentally fell through the hole into the nestbox and the animal made a vain effort to crawl through the small hole to recover the food. Through the hole it could see and smell both the food and the bedding in the interior of the box. Without repeating the effort to get through the hole, it scrambled down the side, ran through the entrance, and seized the food. This response, though facilitated by the food, was of course given to the familiar bedding, but, because the food and bedding were adjacent, the movement led to the food. If the bedding had not been present, the food would not have been recovered. It is thus evident that attending circumstances are often the most important factors in guiding the animal to a consummatory response. 
Judgments are influenced-by temporary reaction tendencies persisting from recent behavior. Going to a funeral distorts our sense of humor for some time afterward. The sentence a magistrate imposes on a criminal is often partly determined by circumstances attending the previous case. The physician's diagnosis is nearly always colored by what he has discovered concerning other patients recently seen.

We often have a tendency to action in the absence of the object whose manipulation constitutes the act. While dressing for dinner, a man may discover that he is without a collar button. If neither shops nor friends are at hand, and $i^{n}$ he is a person of intelligence, he looks about him for a substitute article with which to fasten his collar. None of the objects that his eye falls upon may seem suitable to him until finally he discovers a paper clip, which he fashions into a button. The perception of an object as something that will serve our purpose is a form of judgment that may attain considerable subtilty. The perception of an act as the right thing to do is a judgment of much the same kind, and successful judgments of this sort characterize the highest development of behavior.

A judgment may involve a choice of alternative responses, as when a player makes a move in chess or plays a certain card rather than another. We speak of a situation as offering a choice only when two or more response tendencies are approximately 
equal. When the conflicting tendencies are of almost equal strength, the delay in judgment is greatest.

We are conspicuously lacking in judgment during emotional excitement, and this is because the stress of emotion renders unstable the equilibrium of balanced reaction tendencies.

Judgments are often verbal. The word, which is itself a cue to response tendencies, is elicited by the situation and serves to classify the things we experience.

Reasoning is a series of judgments, each consecutive judgment resulting from the stimulation and from the neural reorganization that the preceding judgment produces. As a result of verbal reasoning, incipient action tendencies may be aroused and consummated, or inhibited and drained into other response mechanisms.

\section{Conviction and Belief}

Conviction and belief may be described as the attachment of response tendencies to verbal statements that are either heard or spoken. These response tendencies may themselves be verbal, or they may be tendencies to other forms of behavior, such as overt acts or emotional expression. The proposition, "Toadstools are poisonous," is believed when we refuse to eat them, when grave apprehension follows our having eaten them by mistake, when we try 
to prevent our friends from eating them, and when, in response to questioning, we declare that to eat toadstools will result in illness. When any of these responses is diminished or absent, we say that the conviction is not complete. Lower animals that avoid eating toadstools are not said to do so as a result of a conviction or a belief, because their avoidance is not conditioned upon a verbal statement.

We are convinced of the truth of the proposition, "Influenza is contagious," if the tendency to say these words follows our discovery of a supposed influenza case and if this verbal response makes us cautious.

The moral conviction that it is wrong to play tennis on Sunday consists first of all in saying so when tennis is suggested. Further than this, our belief consists in a tendency not to play, and in displaying resentment toward those who do such a thing. The belief that debts should be paid involves advocating this statement, having a consequent tendency to pay debts, and a show of remorse when this tendency is prevented. When a hypocrite merely advocates this form of honesty and does not pay his debts and does not regret his failure to do so, we recognize the incompleteness of his belief.

A belief may be said to be systematized when to alter it would involve a modification of many other beliefs, opinions, and habits. It is difficult for the West Indian Negro to give up his belief in ghosts because many of his convictions involve the word. 
His dead friends have become ghosts; many otherwise inexplicable events are caused by ghosts; the graveyard is awful because of the presence of ghosts; and the exact appearance and habits of ghosts have been described to him in voodoo teaching. The college student may be slightly superstitious concerning ghosts, but, because any such belief is unsystematized, it is easily dissipated.

When a belief that is unshared by the believer's associates stubbornly resists persuasive argument, and when it is not the ordinary result of such experiences as the believer has had, we call the belief a delusion. Delusions, like other opinions, may be systematized and emotionally reënforced, in which case they show an obstinate persistency. 


\section{CHAPTER VI}

\section{HUMAN MOTIVES}

\section{The Delayed Reaction}

The acts we perform to-day often seem to be the direct result of the stimuli we received yesterday. We continually make plans for to-morrow and when the time comes we often carry out the previous day's intention. Is this lapse of time between the stimulus and the reaction a true latent period of response, or is the reaction, when finally given, simply a response to sensory memoranda furnished by our body and the external world? If all our sense organs were made anaesthetic, could we bear in mind the fact that in a little while we must meet an engagement or telephone to a friend? Would any serious thinking be possible to a person totally deprived of sensory stimuli and in some way miraculously kept alive? Unless we find in the laboratory the answer to such questions as these, we are in danger of accepting some fanciful hypotheses as to the way in which thinking proceeds.

The central nervous system, while isolated, might conceivably be capable of carrying on a self-contained interplay of processes that would result ultimately in an act, but the fact remains that the cen198 
tral nervous system never is isolated from the effect of constant sensory stimulation. Even in sleep and in surgical anaesthesia the isolation from receptors is only partial.

Hunter constructed a choice-reaction box that had three passageways leading to food. ${ }^{1}$ Any two of these passageways could be blocked and the third left open.' The open passageway, varied at random, was always illuminated. By trial and error, the animals in this box learned to select the illuminated opening and to avoid the others. An animal so trained was then placed in a release compartment that offered a view of all three passageways, but from which it could not escape until freed by the experimenter. The light was turned on in the open passageway until it was observed by the animal. Then, after the light had been turned off, an interval was allowed to elapse before the release compartment was opened. Even after this delay the animal could still choose the correct exit. Such behavior is generally referred to as a delayed reaction. Hunter found that the interval between the light stimulus and the response could be as long as from 1 to 5 seconds for rats, from 1 to 3 minutes for dogs, and more than 20 minutes for a five-year-old child.

Rats, cats, and dogs, in order to respond successfully, had to maintain their orientation throughout the interval. This orientation preserves the stimu-

1 Hunter, The Delayed Reaction in Animals and Children, Animal Behavior Monographs, 1913, No. 1. 
lating effect of the proper exit until the animal is released. The sight of the closed barrier of the release box inhibits the movements of escape. The opening of this barrier removes this inhibition, and furnishes a facilitating stimulus to the escape movements that the sight of the fixated passageway has throughout tended to initiate. The animal that maintains its orientation throughout the interval presents a picture of balanced reaction tendencies, each of which is excited by a persistent stimulus. When one of these stimuli, namely the release barrier, ceases to act, the other, the fixated passageway, causes a response. The situation that is here at work is easily analyzed.

Children, even though they had lost their orientation during the interval, were able to respond successfully. Adults do this with considerable uniformity. If the person acting as subject is carefully observed, this delay in reaction no longer seems to be a true latency of response.

The response tendency toward the door last illuminated would hardly have the lowest threshold just because of recency of excitation, as the other doorways may be the ones last looked at. When an adult subject in this experiment carefully observes his own behavior, one of the following factors always seems to be present to determine his correct choice. Sometimes he assumes an inconspicuous orientation, of parts other than head or eyes, when he sees the light, and maintains this posture until 
the interval has elapsed. This serves as his cue when he is released. He may guard against doing this, however, with some success. More frequently, his seeing the light in a particular doorway is followed by some characteristic movement reserved for that situation, consisting of a slight swaying of the body or head, slight contraction of muscles on one side or the other, or subvocal speech movements corresponding to words that designate the proper doorway. These minimal movements are often wholly unobserved by the experimenter. When the subject is released, a scrutiny of the doorways will revive one of these cue movements, which seems to depend upon recency and upon the emotional reënforcement characteristic of all preparatory responses, for its low threshold. This serves in turn to reënforce the proper orientation and approach responses. The subject usually reports that his choice does not depend on having made merely the original orientation movements, and when his choice is correct, he practically never fails to report the occurrence of some additional cue movement, sometimes a series of such movements, that were begun while the orientation was still maintained.

If a stimulus does not cause an immediate response of one sort or another, it will probably never cause a delayed response of any kind. If a mechanism is stimulated and the response inhibited, the delayed occurrence of the response, in the absence of the original stimulus, is due either to a mainte- 
nance of orientation or to the recurrence of some conditioning stimulus, usually movement-produced.

Suppose that a man is called to dinner while in the midst of work, and delays his response until he has reached a convenient place for stopping. Unless he changes his posture in readiness for rising or maintains an uneasy tension, unless peristalsis jogs his memory, or unless sounds from the dining room remind him that dinner is in progress, his reaction is very likely to remain delayed until he is called again. If, when dinner was first announced, he happened to be looking at the paperweight on his desk as he promised to be down in a moment, a casual glance at the paperweight might later bring him to his feet. Some sensory cue seems essential to call out a delayed response once the original stimulus has ceased to act. Such a sensory cue may be either an organic stimulus or one external to the body, which, having occurred along with the original situation, has become a substituted stimulus for the delayed response. Our environment, our daily routine, and our rhythmical bodily functions are full of memoranda for these postponed reactions. Lacking these helps we would almost never carry out an intention. Having made an engagement for Monday morning we keep it because the events of Monday, when they occur, are different from the events of Sunday. No response is ever given to an abstract 48 hours hence. A delayed reaction is not essentially different from any other conditioned response. 


\section{The Wish}

A wish is an emotionally facilitated tendency toward a consummatory response whose consummation is delayed. This delay may be caused by the inhibiting action of an antagonistic mechanism when the situation for carrying out the reaction is present. Or it may be caused by the absence of the situation necessary for carrying out an act when the tendency is aroused by conditioning stimuli. Pending the consummation of an act, the opportunity for which is present and interference with which is absent, the wish may be slightly in evidence while the act is being carried out. Thus we may wish to take a drink of water while preparing to do so, but this is only because the act of securing the water postpones the consummatory response. The other occasions on which wishing for water is evident are, first, when water is present and we are inhibited from drinking by some such circumstance as the presence of a thirsty friend, and, second, when a dryness of the throat, mention of water, or the sight of an empty glass prompts us to drink, and no water is to be had. During the delay, in either case, there is readily apparent the growing emotional reënforcement that is characteristic of the postponement of any consummatory reaction. All wishes are consummatory response tendencies whose complete expression is interfered with, and whose postponement arouses emotional reënforcement. 


\section{Attention}

The several parts of a situation do not have equal power at any given moment to call forth responses. A person gathering flowers picks some and leaves others, or his attention may be distracted by a lizard on the wall. In the theater we watch the actor and are oblivious of the audience. This is because of the differences in relative intensity of the various stimuli, because of the particular orientation of our sense organs at any moment, because of the variation of conductivity in neural arcs, the result of habit and reënforcement, and because of fatigue.

Attention is the orientation of sense organs toward a source of stimulation and the lowering of appropriate response thresholds. It always involves more or less preparatory innervation of the effector muscles. Usually associated with it is the cessation of most movements that do not serve to explore the object that is attended to. Attention is most evident when there is a balancing of reaction tendencies toward a single object, as the orientation is then more persistent because the muscle contractions by which the orientation is maintained are emotionally reënforced. When opposing orientations are called out by two separate objects, attention to either object is decreased.

After a few seconds of attention the muscular adjustment of the sense organ is partly lost, but, because of movement-produced stimuli that this loss 
occasions, the proper adjustment may be regained. Fatigue also occurs in the large muscle groups involved in orientation, and this has its effect upon attention.

In addition to the fluctuation of muscular adjustment, there is a fluctuation of conductivity of the neural arc, probably resulting from variation in conductivity of the synapses and from the irregular drainage and reënforcement of the system. Thus we always have a sort of fluttering or pulsation in attention, even though careless observation may seem to indicate continuous attention lasting several minutes.

The movements of orientation may shift from object to object following systematic or random changes in a situation. Where this shifting is present, there is likely to be less fatigue and more emotional reënforcement of the movements on which the orientation depends. Attention to one object or to one orderly sequence of events inhibits responses to unrelated stimuli, both because of the low thresholds established by the intense stimuli that result from a steadfast orientation and because of the facilitation derived from many component responses that make up habitual acts.

\section{VoLition}

A voluntary act is the outcome of a delayed reaction when reënforcement reduces a high threshold 
of response or brings to an end the balancing of incompatible reaction tendencies. This reënforcement is furnished by movement-produced stimuli and by external changes in the environment. It is possible that the balance of tendencies might be lost and action result without external coercion, provided one of the two opposed reaction tendencies fatigues sooner than the other. Introspection, however, usually detects either a bodily change or a change of external stimulation as an antecedent of voluntary movement.

We often overlook the external changes that affect our choice. We may be undecided whether to take the morning train for a week-end vacation. With opposed tendencies to action mutually inhibited, we delay our decision to act, but as the time grows short the balance is disturbed, so we pack our bag and start. Here it is the change in the clock that has destroyed the equilibrium of our hesitation, although we are likely to credit ourselves with having made an unaided choice. This disturbance of balance by an external event needs no lengthy discussion. A more interesting antecedent of voluntary movement is the balance-destroying stimuli that our own bodies provide.

The opposed reaction tendencies that are present in delayed choice never leave us wholly unmoved. They always bring about internal responses of one sort or another. The energy that this opposition engenders is drained into other systems, and pro- 
duces either slight skeletal movement or various internal changes. Such responses provide stimuli that are likely to reënforce one or the other of the balanced tendencies. If enough reënforcement is finally piled up on one side to destroy the balance, a voluntary act results.

Some of these internal changes are difficult to observe except introspectively, and such a method never gives wholly accurate information. The respiratory changes antecedent to voluntary movement may be graphically recorded, and serve as a good illustration of balance-destroying stimuli. Such a record is shown in Figure 30. The conditions of the experiment under which this and similar records were secured are as follows:

The pneumograph was adjusted at the axilla level. The subjects selected were always untrained and did not suspect the purpose of the experiment. Most of them did not know that their respiration was being recorded. Each of them was seated before a table on which were placed three small strips of cardboard. The following instructions were then given: "Wait until you feel that you wish to do so, then place these strips of cardboard so that they form some geometrical figure." The time of the first observable movement of the subject's hand as he reached for the strips was indicated by the experimenter's closing a switch. A characteristic respiratory change, similar to that shown in Figure 30, was observed in all but one of the 12 subjects em- 
ployed. These movements consisted of a deep expiration and an inspiration that was interrupted by one or more periods of apnoea. The initial hand movement was executed only after the apnoea had continued for a brief moment. If the reader, pre-

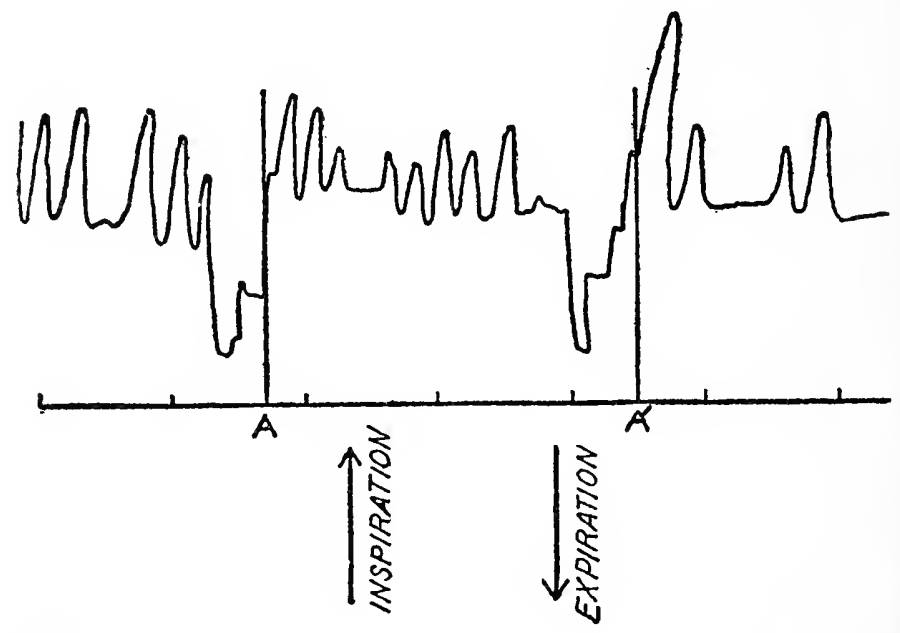

Figure 30. Respiratory antecedents of voluntary Movement. THE PROCEDURE IS DESCRIBED IN THE TEXT. VOLUNTARY HAND MOVEMENTS OCCURRED AT THE POINTS MARKED A ON THE TIME LINE. TIME. IS INDICATED IN 5 SECOND INTERVALS. THE FIGURE IS TRACED FROM THE KYMOGRAPH RECORD. APNOEA, FOLLOWING DEEP EXPIRATION, PRECEDES THE VOLUNTARY MOVEMENTS

ferably with eyes closed, will repeat for himself these respiratory movements, exhaling deeply and interrupting his inspiration by several periods of holding the breath, he will be conscious of a generalized innervation especially affecting the muscles that ex- 
tend the arms. It is easy to see how this stimulation from apnoea may so reënforce the reaching-out tendency as to reduce sufficiently the threshold and bring about the act.

Freedom of the will does not consist in our being able to perform either of two incompatible acts at a given moment, but consists rather in our ability to carry out an intention in the face of distractions. In popular speech the "strong willed" man is one whose good habits are sufficiently well established to triumph over temptation, but this is an ethical classification. Psychologically, the morphine addict shows an equal freedom of will when he disregards the remonstrances of friends and overcomes the obstacles placed in his way by the law.

\section{INTENTION}

When, on rounding a corner, we unintentionally bump into a stranger, we are unprepared to meet the consequences of our act. When pushing him out of our way intentionally, we have not only given the precurrent responses that lead up to this thrusting him aside, but are also prepared for defense against his possible aggression. Intention, like the wish, is present only when a consummatory response is delayed. Intention differs from the wish in that it involves the actual presence of precurrent responses which, in popular speech, "commit" us to the consummatory response. Intention includes 
"making plans," which is a form of precurrent response. This planning for an act is not an essential part of the wish, because in the wish there may be no precurrent responses present. Planning often takes the form of verbal responses or modified movements of rehearsal that serve to adjust our behavior to meet anticipated difficulties and to facilitate the consummatory reaction. If, in the past, we have carried out a consummatory response in the face of familiar difficulties, the total habit so formed makes our tendencies to carry the matter through a second time more an intention than a wish.

\section{DrIVE}

Having considered what kind of response is naturally given to each kind of stimulus, how new stimuli are substituted for old, how responses are integrated into new combinations, and how delayed responses are finally brought about, there remains the question why some acts are more persistent and more energetic than others, why some tendencies are imperious and some are easily discouraged. It is not sufficient to say that a man's tendency to act in a particular way is strong because he "wills", so to act. Energetic action must be a result of a physiological mechanism capable of releasing and conducting the necessary amount of nervous impulse.

We cannot escape the hypothesis that each 
stimulus-response mechanism has its store of nervous energy, and that nervous impulses are drained from one mechanism to another. In this way energy may be borrowed, and a mechanism that so borrows it is said to be reënforced. Probably every stimulus-response mechanism is capable of action without reënforcement, but few mechanisms ever act in isolation.

The mechanisms resulting in acts of love, fear, rage, hunger, pain, shame, and other emotional expressions are supplied with a great amount of latent energy. From these reservoirs many less energized mechanisms receive their additional drive.

Any act becomes emotionally reënforced once it has been elicited along with an emotional response, the emotion becoming a conditioned response either to the stimulus that causes the simple act or to the movement-produced stimuli in which the act results.

Upon the conflict of certain reaction tendencies there result such emotions as grief, anxiety, shame, and remorse. The effect of these asthenic emotions is to depress or inhibit, rather than to facilitate behavior in general. These emotions usually arise when some event has occurred that makes it difficult or impossible for us to carry out an habitual consummatory response. When the death of a baby removes him from his mother's arms, the tendency to fondle him is still present, but can not be expressed. If a child breaks her doll, she is left with a futile tendency to play with it. A man who is put 
in jail is inevitably prevented from engaging in most of the consummatory responses of daily life. In all these cases grief and the depression of activity result. If the obstacles to action in these cases had not been insurmountable, rage, and not grief, would have been aroused and activity increased. The utility of discouragement and melancholy consists in that the victim of circumstances does not spend himself in vain effort.

The internal changes involved in emotional responses affect wide areas and bring about sustained stimulation to many proprioceptors. The diffuse nature of emotional stimulation is easily observed in anyone suffering from a toothache or in a person who is enraged or frightened.

No form of conduct, excepting routine habit, is persistently engaged in unless emotionally reënforced. Routine habit itself is originally established with the aid of a borrowed emotional drive. Dancing, game playing, dangerous sports, gossip, theater-going, controversy, and business speculation are energetically pursued because of the emotional drive the situations arouse. The approbation or disapprobation of our fellows furnishes to otherwise weak reaction tendencies an emotional facilitation without which we would never finish the day's work.

Through social convention the consummatory responses in such acts as love, rage, and fear are often inhibited or blocked. During a conference with a 
business enemy the preparatory responses of rage are aroused, but the general situation inhibits killing. With the blocking of this consummatory reaction an ever increasing amount of dammed up energy is provided, which finds outlet not in physical violence but rather in attending to business with renewed drive. If the competitor wins out in the business deal, however, this energy finds outlet in curses, imprecations, slander, or frequently in the fabrication of a story that, when told to friends, serves to justify failure and to elicit sympathy. After an unpleasant ordeal with a business superior, a man is likely to talk to himself on the way home, or possibly later in the evening to find some excuse for disciplining the children.

The fascination of literary fiction is produced by the author's postponing any description of his hero's consummatory responses, and by elaborating his preparatory responses. By such devices to secure suspense the reader's interest is aroused and maintained. Always the dawn breaks and Scheherazade ceases saying her permitted say just as the hero is about to be discovered in his hiding place, or while he is still in full flight. When true love begins to run smoothly, the story is ended.

Emotional reënforcement is largely responsible for the tenacity of certain memories of early childhood. The situations thus remembered are nearly always exciting. Out of 700 "first memories" recently collected, more than 97 per cent were the re- 
sults of highly charged emotional experiences. The event that leaves us unmoved is soon forgotten, and it is well that this is so, for an event's importance is usually proportional to its emotional effect.

\section{Sublimation}

In the laboratory, when men and girls are working together, much diffuse and purposeless movement may be observed, which would not occur in other than a coeducational university. Properly utilized, this additional drive may result in effective work. The utilization of dammed up drive for acts other than the consummatory reaction to which it would lead if uninhibited is called sublimation.

When a person becomes apathetic toward his work, he is frequently not fatigued. When this is so, what he needs is recreation, not rest. He may go to the theater, visit a friend, or play a game of cards, and then return to his work with new enthusiasm. This drive is not so much the result of rest as it is the outcome of recent precurrent emotional responses in one form or another. Thus we distinguish being tired from being stale.

In the case of children, when rage, love, or fear behavior is initiated but blocked, the outlet for the resulting drive is often in tears or laughter. Giggling is characteristic of older children under similar conditions, and may be shown in church, in school, or anywhere in the presence of the opposite 
sex. The theater audience laughs most heartily at indelicate allusions. Laughter may occur upon the sudden passing of danger or upon the averting of a quarrel. Any incongruity in a situation may cause a blocking of emotional response, and this is probably why the incongruous is often whimsical.

The sublimated drive that enables men to surmount obstacles is of various kinds. The competitor shows a doggedness of conduct that is not found in the man who has no rivals. Love makes the world go round. "The fear o' hell's a hangman's whip to haud the wretch in order." Many emotional states are derived from the basic elements of rage, love, and fear. It is seldom that one of these elements is lacking when any ambition is pursued with great tenacity of purpose.

It is necessary to recognize certain coenotropic tendencies that may be observed in all young children. Children seek opportunities to inflict pain on others, and this inclination is called sadism. They also tend in certain situations to seek painful stimuli. This is known as masochism. They show a propensity to exhibit their bodies and, especially from concealment, to observe the bodies of others. All these tendencies are undoubtedly a part of sex behavior. A derivative form of the tendency to cause pain to others is seen in bossing and bullying other children, in teasing and in ridiculing them, and in compelling their submission. These acts borrow the drive of the behavior from which they originate. 
Submitting to coercion may be developed from the more original tendency to seek pain. To be conspicuous in any way, as when wearing unusual clothes or occupying the center of the stage, may be a modification of the tendency to exhibit the body.

As the child grows older, his masterful, submissive, and exhibitionary tendencies conform more and more to the requirements of this world, and the origin of these tendencies is obscured. Sadism plays its part in taking people to prize fights, in causing them to read newspaper atrocities or to punish children, and in a more useful form the same motive gives drive to the physician, the magistrate, or the army officer. Willingness to submit to pain makes men tolerant of the imposition practised on them by those they love. Derived from exhibitionism are the acts of having one's picture taken, seeking newspaper publicity, wearing lodge regalia, crusading for dress reforms, speaking in public, or running for political office.

\section{Conflict}

The blocking of a consummatory response tendency, combined with the absence of any adequate outlet for the resulting emotion, is called a conflict. When a conflict arouses an unusual amount of unliberated drive, a form of behavior known as hysteria may result. The symptoms of hysteria are sometimes shown in relatively futile acts, more or less suggestive of the consummatory act that is so well 
inhibited. Thus a mother who has lost her baby may lavish care upon flowers or household pets. More frequently, however, the hysterical symptom is an act that serves the same purpose as the act that is inhibited. For example, in Dr. Ames' case, the patient who could not bring himself to desert his wife became hysterically blind and thus succeeded in being removed from home. It should be borne in mind that the hysterical act or symptom is beyond the patient's control.

A persistent tendency to perform some useless, silly, or distasteful act is called in psychiatry a fixed or imperative idea. This is seen when a person cannot avoid humming to himself a haunting melody that has become displeasing, when the effort to inhibit obscene, profane, or apparently commonplace words persistently fails, or when a distasteful act is repeatedly the final outcome of mutual inhibition. The reënforcement that makes such acts imperative is usually a proprioceptive mechanism, such as sex or anger, which has become linked up with the original action system through conditioning. The fear that results from a person's imagining that he is becoming insane serves as such a reënforcement, and by frequent use the fear of insanity increasingly occupies the mind. When the reënforced act is useful, and not displeasing to the subject, its frequent occurrence causes no anxiety and is never thought morbid, although the drive mechanism may be the same as in the case of a fixed idea. 
Forgetting an act may sometimes be due in part to the inhibition of tendencies with which the act has become associated. ${ }^{2}$ Our failure to remember the name of an acquaintance may be the simple result of long disuse, but if speaking the name has become associated with inhibited action tendencies, the word threshold is further raised and we are often powerless to recall the word.

Dreams correspond to reaction tendencies that are commonly inhibited in waking life. In sleep the inhibitions are partly removed by the absence of certain sensory stimuli that affect us when awake. Responses are prevented by the resistance in motor conduction paths.

Undirected by any very rich sensory experience, and partly rid of inhibitions, the imagery of dreams follows the course of wish fulfillment in a way unknown to waking thought. Thus our dreams, when properly interpreted, reveal to us many unsuspected propensities. In this way dreams become useful material in the detection of conflicts in hysterical subjects.

\section{OverCORRECTION}

One of the richest sources of the stimuli that inhibit our responses is the social sanction of our fellows. The world demands of us many virtues we do not possess. By simulating such virtues as we lack,

2 Many instances of such forgetting are described in Freud's Psychopathology of Every Day Life. 
and so disguising our inmost tendencies, we gain approbation and escape contempt. We ourselves, however, are never wholly deceived by the superficial artifices we substitute for the more spontaneous tendencies observed in others. In our effort to conform to social standards we frequently overcorrect for our faults, so that our virtues are too conspicuous to seem real.

Persons who laugh loudest at the Saturday night bath stories are likely to have acquired punctilious bathing habits late in life. The genealogical bore is usually a man of humble origin in at least one unstudied line of descent. Ostentatious modesty is impossible in anyone who is not immodest at heart. A man who subscribes himself "very sincerely" should be watched. It is a fairly safe generalization that the noisiest reformers all possess the tendencies they spend their lives in condemning. 


\section{CHAPTER VII}

SOCIAL PSYCHOLOGY

Social psychology deals with the concerted behavior of groups of individuals, and with the individual's responses to his fellow man.

\section{Fellow Man as a Constant Situation}

We pay more attention to people than to any other part of our environment, and they furnish the occasion for our most elaborate behavior. The complex variety of their activities calls out in us a correspondingly rich assortment of responses. They are not passive objects, but are possessed of pent up tendencies to action that may be released at our slightest intervention.

Every culture presents to man a distinctive, peculiar, and individual environment. An island in the. South Seas has few resemblances to the make-up of a large city. The food, the habitation, and the outdoor life of the Esquimaux differ greatly from those of the Louisiana Negro. Aside from such universal features of the environment as light, atmosphere, gravitation, and the uniformity of nature, which science attempts to describe, the one thing common 
to all societies is fellow man, his anatomy, and his original nature. He is fairly constant from one generation to another and fundamentally the same in all localities. For this reason there is an obvious fitness and propriety in the fact that, no matter where we may be born or who we may be, we respond to him with many instincts and habits common to humanity. He has always been the necessary object when we nurse as babies or love as adults. He is essential to our conversation and our quarrels. Without him we could not steal, murder, or disturb the peace. In his childhood he actuates us to nurse, shelter, and protect him. In short, because of his invariable structure, conduct toward him shows a persistent similarity in all societies.

\section{Other Prevalent Situations}

Gravity, the earth's surface as a dwelling place, rain, sun, day, night, and the seasons, are relatively changeless situations in the history of the race. Vegetation, animal neighbors, and the sources of food, though somewhat the same in every epoch and every climate, show more variability. Houses, velicles, tools, highways, industries, superstitions, ceremonies, recreations, language, and human institutions in general, characterize particular times and places. According as these situations are generally met with, a similarity of habits is established in all members of society. The possession of com- 
mon habits is what distinguishes a society from a mere aggregate of people. It is our task to discover the situations that accomplish this unification of response. Although the history of social machinery is the legitimate subject matter of sociology, man's creation, acceptance, and rejection of the artificial forms of society is a question for psychology.

People show great similarity of behavior toward all oljects commonly met with. They sit in response to chairs, sleep in beds, ride on trains, hoard money, distrust strangers, and wear clothes. There are other objects toward which the world as a whole does not respond so uniformly. Christians have a particular way of acting toward the Bible, Americans toward their flag, women toward jewelry, the voodoo worshipper toward his fetish, certain groups toward their totems, and each household toward its belongings. The possession of similar response tendencies toward these objects defines and unifies a group.

Places, like objects, elicit characteristic responses in the group. There is a conduct proper to church, to the dining-room, the graveyard, the school-room, the ball park. Dress that is proper on the bathing beach is inappropriate on the street car. While in a conveyance that moves vertically we remove our hats, but when in one that moves horizontally we feel no compulsion to do so.

Times, like places and objects, stimulate us all to common action. We work by day and sleep by night; we show good will toward men on Christmas and ill 
will on Hallowe'en; we are boisterous on July Fourth and sedate on Sunday. We glance at the clock and say it is time for the children to be in bed, or again we say it is time to get up. There is a usual time for tea, vacations, and formal calls. Birthdays, festivals, weddings, funerals, puberty ceremonies, and harvest time all demand their particular observances, and unconventional behavior is on such occasions regarded as improper.

We respond in a characteristic way to people recognized as belonging to certain classes. We reserve deference, affability, or generosity for some, and arrogance, contempt, righteous indignation, or fear for others. Thus toward servants, policemen in uniform, royalty, the graybearded, our betters, negroes, clergymen, prostitutes, blood-relatives, parents, criminals, reds, radicals, women, and children we acquire distinct and conventionally organized responses.

The efficiency of words depends upon their arousing similar reactions in everyone. Some words, like some places, objects, times, and classes of people, provoke not only a conventional response but arouse along with it an emotional drive that is particularly effective in unifying the crowd. The shrewd orator can rouse in his audience shame, awe, anger, pride, fear, or pity, by the proper choice of words or phrases or by employing a particular tone of voice. "Americanism," "gentlemanly," "honorable," "profiteer," "hell," are examples of drive-arousing 
words. Titles are valued because they command respect. "Sir," "captain," "doctor," "professor," are titles that often carry an unmerited prestige. Academic degrees may be sought as an end in themselves. Children hang their heads when told that they are "naughty," regardless of what they have done. Political catchwords stir up enthusiasm without much dependence upon their literal significance, and obscene words always secure the attention of polite people.

\section{Formation of Habits in Common}

The formation of common habits in a group is due to imitation and other forms of conditioned response and to adaptation. Given the proper environment, society as a whole may form almost any habit that it is possible for the individual to acquire. Outlandish customs are not the fruit of anomalies of human nature in strange peoples, but merely the growth of a social inheritance guided by the strange world in which they live.

Properly regulated behavior in a community involves something more than mere similarity of response among the individuals concerned. There is always to be found another sort of unity of action, which may be called complementary behavior. The way in which mother and child secure best results is not to behave alike but to behave differently. A mother acts in much the same way as mothers in gen- 
eral, and a child learns the way of children. Thus commonality of behavior attaches to classes of persons, but the proper interplay of responses of two persons of different classes necessitates not similar but reciprocal conduct. Indeed, coöperation between any two individuals demands complementary as well as like responses. Officer and enlisted man, physician and patient, merchant and customer, master and servant, teacher and pupil, husband and wife, lawyer and client, each acts according to his conventional part in the relationship, but not necessarily in the same way as the person with whom he is holding social intercourse.

Complementary behavior, when it occurs, is the inevitable result of the difference in situation confronting two people who are together, and of the difference in their nervous organizations. For social organization, it is a happy fact that the behavior the baby shows toward his mother is useful in securing him food, and that the behavior he calls out in her is adjusted to the same end. These are, however, no more mysterious facts than is the elasticity of the limbs of a tree a mysterious adjustment to its successful spilling of the wind. When these fortunate reciprocal relations occur in nature, they become fixed by the preservation of the organisms that show them.

In the case of groups, as in the case of individuals, a habit response originally given to one situation may later be given to another situation, because of 
the similarity or partial identity of the two. A parent learns to discipline his child and the child to obey his parent, and later, when the child becomes an adult, this coercive and submissive relation persists and is often detrimental to good government in the tribe. The "rule of the elders" in primitive culture depends upon this undue pertinacity of children's habits of obedience and parents' habits of domineering, and involves a limitation of liberty for the young and an extension of privilege for the old.

The treatment of the dead depends upon the persistence of habits formed toward the living. The name, the personal belongings, and the dwelling place of a deceased friend call out responses that are wholly inappropriate when he is gone. So, until these habitual responses of the survivors are dissipated, his ghost still walks. Weapons are put in his coffin and food is placed upon his grave. His name is spoken with caution and only his virtues are mentioned, lest he overhear. If he was a headman or chief, there still adheres to his sword some of his valor which makes the weapon deadly, and his manthe gives to his successor a contagious wisdom.

The sentimental value of belongings, the attachment we show to places in which we have spent happy days, the thrill aroused by the name of someone we love, are all due to the former presence of situations in which these symbols were incidental features. The power of the symbols to call out these conditioned emotional responses makes men more 
willing to pay taxes on their homes and gives men a common interest in the symbolism of art, drama, and fiction. The transfer of response to substituted stimuli may also be due to a mere similarity between the new stimuli and the old. It is hard for us to mutilate the photograph of a friend, even though we realize that it is a mere bit of paper. Because women have learned to call little children "cute" or "dear," any object that is a miniature duplicate of something usually seen in large size is apt to be described in these words. We hear such expressions as, "What a dear little house," "What cute little biscuits." The smallest entry in the dog show always has an attentive feminine audience.

In childhood many responses are organized around human beings and are later given to situations in which fellow man does not figure. Children learn to seek their parents' protection when in danger, or their assistance when in trouble. Parents and playmates often interfere with the children's undertakings, and children learn to overcome this interference with supplicating, placating, and ingratiating behavior, with plausible excuses for misconduct, or by sharing their possessions with these older and stronger companions. To danger, pain, sickness, misfortune, ridicule, loneliness, or failure, the child, when he grows up, because of the tenacity of early habit, often responds in a childish way.

If he is a benighted savage, he may not realize that sometimes inanimate nature alone is respon- 
sible for his misfortune, and, seeing no human cause in the situation, may make up for its absence by inventing or by accepting as present the evil spirits, demons, fays, and goblins that are part of all savage superstition. These he placates in childish fashion by gesture, cringing posture, words of praise, promises of good conduct, circumspect behavior, and the offering of sacrifice. Because the storm wind is destructive he assumes it to have a personality. The dangerous waterfall, the unscaled mountain, he treats as he would treat mighty human beings. When plague, sickness, drought, famine, flood, shipwreck, invasion, or other misfortune occurs, the tribe as a whole appeal to the spirits of their ancestors or to graven images for the assistance that, as children, they had learned to expect from parents.

The combined appeal to the spirits is often supposed to be answered by a sign or augury. This gives confidence to the idolaters that they will be saved, and there results such a practical good as the passing of fear or the unification of group effort in meeting the misfortune. This persistence of childish reactions in the group makes fertile ground for the growth of certain vocations connected with ceremony, divination, magic and sacrifice. Thus there are found groups of professional conjurers, magicians, medicine men, priests, and augurs who select and organize the ritual of festivals, incantation ceremonies, and temple life.

In our own civilization childish responses in the 
face of danger or misfortune are by no means lacking. The adult male, his early tendencies to depend on nurse or mother long overlaid by habits of practical self-reliance, will, when sick and taken to the hospital, exercise again his infantile responses. He tolerates with considerable satisfaction the personal service of his nurse, querulously demands attention, is jealous of other patients, becomes fretful upon small provocation, and is pleased by trifles.

Man first shows generosity and kindliness in general to his family group because his early childhood is spent at home. The attachment of these response tendencies to the father, mother, brother, sistersituation makes it useful to employ family names to elicit these friendly responses toward society when the child becomes an adult and leaves his home. Hence we have the terms "brother man," "brother Elk," "little brown brother," "less fortunate sister," "sister republic," "mother church," "the greatest mother of all," "mother country," "fatherland," "city fathers," "father of his country," and many others. Because the husband-wife relationship does not exist for the child, these terms do not elicit responses of the sort just mentioned, and are not found to have this derived meaning in popular speech.

Language includes names for many wholly mythical situations, and society may react to these names as though the situations were real. In order to explain the fact that these situations fail to stimulate 
sense organs, the believer calls them immaterial, disembodied, incorporeal, astral, intangible, invisible, shades, or ghostly shadows, although such words afford no real explanation. The happy hunting ground and the Moslem paradise may conceivably be beyond the reach of our sense organs because of their great distance, but it requires more explanation to make plausible living beings who may work good or evil in a physical world, but who cannot affect the organs of vision or touch. The ghost in the dark is the frightened person's rationalization of his fright; the evil spirit is the unfortunate's rationalization of his bad fortune; just as the careless person explains the loss of a misplaced article by saying that a thief must have taken it, or just as the farmer explains the cool breeze in summer by saying that hail must have fallen in the vicinity.

There is a tribe of Sioux in Manitoba who believe in the existence of a beast that has a convenient way of making itself invisible when looked at. ${ }^{1}$ Many Indians have been pursued by it along forest trails after dusk, to fall exhausted at the outskirts of the village. Similar beings rattle tambourines, write on slates, move tables, and speak through the lips of mediums. If the credulous Indian or the devotee of spiritism is asked why these odd beings do not perform in the sunlight, he takes refuge in the answer that it is the nature of the creatures to live in

1 Reported by W. D. Wallis. 
darkness. The influence of unseen spirits was the fundamental doctrine of witcheraft; it explained to our forefathers the eccentric behavior of the insane, and even now is used by the uneducated to account for the tricks of the professional clairvoyant. As the Indian's flight from the noise in the dark is exactly the same as his flight would be from such a beast as the tribe has talked about, a noise has for him all the meaning that a real beast would have. In so far as the old dupe gives the same emotional response to his dead son's name on the lips of the medium, or to an alleged message written on a slate, that he would give to the son's presence, the situation seems real to him. When we consider the ease with which an individual may fall victim to a belief in unrealities, though modern scientific method is at his disposal for checking up his belief, it is not surprising that, in cultures lacking the methods of science, credulity for erroneous tradition should be the rule.

One result of society's conforming to manners and customs is that thereby men are able to react not only to what their neighbors have done but also to what they are about to do. This simplifies the world and makes life in communities possible. The amenities of polite society expedite our taking leave of our hostess, make ponderous explanations of our comings and goings unnecessary, and prevent much of the ill feeling that a candid analysis of situations would produce. Similarity of custom produces soli- 
darity within a social group. The strangeness of contrasting custom seen in outsiders emphasizes caste and prevents the cohesion of diverse classes.

\section{The Spread of Tradition}

Tradition is the whole body of transmitted directions for dealing with situations. Through the instrumentality of words we may be properly prepared for events that we have not before experienced. Both common sense and science have this function, and tell us what to expect of objects and people. Applied science includes the description of the effects of situations on society. Knowledge is passed down to us concerning what plants are poisonous, what to do when we wish to cross a river, when to plant corn, the way to trap animals, the kind of weather that is likely to follow an east wind, or how to insure good luck.

Morality consists of traditional directions for conduct, reënforced by social coercion. This coercion is accomplished not only by force but by approval and disapproval, praise and censure, friendliness and hostility. To the expression in word and action of these emotions in others we ourselves give emotional responses. It is these emotions in us that constitute the drive toward moral conduct.

Approach and avoidance responses have their analogues in the vocabulary of morals; and the words good and bad, right and wrong, brave and cowardly 
are stimuli to which we learn to respond in early childhood. Although social pressure is necessary for the original establishment of morals, when the moral habit is formed, it acts in the absence of coercion. We do not read another's postcard when we are alone because we have learned to avoid doing so while in the presence of others. The habit is reenforced by the words we have heard applied to this ungentlemanly act. The student will find many interesting examples of moral tradition and moral habit in the anthropological literature concerning taboo. Morals are taught by anecdote and fiction as well as by precepts, proverbs, golden rules, and commandments. The words of the anecdote suggest the situation and arouse the emotions that govern the moral response. In this way fables and stories become the common heritage of society and usually involve the ambivalence of hero and villain.

Traditions are built up through use. Temporary fads in conduct are absorbed into the teaching of society when they are fit, and eliminated when unfit. Even though aided by this process of selection, tradition is always old-fashioned and lags somewhat behind practical needs. Only after words are coined for new predicaments, and these words have wide acceptance, is it possible for tradition to operate.

An individual's opinion includes some traditions but not others. It also includes a statement of facts based upon his own experience. Thus opinion is 
built up from suggestion and from induction. It is usually impossible for the individual to experiment in the various sciences, so that he is forced to depend upon the statements of others for many of his views. Whether he accepts the unscientific statements of laymen or the conclusions of experts depends but little upon the intrinsic merit of their assertions. Statements are likely to be accepted that reënforce emotionally colored opinions already held, or that are uttered in such surroundings, by such persons, or in such words as arouse reënforcing emotions. Acceptance is inhibited when the statements oppose existing beliefs, or when the situation in which they are heard arouses emotional resistance.

Thus individual opinion may include belief in erroneous causes due to the acceptance of tradition outside the domain of science. In this way superstitions result from the borrowing of opinions. These "idola theatri" may have widespread acceptance and pernicious social effects. People believe in the unlucky nature of Friday, or of the number 13; they even accept the divine right of kings, and the efficacy of homeopathic medicines, of amulets, of rain-making ceremonies, and of "character analysis."

When we utter an opinion, we usually do so in response to a listener. He may be a friend, or an enemy, a sweetheart or a rival, an employer or a servant, a guest or an insurance agent. Our audience may be a crowd of one kind or another, a congregation, a college class, or a political meeting. The 
words we say are always in part determined by the character of the listener.

What we say is further determined by the thresholds of our verbal response tendencies. We have low thresholds for certain truth telling and for certain lying. We have high thresholds for other statements, both true and false. That which "occurs" to us, whether it be expressed or inhibited, is a statement whose threshold is low. It usually describes things as we wish them to be, and is often designed to elicit from society a response that we desire. We have a low threshold for saying that the runner of the home team is safe on first, no matter whether this is true or false. The lonely child in bed has a low threshold for making the statement that he is thirsty, because this brings him temporary companionship. High thresholds attach to admitting that our family is of lowly origin or subject to insanity, to telling our hostess that we have had a tedious evening, or to using profane language.

At times customary inhibitions to speech are removed, and unusual facilitations enter into the situation. During a war, a political campaign, or a class conflict, partisan feeling and hostility toward opponents drive us to inaccurate expression and weaken many old inhibitions. In his appeal to the jury the attorney makes biased statements, and in the heat of eloquence the orator often garbles the truth.

The responses of the listener are likewise determined by the habits he has formed, as well as by the 
external situation. He has tendencies to accept some statements and to reject others. The tendency to act upon or to repeat the assertions of others is called suggestibility, and when these assertions are false it is called credulity. The listener, like the speaker, is affected by partisan movements, and his suggestibility is modified accordingly. He is credulous of slander concerning political enemies and of eulogy of his leaders. Many Englishmen, but no Germans, believed a report that St. George led a British detachment to victory in one of the engagements of the late war.

\section{Opinjon Spreads from Mouth to Mouth}

Where the subject matter is outside the field of common sense, and thus not controlled by a common habit of statement in the group, or where common habits are disrupted by newly acquired social prejudice, a statement of alleged fact undergoes successive modifications as it is passed on from speaker to speaker. The cumulative error that increasingly attaches to the story is a product of the uninhibited reaction tendencies of the successive narrators. A story so embellished is called a rumor.

An act can not be imitated by anyone who has not formed a habit of acting in a like way. Inaccurate imitation results when this habit is not quite the same as the observed act that is the stimulus to imitation. This fact is illustrated by a simple experi- 
ment. Write five digits such as 48275 on a card. Select a number of subjects and have the first one copy the writing on another card. Have the second reproduce the copy made by the first, the third the copy made by the second, and so on serially through the group. The digits written by the last subject will probably be 48275 , although the form and size of the digits will be considerably altered. Now make a nonsense drawing of random lines and have it serially transcribed by the same subjects. A comparison of the original drawing with the final transcription will show very little likeness. The reason that the digits are reproduced throughout with fair accuracy is that all the subjects possess in common the habitual response of writing these symbols. The cumulative error in the serial transcription of the nonsense drawing is due to the absence of any common habit. The modification of opinion as it is passed from one person to another is greatest when its expression is not a common habit in the group. Myth building occurs in essentially the same way. The myth grows as generations of narrators add to the account the expression of their own wishes. Through much addition and filtration its final form is a composite story voted on by many auditors.

\section{Human Institutions}

The foregoing discussion has dealt chiefly with shared environments that regulate in society be- 
havior that would otherwise be dispersed and uncooperative. Original nature, as well as a commonly experienced world, furnishes all men with tendencies to act alike. Of these tendencies, the emotional expressions, depending only in part upon training for the order and the composition of their elements, are the most elaborate of our instinctive behavior patterns. Coenotropes with emotional components, such as flight, repulsion, curiosity, pugnacity, subjection, self-assertion, parental care, reproduction, gregariousness, acquisition, and construction, are often called "instincts." Although they are habits and not instincts, they are acquired by everyone due to the similarity of environment in which all men are reared. Given our repertoire of natural response tendencies and a world order such as we have all lived in, our learned behavior inevitably combines with certain emotional expressions to form these almost universally shared habit patterns.

In sciences related to psychology it is often attempted to explain all human conduct in terms of a selected few of these coenotropes. It is then that the danger of giving the name "instincts" to these habit patterns and the necessity of challenging such an error are made evident. Freud's "Libido," Le Bon's "suggestion," Tarde's "imitation," Trotter's "'gregariousness," and Veblen's "instinct of workmanship" are all conceived as vague, unanalyzed forces that drive men to action. Even when these widespread habit patterns are correctly analyzed and 
clearly defined, they furnish a wholly inadequate description of human motives. They are at best rough and convenient terms, which we use to portray conduct, but each of them applies to many forms of conduct of diverse origin, and all of them taken together fall short of describing the majority of the acts of every day life.

Human institutions are social habits maintained and directed by the material equipment that is used in their exercise. Banking, commerce, manufacturing, agriculture, transportation, education, slavery, marriage, war, the state, the church, the theater, and the press, all have their peculiar tools, and are established not only in custom but in legislation as well. It is futile to attempt a description of the origin and maintenance of any one of these human institutions in terms of component instincts, emotions, or coenotropes. The institutions are too complex to permit such analysis. Although certain emotions obviously predominate in some, emphasis on these prevailing emotions is likely to obscure the fact that nearly all man's capacities are involved in each one. 

APPENDIX 



\section{APPENDIX}

CONSCIOUSNESS

When two men are stung by a bee, an observer might describe both events in the same way. But if the observer happens to be one of these two men, he will describe the two events differently. In a way this is not surprising, because his eyes have witnessed the stinging of his fellow and his cutaneous sense organs have witnessed the stinging of himself. Because those of his sense organs affected when he himself is stung are different from those affected when another is stung, his responses to the two situations are very dissimilar.

Almost any man will say that the description of his behavior by another overlooks certain facts in the case. He will say that he knows more about the events that constitute his own life than anyone else knows. And he may say that the difference between being stung and seeing another stung is not entirely reducible to the difference in the sense organs affected and the responses evoked.

A description of mind in terms of stimulation, neural action, and responses is by no means the only one in use. There is another language, which the individual may employ in describing the world as his 
own experience, and which includes terms that are useless in a description of behavior. This is the language of consciousness, and its importance is established by its popularity.

Every man's behavior includes conversation about his consciousness, though his consciousness is not open to the observation of others. In seeking information about his private consciousness, he employs the method of introspection, namely a minute description of his experience as he knows it at the time. The introspector may report in some such way as this: "The hunger pang seems to be located in my stomach;" or, "The feeling of being about to say 'yes' involves less excitement than the feeling of being about to say "no" "; or, "I have a clearer memory of the visual appearance of digits than of the visual appearance of letters."

Viewed as behavior, introspection is usually made up of verbal responses to organic states, and these responses are often indicative of what is taking place in the body. The hunger pang is actually coincident with a peristaltic contraction of the stomach. The consciousness of excitement is usually coincident with demonstrable changes in pulse, respiration, and muscle tone. It is probable that a clear imagery of digits is coincident with cortical action corresponding to a part of the cortical process that takes place when the digits are being read.

For successful introspection, the thresholds of the verbal responses must be made unusually low by ex- 
cluding distractions and by providing the subject with directions for self-observation.

\section{Consciousness and the Nervous System}

Consciousness is supposed to occur only when there is nervous action in certain parts of the cortex. The kind of consciousness that occurs depends upon the part of the cortex that is active. Destruction of the visual cortical area results in the loss of all visual sensations, and destruction of other sensory areas brings about a corresponding anaesthesia. Having conscious memories and ideas requires that certain parts of the cortex shall be intact. A decerebrate dog has presumably no sensations, thoughts, or feelings.

\section{Sensation}

If we analyze consciousness into its parts, the most conspicuous of these are sensations. We receive a sensation of green when looking at the lawn, a sensation of sour when eating a pickle, a sensation of pain when we burn our hand, and sensations of movement when we walk.

Sensations require the stimulation of sense organs and the conduction of nervous impulses to the sensory areas of the cortex. Sensations may be divided into classes according to the kind of sense organs involved. Thus we speak of visual sensations, 
auditory sensations, or olfactory sensations. They may be distinguished also according to their qualities. A color may have such a quality as red or green. A taste may have the quality sour or bitter. Sounds may be high pitched or low pitched. Among these qualities degrees of likeness and difference may be distinguished. Blue seems more like green than like red. Each different quality of sensation is likely to be accompanied by a characteristic group of responses.

The qualities of tonal sensations may be ranged in a continuous series. Any tone may be assigned a place within the pitch scale, and we can pass from any one pitch to any other through imperceptibly small gradations. Other sensation qualities can not be arranged in such a series.

The spectrum arouses a series of sensations that has some resemblance to the pitch scale, yet all but a few of these sensations are analyzable into two components. The only colors that can not be introspectively analyzed are red, yellow, green, and blue, and there is only one pure red, one pure yellow, one pure green, and one pure blue. Other colors seem to have more than one quality.

The unanalyzable colors are sometimes called "physiological"' colors, because each is supposed to be the sensation resulting from a certain kind of stimulation of a certain kind of sense organ. Almost all people agree in their identification of these physiological colors as points in the spectral series. Any 
deviation from these points brings us to a color that seems to be a mixture of two physiological colors. Thus, although we speak of a series of greens in the spectrum, these may be divided into blue-greens and yellow-greens, which lie on either side of the physiological, or unanalyzable, green.

A continuous qualitative series free from blends is not possible in sensations of vision, odor, taste, touch, warmth, cold, pain, movement, or in the organic sensations.

In the various combinations of pure sensation found in the consciousness of a given moment there are degrees of fusion or blending. Two sensations may so blend that only careful introspection will analyze them. A note and its octave sounded together on tuning forks, or the touch and temperature stimulation from a cold metal object, give such blended sensations.

Two sensations occurring at the same time may fail to blend and may appear quite separate and distinct. The color and odor of a flower do not blend, though they are experienced together. Introspective analysis of a sensation compound is possible only when its component sensations have been experienced separately.

Sensations may combine not as blends but in the slightly less intimate association of patterns. Sensation patterns are produced by an aggregation of objectively separate stimuli, such as the parts of a picture, or the simultaneous bending of many joints. 
The objective stimuli may also operate not at the same time but in succession, as when a melody is played, a sentence uttered, or a golf stroke executed. Any combination of easily separable sensations that is consciously felt to be a whole is called a pattern.

Sensations have duration, and this corresponds roughly to the duration of the stimulus.

The intensity of sensation depends mainly upon the intensity of the stimulus. There is a liminal threshold for sensation just as there is for responses, and the sensation does not occur unless the stimulus is of a certain intensity. In Weber's law the term "sensation" may be substituted for "response."

Summation effects are observable in sensation as well as in responses, and are brought about by the repetition of subliminal stimuli at short intervals. A sound that is too faint to be heard when it occurs once, may be heard when it is rapidly repeated several times.

Sensations manifest initial torpor. After listening to a watch we may hear it at a greater distance than was originally possible. This is probably not wholly the result of a muscular adjustment of the sense organ.

Continuous stimulation results in the fatigue of sensation, and is greater in the case of odor, taste, and touch than in the case of pain.

The threshold of sensation may be altered in positive and in negative adaptation in much the same way that the threshold of response is modified. The in- 
frequent repetition of a subliminal stimulus, that is, one that is not sufficiently intense to arouse a response, raises the threshold for both sensation and response. When a stimulus that is above the threshold is repeated to the point where fatigue interferes with the response, both the response threshold and the sensation threshold may be raised. When a response threshold has been raised as the result of the repeated action of an inhibiting stimulus, the threshold of sensation will be raised also.

An ascetic is originally prevented from enjoying the luxuries of life by the influence of his austere companions. If he remains an ascetic, it is because one of two things has happened. He has either come to disregard the things of the flesh, in which case he develops negative adaptation, both of sensation and of response, to these situations, or these situations have produced in him a conditioned response of active antagonism, in which case his threshold of sensation is lowered rather than raised.

Positive adaptation of sensation always involves positive adaptation of some response. This may be merely an increased tendency to orientation. On the other hand, practice in responding to situations may result in a decreased intensity of sensation. That is, positive adaptation of response may be accompanied by negative adaptation of sensation. If we have attained skill on the typewriter we may, when writing, be almost unconscious of what we are doing. This 
diminution of consciousness accompanies freedom from inhibitions.

\section{Emotion and Affection}

Introspective psychology has not fully decided the question whether emotional consciousness can be identified with organic sensations, the results of internal responses. There is a growing tendency, however, so to regard them. Though essentially sensational, they may be made up in part of memories of past organic experiences.

Among the affective states of consciousness, the most generally recognized are pleasure and unpleasure. These are by some regarded as qualities of sensation, and by others as separate conscious elements.

\section{IMAGES}

There is always a short interval between the stimulation of a sense organ and the occurrence of the sensation. This time is consumed in overcoming inertia in the sense organ and in the transmission of the impulse from sense organ to brain, and is known as the latent period of sensation. After the stimulus ceases, the sensation continues for a very short time, and this interval between the end of the stimulus and the end of the sensation is called the period of lag of 
the sensation. When strong stimuli are used, the period of lag is greater than the period of latency.

The lag of sensation may be divided into two parts. The first is due to the continued action of the sense organ after the stimulation has ceased, and is called the positive after-image. A second part following this is probably due to a similar momentum in sensory areas of the brain, and is called primary memory. This whole period of lag may last for but a second or two. It accounts in part for our ability to distinguish two tones of almost the same pitch sounded in quick succession, when this would be impossible if a longer time intervened between the two. It also accounts for continuous sensation from the intermittent stimulation of a motion picture.

After primary memory has disappeared, what is known as a memory image may appear in consciousness. Such images may occur many years subsequent to the original sensation. Some people retain clear images of childhood experiences and probably everyone has memory images to a greater or less extent, although there are great individual differences in this kind of retention. In general, the memory image is clearer for recent experiences, for experiences that are novel, for experiences that are emotionally reënforced, and for experiences that have been long continued. A day spent over the microscope is usually followed by clear memory images of the material studied. We remember vividly an accident or a hairbreadth escape, our first kiss or our 
first day at school, the hospital room in which we spent two weeks, or the pocket knife we carried for years. In brief, our memory images are clear in proportion to the recency and duration of the original experiences and in proportion to the attention that was given to them.

Memory images and ideas are never wholly divorced from response tendencies. Overt action may or may not follow thought, but consciousness is most in evidence while a response is pending. Delayed responses are usually attended by a rich conscious experience. When responses follow immediately upon stimulation, sensations are usually shorter lived and do not wholly lose their initial torpor.

\section{Association of Ideas}

Before the science of behavior was developed, certain laws of association were formulated to describe the origin of the sequence of ideas. These laws state that in any train of thought one idea follows another only when the experiences from which these ideas result have occurred in certain relationships. It was shown that if two experiences occur in immediate succession, the first, being repeated either as a sensory experience or as a memory, was capable of calling up the other. When we smell or think of the odor of roses, we are reminded of their visual appearance because roses have been smelled and then seen many times. When we see lightning or even think 
about it, the idea of thunder is apt to come to mind. The law describing this sequence is that of association by temporal contiguity. The law that describes associations as due to spatial contiguity is reducible to the first law. Objects experienced together in space are also experienced adjacent in time. Even where two experiences, though separated in time, occur in the same place and are later associated, such as becoming acquainted with two individuals on separate occasions at the house of a friend, the matter may be described as a double temporal association. Cause and effect become associated ideas, but only when these ideas or the experiences that underlie them have been known to us in immediate succession. Ideas that are similar tend to arouse each other because they are partially identical. Thus rats may make us think of mice on account of their similar shape and odor, though the two have never been seen together; cigars may remind us of cigarettes because both are made of tobacco; red flowers may call to mind blood. Some consecutive ideas that seem to be associated on the basis of their similarity show a likeness that is not so evidently an identity of elements. There is, for example, a similarity between any musical note and its octave, or between the colors red and violet. Though in these cases the physical stimuli are far from similar, the neural mechanisms they stimulate are probably in part identical.

These laws of association state for ideas what the conditioned response describes in behavior. 
Cortical activity must underlie the apparently random train of thought found in revery and dreams. It is clearly necessary that the nervous energy for such a chain of processes must come from somewhere. Is there any reservoir of energy that is constantly available for the maintenance of cortical processes in general?

The energy derived from looking at a mutton chop does not cause us to think of the logarithm of seven because this decimal was never thought of while the mutton chop was in sight. The mutton chop does not contribute energy to cortical processes that have not previously taken place while it is being looked at.

There are, however, certain forms of stimulation that are almost constantly present and, for this reason, have in the past accompanied practically all our acts and all our thoughts. These are the stimuli resulting from respiration, heart beat, and the muscle strain involved in maintaining equilibrium. As these stimuli are almost always acting, every act and every thought is in some degree conditioned upon them. Thus many cortical pathways are open to these impulses and the impulses are available to maintain many trains of thought. An infrequent stimulus, such as the mutton chop, could energize only a few ideas.

Stimuli that are constantly present tend to be followed by so many thoughts and responses that they are regularly followed by no one in particular, except, perhaps, those that have most recently occurred 
and thereby have a low threshold. This may be an explanation for the tendency of recent thoughts and responses to recur in the absence of specialized stimulation. When we go to bed, the organic stimuli that have accompanied our conscious experiences of today are more likely to revive memories of to-day than memories of yesterday, because the thresholds of to-day's ideas are lower than those of a time more remote. Thus the imagery of dreams is of events of the day just past and of such events of childhood as at that time established for themselves a permanently low threshold. Thought is directed when the stimuli that are present have attached to them only a few definite responses. The undirected nature of dreams and of waking revery is to be accounted for in large part by the absence of varied and unusual stimulation and by the ever present residuum of organic stimuli.

That most people are unable to recall their dreams is probably due to the fact that few experiences of waking life were present during the dream and so cues for dream revival are lacking.

\section{Imagination}

Just as two response tendencies may combine into a compromise response when simultaneously aroused, so two or more memories simultaneously excited may be condensed into a resultant idea, thought, concept or notion. 
In imagination there come into consciousness thoughts and memory images more or less distorted. This sequence of imagery may seem wholly casual upon first inspection, but on careful analysis turns out to be determined first of all by the sequence of experiences of which these memories are the "copies." No memory is isolated, but each memory is always introduced by either a preceding memory, or a sensation, or a subliminal stimulus. The image follows such an event because it, or the past sense experience to which it corresponds, has previously followed this event.

The sequence of previous sense experiences is not the only factor in determining the train of thought. The train of thought takes one direction at one time and another direction at another time, because of the varying resistance at synapses. In behavior, although many responses are attached to a single stimulus, usually, only one response of lowest threshold is elicited. In conscious thought, although any idea has many associates, not all possible associates appear each time the idea comes to mind. The threshold of any associate varies from time to time.

\section{Attention}

Objectively, attention is the orientation of sense organs toward the source of stimulation, the lowering of the response threshold, and the cessation of movements that do not serve to explore the object 
that is attended to. Subjectively, attention is the dominant presence in consciousuess of either a sense experience or an idea, or of a group of sensations or ideas that have a systematic relation to each other. As in the case of behavior, subjective attention involves the disregard of distracting stimuli. The clearness of attentive consciousness that results from the absence of rivalry is often accompanied by sensations from the muscular contraction involved in orientation and preparation for action. These sensations account for the "effort" that seems to characterize the conscious state of attention.

The sensation or idea attended to is determined by the conductivity of rival pathways in the nervous system, and by accompanying facilitations and inhibitions. After the lapse of a few seconds, a sensation loses its intensity or an image its clearness. This is analogous to other forms of fatigue and invites description in terms of increased threshold. After a brief time the threshold is again lowered and the sensation or image may recur with its original clearness. The pulse of attention usually lasts less than a second. Attention is most evident when there is a balancing of response tendencies.

\section{Perception}

Perception as a conscious event may be analyzed into two parts. On the one hand there are the sensations that result from sense-organ stimulation, and, 
on the other hand, there are certain components that are non-sensory, but which blend with the sensations. These non-sensory components correspond to memory images, though they are too well fused with the sensations to permit of easy analysis. Herbart gave the name apperception to the non-sensory component of perception.

One of the common errors of careless introspection is to mistake the organic sensations of a perceptual response for apperception. When we see a snake, the sensory part of the perception is by no means limited to visual sensations, but includes sensations produced by muscular and visceral changes.

\section{The Unconscious}

Sometimes we are conscious of what we are doing, and sometimes we are not. When we enter a strange house, when we answer a difficult question, when we eat unfamiliar food, or when we are overtaken on a railroad trestle by an approaching train, we are decidedly conscious of the situation, if not of the acts, we perform. Usually vivid memories of these situations persist and we are able to describe the things that have happened.

Consciousness of our own acts is most likely to result when we are doing something to ourselves, and are thus in a position to observe our own movements and our own bodily states. When a man removes a splinter from his own finger, tries on a new suit, 
or learns a new dance step, he has a clear consciousness not only of the external situation but also of what he is doing.

On the other hand, a great many situations and a great many acts do not produce a state of consciousness. Light from a multitude of surrounding objects affects the retina, sounds stimulate the ear, and objects touch the skin, often without our knowing anything about it, even though they may cause responses. Frequently we may take articles from our pockets, or walk some distance along a familiar street, or draw diagrams on the wall of a telephone booth, without being at all conscious of acting. The great majority of the movements we make certainly leave behind them no conscious memories and probably arouse no consciousness at the time. Delayed responses, compromise responses, and blocked emotional expression nearly always have a conscious accompaniment. In other words, conscious states are usually found when there is interference among response tendencies.

Although acts unaccompanied by consciousness might well be called unconscious acts, the term, "the unconscious," is generally reserved as a classification and as a somewhat too easy explanation for acts whose lack of preceding conscious motive, whose lack of conscious accompaniment, or whose lack of resulting conscious memory is a matter of surprise. The man who has a horror of Gothic windows but who does not know why, is said to have an uncon- 
scious motive for his fear. It might possibly be discovered on investigation that as a baby he strayed away and was lost in a gloomy cathedral, but has retained no conscious memory of this occurrence.

Most of our motives are unconscious in the sense that we are not aware of the circumstances under which our reaction tendencies were established. We are also unable to say what kind of emotional reenforcement drives us to act as we do. The parlor maid who accidentally breaks the ornate vase, the dusting of which has often caused her annoyance, is supposed by Freud to be actuated by a subconscious motive in her act of destruction. Many psychologists, however, are content to describe this occurrence as an awkward act resulting from the conflict of two tendencies, both of which are aroused by the sight of the vase. One of these is a tendency to dust the object, and the other is a tendency to smash the annoying thing. It is by no means necessary to assume an unconscious mind that plots evil against a more righteous consciousness.

An anomalous lack of conscious accompaniment is seen in the automatic writing performed by the hand of an hysteric. He is unconscious of his act and his attention seems to be fully engaged on other matters. This is described as an automatism.

The absence of memory for events that would usually be remembered is called amnesia. 


\section{BIBLIOGRAPHY}

ARISTOTLE:

De sensu, $436 \mathrm{~b}$.

BLANTON :

"Behavior of the Human Infant," Psychological Review, 1917, pp. 456-483.

Cannon, W. B.:

Bodily Changes in Pain, Hunger, Fear, and Rage, New York, 1915.

Colvin, S. S.:

The Learning Process, New York, 1915.

DARwIN, Charles:

The Expression of the Emotions in Man and in Animals, New York, 1892.

DoLL:

"Anthropometry as an Aid to Mental Diagnosis," Research Publication 8. Training School, Vineland, New Jersey, 1916.

Ebbinghaus, Hermann:

Memory. Publications of Teachers College, Columbia, New York, 1913.

Goldmark, Josephine :

Fatigue and Efficiency, Russell Sage Foundation, 1912, p. 71.

Herrick, C. J. :

Introduction to Neurology, Philadelphia, 1915.

HILL, REJALl, and THORNDIKE:

Practice in the Case of Typewriting, Pedagogical Seminar, 1913, pp. 516-529.

HOLLINGWORTH, H. L.:

The Psychology of Functional Neuroses, New York, 1920. 
Holmes, J. J. :

Studies in Animal Behavior, Boston, 1916.

HuNTER, W. S. :

The Delayed Reaction in Animals and Children, Animal Behavior Monographs, 1913, No. 1.

JAMES, William :

Principles of Psychology, New York, 1890. JeNnings, H. S.:

The Behavior of Lower Organisms, New York, 1906. LAdD, G. T., and WoodworTH, R. S.:

Elements of Physiological Psychology, New York, 1911. LASHLEY, K. S. :

"A Simple Maze; with data on the relation of the distribution of practice to the rate of learning," $P s y$ chobiology, 1918, pp. 335-367.

The Acquisition of Skill in Archery, Carnegie Institute, 1915.

LYoN, D. O.:

Memory and the Learning Process, Baltimore, 1917. Locke, John :

Essay Concerning Human Understanding. MeumanN, Ernst:

Psychology of Learning, New York, 1913. Pechstein, L. A. :

Whole vs. Part Methods in Motor Learning, Psychological Monographs, 1917.

Peterson and Rainey :

"Beginnings of Mind in the New Born," in the Bulletin of the Lying-in Hospital of the City of New York, 1910.

Preyer, W. T.:

The Mind of the Child, New York, 1905.

PyLe:

"Economical Learning," Journal of Educational Psychology, 1913, pp. 148-158. 
PyLE and SNYDER:

"The Most Economical Unit for Committing to Memory," Journal of Educational Psychology, 1911, pp. 133-142.

SHERRINGTON, C. S.:

The Integrative Action of the Nervous System, New York, 1906.

Singer, E. A., Jr.:

"Mind as an Observable Object," Journal of Philosophy, 1911, p. 180 ; also 1912, p. 206 ; "Consciousness and Behavior," Journal of Philosophy, 1912, p. 15; "The Pulse of Life," Journal of Philosophy, 1914, p. 645; "On Sensibility," Journal of Philosophy, 1917 , p. 337.

SMiтh, Stevenson:

"The Limits of Educability in Paramoecium," Journal of Comparative Neurology and Psychology, 1908, p. 503; "Regulation," Journal of Philosophy, 1914.

SPALDING :

Nature, vol. 12, p. 507.

ThoRNDike, E. L.:

Animal Intelligence, New York, 1911.

Educational Psychology, New York, 1918.

"Fatigue in a Complex Function," Psychological Review, 1914, pp. 402-407.

"Notes on Practice, Improvability, and the Curve of Work," American Journal of Psychology, 1916, pp. 550-565.

TRIPLETT:

"The Educability of the Perch," American Journal of Psychology, vol. 2, p. 419.

TWTTMYER :

A Study of the Knee Jerk, Philadelphia, 1902. 
Watson, John B. :

Psychology from the Standpoint of a Behaviorist, Philadelphia, 1919.

Watson, John B., and RAYNER :

"Conditioned Emotional Reactions," Journal of $\boldsymbol{E} x$ perimental Psychology,"' 1920, pp. 1-14.

WoodworTH, R. S. :

Dynamic Psychology, New York, 1918. 


\section{INDEX}

Act, 44

Adequate stimulus, 3

Adrenal glands, 37

Adrenin, 38

Affection, 250

Afferent neurone, 27

Alimentary tract, 36

sense organs in, 21

Ames, 217

Amnesia, 260

A pnœa, 208

Apperception, 258

Approach responses, $119 \mathrm{ff}$,

Aristotle, 6 142,232

Association of ideas, 252

Associative inhibition, 99

Attack, 142

Attention, 204, 256

Automatism, 260

Autonomic nervous system, 24, see Fig. 8

Avoidance reaction, $118,119 f$, 142,232

Awkwardness, 258

Axis of vision, 8

Babies, behavior of, $139 f f$

Basilar membrane, see Fig. 5

Behavior, 3

dependent on bodily structure, 3

Behavioristic description of

Belief, 195 mind, 1

Binocular accommodation, 174

Blanton, 51
Blinking, 52

Blocking, 212, 216

Brain, 23, 25

Central nervous system, 23

Cerebral cortex, 26

Cerebral hemispheres, 25

Chain reflex, $54 f f$, see Fig. 13

Childish responses, persistence

Choice, 194 of, $227 f f$

Ciliary muscles, 10

Cleanliness, 54

Cochlea, 15, see Figs. 4 and 5

Cœnotropes, 134, 238

definition of, 137

Cold organs, 19

Cold, paradoxical, 19

Cold, stimulus to, 19

Collecting, 138

Color, 11

Color vision, 12

Colvin, 111

Common modes of behavior, $145,222,224$

Compromise responses, 111, 170

Complementary behavior, 224

Conductivity, 5, 205

Conflict, 216

Conditioned response, 88

Cones in retina, 12

Connecting neurones, 27

Consciousness, 1, 243

and nervous system, 245

Consummatory response, 60, 62,203

lacking in play, 152 
Contiguity, 253

Convergence, binocular, 14

Conviction, 195

Coördination, $129 f$

Cornea, 8

Credulity, 236

Crying, 51

Cumulative error, 237

Curiosity, 156

Custom, 224, 231

Darwin, 37

Dead, treatment of, 226

Delayed reaction, 198

Delusion, 197

Depressing emotions, 211

Differential threshold, 42

Digestion, 36

Distance receptors, 6

Distraction, 45

Doll, 140

Drainage, 97, 99, 211

Dreams, 218, 255

Drive, 134, 210 ff

Dunlap, 104

Duration, 248

Ear, 14

stimuli to, 15

Ebbinghaus, $105 \mathrm{ff}$

Effectors, 3, 5

Efferent neurone, 28

Electric current, as stimulus, 4

Emotion, 250

Emotional expression, 2, 37 in infants, 54

Emotional reënforcement, 123 in play, 153

in curiosity, 156

Emotional responses, conditioned, $91 \mathrm{ff}$

Enteric responses at birth, 51

Enteric tract, 36

Equivocal stimuli, 167, 191
Events, perception of, 161

Exhibitionism, 215

Exteroceptors, 6

Eye, 8

dark adapted, 14

-hand coördination, 50

movements, instinctive, 51

stimuli to, 11

Eyes, convergence of, 8

Facilitation, 44

by conditioning stimuli, 95

Fatigue, 87, 248

Fear, 82, 134

of darkness, 155

of strangers, 154

Fellow-man, 220, 227

Fixation, 173

Fixed idea, 217

Following, 131, 143

Forgetting, 79, 109, 111, 218, see Fig. 25.

Fovea, 12

Free will, 209

Freud, 218

Fusion, 247

binocular, 14

Glands, 3

adrenal, 37

Goldmark, 87

Greasiness, perception of, 172

Habit, inheritance of, 72

Hallueination, 168

Hardness, perception of, 171

Herrick, 102

Hill, 79

Hollingworth, 93

Homesickness, 155

Hunger, 21

Hunter, 191

Hysteria, 216 
Illusion, 168

Images, 250

Imagination, 255

Imitation, $130 \mathrm{ff}, 163$

Individual differences, $70 \mathrm{ff}$

Inheritance of habit, 72

Inhibition, 45

associative, 99

mutual, 46

Initial torpor, 85, 248

Instinct, 48, 136

classification of, 60,64

definition of, 48,145

transiency of, 145

Intelligence tests, 71

Intention, 198, 209

Interoceptors, 6, 20

Intervention, responses of, 33, 35

Institutions, 239

Introspection, 244

Iris, 8

James, 82, 143

Jennings, 118

Judgment, $190 \mathrm{ff}$

Kinæsthetic organs, 23

stimulus to, 23

Ladd and Woodworth, 8

Lag, 251

Language, 162

acquisition, 132

in judgment, 195

sounds, 51

subrocal, 162

Lashley, 79, 89, 116

Latency, of response, 198

Latent period, 250

Laughter, 214

Learning, $75 \mathrm{ff}$

neural basis of, 97, see Fig. 19

whole vs. part, 113
Lens, $8 f$

Liminal stimulus, 39

Locke, 90

Locomotion, 33

Lyon, 115

Maintaining stimuli, 61,69

Masochism, 215

Maturation, 48, 50

of premature infants, 49

Memorizing, 115

Memory image, 251

Memory of childhood, 213

Mental tests, 71

Meumann, 110

Mind, 243

Monocular accommodation, 174

Motives, 198 ff

Motor nerves, 23

Morality, 232

Movement produced stimuli,

Muscles, 3 130, 204, 206

Muscle and tendon sense organs, 23

Muscles, involuntary, 24

Negative adaptation, 80, 248 neural basis of, 99

Nervous impulses, 4

Nervous system, 3,23

Nest building, 67

Neural arc, 4, 27

Neurones, 4 efferent, 27

Nonsense syllables, 105

Nose, 17

Noise, 182

Nursing, $56 f$

Observation, 162

Odor, sense organs of, 17, see Fig. 6

Opinion, 233

spread of, 236 
Orientation, 33, 119, 199, 204 Otoliths, 22

Overcorrection, 218

Overlapping of responses, 128

Overlapping of situations, 129, 161

Pain organs, 19

Pain, stimulus to, 20

Papillæ, 20

Paramœeium, 117

Pathways, neural, 23, 29, see Fig. 12

Patterns, 247

Pavlow, 89

Peckham, 59

Pechstein, 115

Perception, 158 ff, 257 kinæsthetic and static, 186 of language, 178

of objects, $178,181,222$

of occasions, 222

olfactory, 183

of people, 223

of places, 222

of space, $172 \mathrm{ff}, 180$

of time, 187

touch, 186

Peripheral nervous system, 23, see Fig. 8

Peristalsis, 36

Perseveration, 112

Physical object, man a, 1, 175

Play, $148 f f$

Pleasure, 250

Positive adaptation, $76 \mathrm{ff}, 248$ neural basis of, 97

Practice curve, see Fig. 17

Practice, distribution of., 115 in serial response, 105, $106 \mathrm{ff}$, see Figs. 22 and 23

Precurrent responses, 209

in play, 153

Pressure, as stimulus, 4 Primary memory, 251
Proprioceptors, 7, 21

Psychoneuroses, 93

Pupil, 8

Puzzle box, 118, 124 ff

Pyle, 115

Pyramidal tracts, 28

Quality of sensation, 247

Rage, 37

Rayner, 91

Receptors, 3

Reasoning, 195

Rëenforcement, emotional, 123

Reflex, 49

arc, 28

ares of higher level, 49

conditioned, 89

grasping, 52

salivary, 89

scratch, 30

time of, 190

tongue, 30

Rejall, 79

Respiration and voluntary movement, 125

Response, absence of utility in, 32

compromise, 46

conditioned, 88

delayed utility of, 31

internal, 36

precurrent, 62, 67, 209

in play, 153

regulatory, character of, 5 , 28

serial, $100 \mathrm{ff}, 116$

Responses, incompatible, 100

overlapping of, 128

Right-handedness, 140

Retina, 8, 11

fatigue of, 13

photochemical substances in, 12

Rods in retina, 12 
Roughness, perception of, 171 Rumor, 236

Saccule, 22, see Fig. 4

Sadism, 215

Saving method, 108, see Fig. 24

Sclerotic, 8

Semicircular canals, 21, see Fig. 4

stimulus to, 22

Secretion, action on muscles, 38

Sensation, 245 ff

Sense organs, 3 classes of, 6 position of, 5

Sensory nerves, 23

Sensory neurone, 27, see Fig. 10

Serial response, 100 ff, 116

Sherrington, 6, 9, 46, 102, 228

Similarity, association by, 227, 253

Singer, 2

Situation, 44, 221

Skeletal muscles, 23

Smiling, 52, 131

Smith, 30, 126

Sneezing, 51

Snyder, 115

Sociology, 222

Social psychology, 220 ff

Spalding, 139, 143

Spinal cord, 23, 25, see Fig. 9 columns in, 25

Spirits, 228

Static organs, 22 stimulus to, 23

Stereognosis, 172

Stickiness, perception of, 172

Stimuli, 3

adequate, 3

conditioning, 125

kinds of, 4

maintaining, 69

movement-produced, 55

proprioceptive, 101
Stimulus-response mechanism, 39

Stimulus-response mechanisms, interaction of, 43

Sublimination, 214

Suggestibility, 236

Summation of stimuli, 40, 84, 248

Summation of diverse stimuli, 40

Superstition, 228, 234

Suspensory ligament, 9

Swimming, not instinctive, 54

Symbols, 226

Synapse, 4, 97

Taboo, 233

Taste and smell, 20

Taste organs, 20

Taste, stimuli to, 20

Thinking, 1

subjective nature of, 2

Thirst, 21

Thorndike, 79, 88, $11 \mathrm{~s}$

Thought, train of, 253, 256

Threshold, 76, 119

Threshold stimulus, 39

Throwing, 140

Tickling, 172

Timbre, 182

Time perception, 187

Tone, 181

Touch corpuscle, 18, see Fig. 7

Touch, organs of, 17

Tradition, 232

Trial and error, $117 \mathrm{ff}$

Trial and error simplification of responses, 119

Triplett, 83

Tympanic membrane, 14

Twitmyer, 89

Unconscious, 258

Utricle, 22, see Fig. 4 
Visceral muscles, 36

Visual stimuli, responses to, 134,142

Vision, distant, 11 double, 14 near, 11

Volition, 205

Walking, 139

Warmth organs, 18
Warmth, stimulus to, 19

Wasp, 59

Watson, 50, 54, 89, 91, 134, 141

Weber's law, 42, 248

Wetness, perceptior of, 171

Wilson, 112

Wish, 203

Wish, fulfillment, 218

Yawning, 51 


$$
\text { . }
$$





\section{VALUABLE BOOKS ON PSYCHOLOGY}

APPLIED PSYCHOLOGY

By H. L. Hollingworth and A. T. Poffenberger, Jr.

AN INTRODUCTION TO SOCIAL PSYCHOLOGY

By Charles A. Ellwood

VocationaL PSYChoLogy (The Conduct of Mind Series)

By Harry L. Hollingworth

PSYCHOLOGY IN DAILY LIFE (The Conduct of Mind Series) By Carl Emil Seashore

MENTAL ADJUSTMENTS (The Conduet of Mind Series)

By Frederick Lyman Wells

CHARACTER AND TEMPERAMENT (The Conduct of mind series)

By Joseph Jastrow

A SCALE OF PERFORMANCE TESTS

By Rudolf Pintner and Donald G. Paterson

THE MENTAL SURVEY

By Rudolf Pintner

PSYCHOLOGY, GENERAL AND APPLIED

By Hugo Munsterberg

SOCIOLOGY IN ITS PSYCHOLOGICAL ASPECTS

By Charles A. Ellwood

THE MIND AND ITS EDUCATION

By George H. Betts

THE PSYCHOLOGY OF LEARNING

By E. Meumann

THE PSYCHOLOGY OF NATIONALITX AND

INTER NATYONALISME

By W. B. Pillsbury

THE PSYCHOLOGY OF FUNCTIONAL NEUROSES

By H. L. Hollingworth

THE PSYCHOLOGY OF STGGESTION

By Boris Sidis. Introduction by William James.

THE PSYCHOLOGY OF LAUGHTER

By Boris Sidis

FOUNDERS OF MODERN PSYCHOLOGY

By G. Stanley Hall

PRINCIPLES OF PSYCHOLOGY

By Herbert Spencer. Two volumes.

OUTLINES OF PSYCHOLOGY

By James Sully

TEACHERS HANDBOOK OF PSYCHOLOGY

By James Sullý

\section{APPLETON AND COMPANY}

\section{LONDON}

NEW YORK 



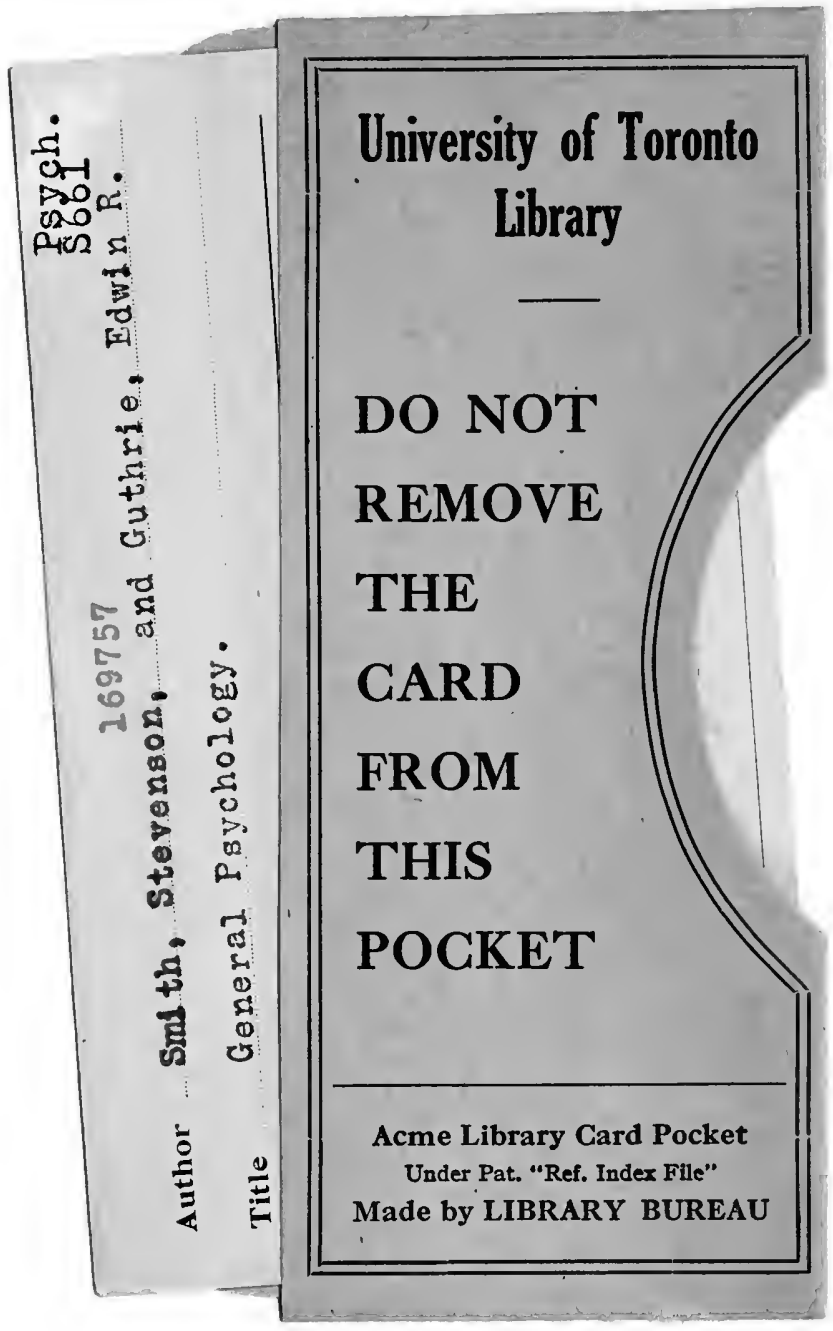


